\title{
Vulnerability and adaptive capacity of community food systems in the Peruvian Amazon: A case study from Panaillo
}

\author{
By \\ Mya Sherman
}

A Thesis Submitted in Partial Fulfillment of the

Requirements of the Degree of Master of Arts in Geography

Department of Geography
McGill University
Montréal (Québec) Canada

April 2014

(C) 2014 Mya Sherman 


\section{Acknowledgements}

I am extremely grateful to my family, friends, peers, colleagues and collaborators for their unwavering support, patience, and encouragement through this process.

I would like to first thank the community of Panaillo for being such a wonderful, gracious host and for welcoming me into the community with open minds and open hearts. The community members of Panaillo taught me so much that extends far beyond this research and have inspired me to work harder and to be better. I deeply appreciate their friendship, their faith, and their endless supply of paranta shui. The quality, scope and meaning of this research are a direct result of their hard work.

I am extremely grateful to my supervisor, Dr. James Ford, for serving as an invaluable mentor to me for several years. He introduced me to the concepts and politics surrounding climate change adaptation and has inspired me to continue working in this field for many years to come. He taught me to think critically about my own work and the work of others and I admire his commitment to community engagement and to resolving these 'wicked' problems. Through his guidance and example, I have learned how to make meaningful impacts in climate change adaptation research and I truly appreciate the freedom he has given me in carrying out this research.

I am also grateful to Dr. Lea Berrang-Ford for providing my first and continuing opportunities in climate change adaptation research. She helped me to find my passion and purpose. Thanks to the confidence that both Lea and James have had in my abilities, I have been able to accomplish much more than I thought possible.

I would also like to thank my committee members, Dr. Sarah Turner and Dr. Oliver Coomes. Their perspectives and insights have helped me to make this work both meaningful and pragmatic.

I am very grateful to my research collaborators with the Indigenous Adaptation to Climate Change research program in Peru, including Dr. Alejandro Llanos, Maria-Jose Valdivia, Alejandra Bussalleu, Jahir Anicama, Dr. Carol Zavaleta, Irene Hofmeijer, and Rebecca Wolff. Their support, feedback, and insights into the IHACC communities and the Peruvian system were crucial for this research. I would like to specifically thank Henri Urquia Rojas for taking such good care of me during my fieldwork and for constantly going 
beyond the call of duty in advocating for the IHACC communities. I am grateful for the laughs we shared and I admire his priorities, work ethic, and disposition.

I would also like to thank my first research assistant for teaching me about Shipibo culture and for helping me to revise my interview guide and focus group activities. I am extremely grateful for my two research assistants from Panaillo, without whom I could not have completed my research nor maintained my sanity. Their intelligence, insights, work ethic, and commitment to my research made this thesis possible. Ichibiras irake, pui.

There are many other individuals and institutions in Ucayali who helped make this research possible. I appreciate the local Peruvian institutions that participated in semistructured interviews for their time and effort in explaining to me the intricacies of the Peruvian system and for sharing their personal experiences. I am also thankful for the safe lodging I received at Hotel Gavilanes and for the rosquitas that kept me going from my friend in the market.

Financial support for this research came from the International Development Research Centre (IDRC), Social Sciences and Human Research Council (SSHRC), Canadian Institutes of Health Research (CIHR), and Natural Sciences and Engineering Research Council of Canada (NSERC) through a grant awarded to the Indigenous Health Adaptation to Climate Change research program. This thesis research was also funded by the Young Explorer Grant from National Geographic and the Graduate Research Mobility Award from McGill University.

I would also like to thank my labmates at the Climate Change Adaptation Research Group. Every member of that lab is impressively intelligent and a living example of doing good, honest work. It has been so important to have their encouragement, academic support, and solidarity in this process. Thank you for the collaborative environment, feeding my coffee addiction, and all of the lab drinks and other necessary distractions. I would also like to extend an extra special thanks to Michelle Maillet for helping me with so many things over the past two years, not the least of which was translating my abstract into French and printing my final thesis.

I am also so grateful for my friends and family, who have all been so wonderful in making this process as easy as possible. I especially appreciate my brother for helping me keep things in perspective and my parents for their constant love and support, even when 
it means I may jump over a snake.

Words cannot express my gratitude to Tom Marcello, my partner in life and crime. He kept me sane before, during, and after my fieldwork and I am so grateful for his confidence boosting, necessary distractions, and love. I could not have gotten through this without him. Thank you for keeping me grounded and for patiently riding this academic roller coaster with me. 


\section{Abstract}

Rainfall variability and related hydrological disasters are serious threats to agricultural production in developing countries according to the Intergovernmental Panel on Climate Change (IPCC). Since projections of climate change indicate an increase in the frequency and intensity of climatic hazards like flooding and droughts, it is increasingly important to understand communities' adaptive capacity to extreme hydrological events. This research uses a case-study approach to characterize the current vulnerability and adaptive capacity of the food system to a climatic hazard in Panaillo, a flood-prone indigenous community in the Peruvian Amazon. Participatory methods were utilized to examine how biophysical and socioeconomic factors constrain or enable local adaptive capacity to climatic hazards over time. Seasonal flooding was shown to strongly influence agriculture and fishing cycles. Panaillo residents have developed several adaptive strategies to adjust to hydrological extremes, such as food preservation and the cultivation of fast-growing crops on riverbeds. However, Panaillo residents generally lack the necessary human, physical, social and natural resources to effectively employ their adaptive mechanisms as a result of major social and environmental changes in the area. The temporal analogue of the extreme 20102011 floods highlighted the multiple drivers of vulnerability that exist at different spatial and temporal scales. Economic development, low institutional capacity, climate variability, and the assimilation social model in Peru all have profound effects on the food system and health by affecting the ways in which adaptive strategies and livelihoods are practiced. Climate change has the potential to exacerbate these socioeconomic and biophysical drivers and further compromise community food systems in the Peruvian Amazon in the future. 


\section{Résumé}

La variabilité des précipitations, et les désastres hydrologiques qui y sont reliés, sont des menaces sérieuses à la production agricole dans les pays en voie de développement, selon le Groupe d'experts intergouvernemental sur l'évolution du climat (GEIC). Comme les projections des changements climatiques prévoient une augmentation de la fréquence et de l'intensité des risques climatiques tels que les inondations et les sécheresses, il devient de plus en plus important de comprendre la capacité d'adaptation des communautés aux évènements hydrologiques extrêmes. Ce projet utilise l'approche d'étude de cas dans le but de caractériser la vulnérabilité actuelle et la capacité d'adaptation du système alimentaire aux risques climatiques à Panaillo, une communauté indigène localisée dans une région prône aux inondations dans l'Amazonie Péruvienne. Des méthodes participatives sont utilise afin d'examiner la façon dont les facteurs biophysiques et socioéconomiques peuvent contraindre ou faciliter la capacité d'adaptation locale aux risques climatiques au fils du temps. Les résultats démontrent que les inondations saisonnières ont une forte influence sur les cycles agricoles et de pêche. Les résidents de Panaillo ont développés plusieurs stratégies d'adaptations pour s'ajuster aux extrêmes hydrologiques, tels que la préservation des aliments et la culture de plantes à croissance rapide sur les lits des rivières. Par contre, les résidents de Panaillo en général manquent de capital human, physique, et social, ainsi que de ressources naturelles pour déployer effectivement leurs mécanismes d'adaptation compte tenu des changements sociaux et environnementaux majeurs qui ont eu lieu dans la région. L'analogue temporel des inondations extrêmes de 2010-2011 surlignent les causes multiples de la vulnérabilité qui existe à différentes échelles spatiales et temporelles. Le développement économique, la faible capacité institutionnelle, la variabilité climatique, et le modèle d'assimilation sociale au Pérou ont tous des effets profonds sur le système alimentaire et la santé en affectant les façons dont les stratégies d'adaptation et les moyens d'existence sont pratiqués. Les changements climatiques ont le potentiel d'exacerber ces effets socio-économiques et biophysiques, compromettant d'avantage les systèmes alimentaires communautaires de l'Amazonie Péruvienne dans le futur. 


\section{Table of Contents}

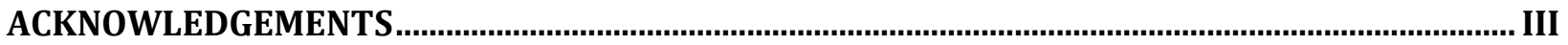

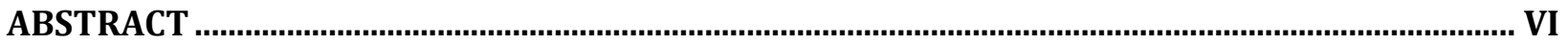

RÉSUMÉ .......................................................................................................................................... VII

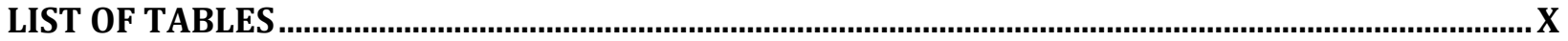

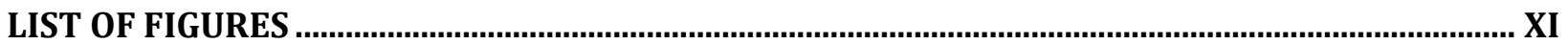

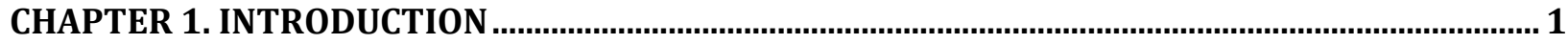

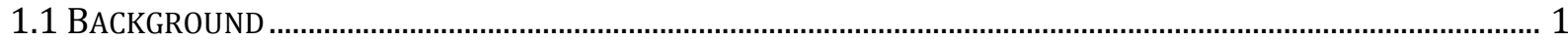

1.2 RESEARCH AIMS AND OBJECTIVES........................................................................................................... 2

1.3 THESIS OVERVIEW............................................................................................................................................ 3

CHAPTER 2. LITERATURE REVIEW................................................................................... 4

2.1 VULNERABILITY APPROACH ........................................................................................................................... 4

2.2 FOOD SECURITY AND FOOD SYSTEMS .............................................................................................................. 8

2.2.1 Food Security and the Food System in the Amazon ........................................................................10

2.3 FoOd SYSTEM VULNERABILITY TO CLIMATIC EVENTS ...................................................................................11

2.3.1 Food System Vulnerability to Climatic Events in the Amazon.............................................................14

2.4 Food SYSTEM VULNERABILITY AND CLIMATE CHANGE ..........................................................................................

2.4.1 Food System Vulnerability and Climate Change in the Amazon ...................................................18

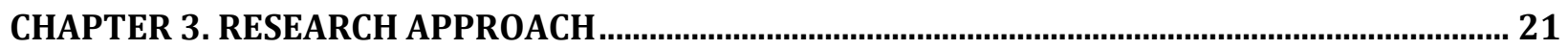

3.1 CASE STUdY AND ANALOGUE BASED RESEARCH APPROACHES ..................................................................2

3.1.1 The Case Study of Panaillo .......................................................................................................................21

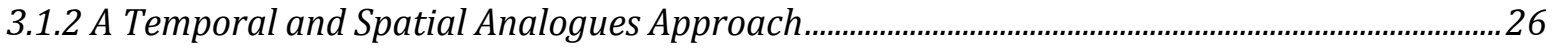

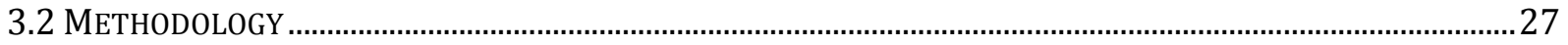

3.2.1 Participatory Rural Appraisal Methods...........................................................................................27

3.2.2 Participatory Rural Appraisal Focus Groups........................................................................................22

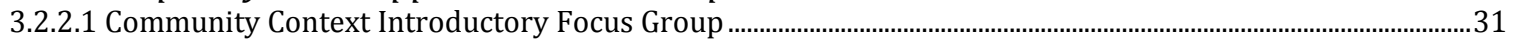

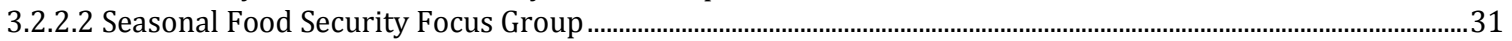

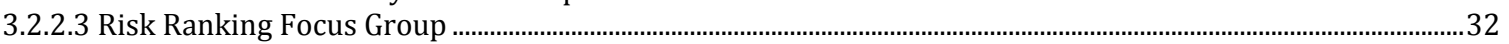

3.2.2 Semi-structured Interviews ............................................................................................................32

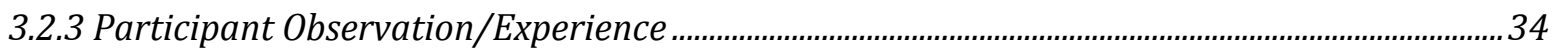

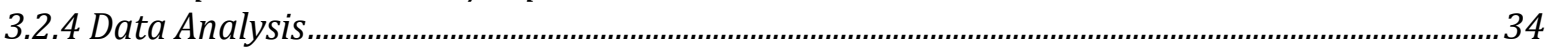

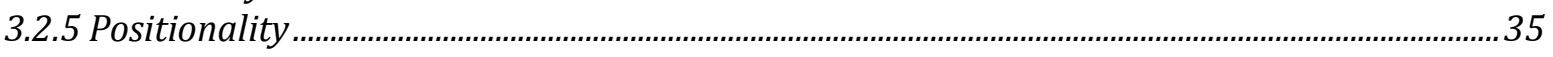

CHAPTER 4. RESULTS - HOUSEHOLD FOOD INSECURITY AMONG CURRENT AND FORMER

PANAILLO RESIDENTS....................................................................................................................... 39

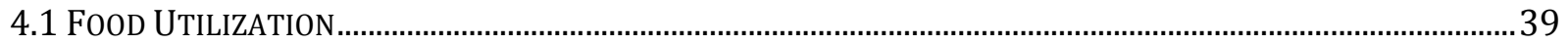

4.2 Food AVAILABILITY AND FoOd ACCESS IN PANAILLO HoUSEHOLDS................................................................40

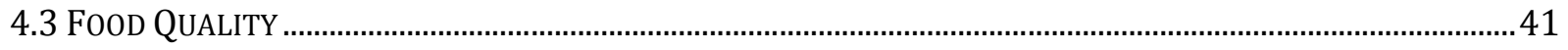

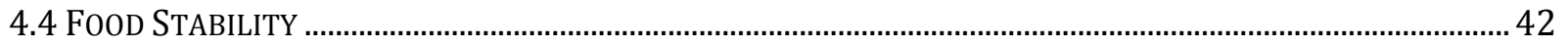

CHAPTER SUMMARY ............................................................................................................................. 43

CHAPTER 5. RESULTS - DISTAL DRIVERS OF FOOD SYSTEM VULNERABILITY ........................... 45

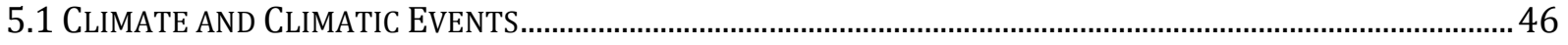

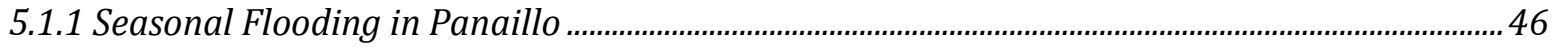

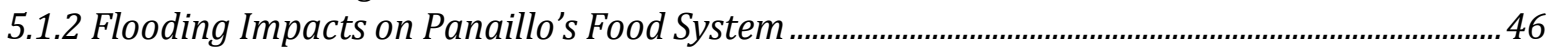

5.2 ECONOMIC DEVELOPMENT............................................................................................................................50

5.3 LOW INSTITUTIONAL CAPACITY................................................................................................................5

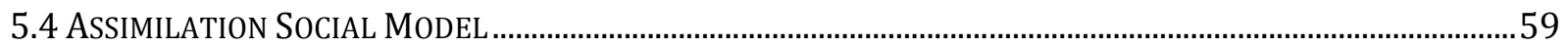




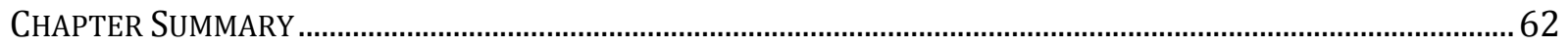

CHAPTER 6. RESULTS - PROXIMAL DRIVERS OF FOOD SYSTEM VULNERABILITY .................... 64

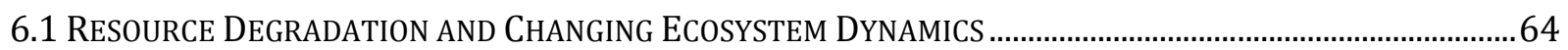

6.2 SHIFTING CLIMATE REGIMES............................................................................................................... 67

6.3 LIMITED RESOURCES AND SERVICES REACHING INDIGENOUS COMMUNITIES................................................68

6.4 DifFICULTIES IN TRADITIONAL ADAPTIVE STRATEGIES ...............................................................................69

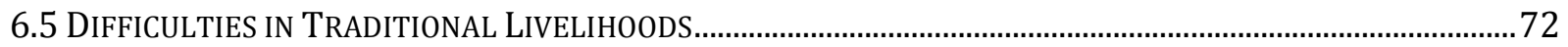

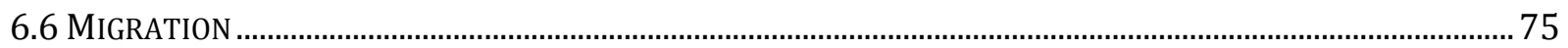

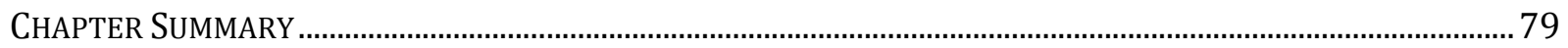

CHAPTER 7. RESULTS - FOOD SYSTEM VULNERABILITY TO EXTREME FLOOD EVENTS ........... 80

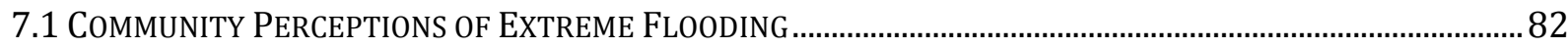

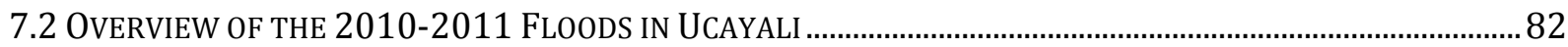

7.3 IMPACT OF THE 2010-2011 FLOODING ON LIVELIHOODS............................................................................... 84

7.4 IMPACT OF THE 2010-2011 FLOODING ON ADAPTIVE STRATEGIES ............................................................. 85

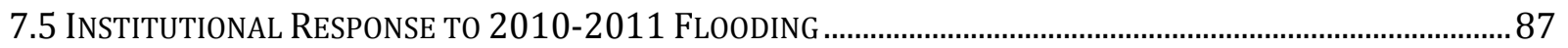

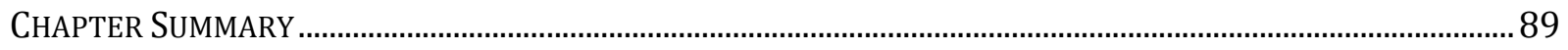

CHAPTER 8. DISCUSSION AND CONCLUSION

8.1 CURRENT FOOD SYSTEM VULNERABILITY …….................................................................................... 91

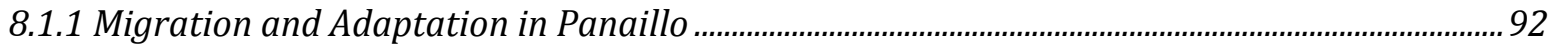

8.2 DyNAMIC VulNERABILITY AND EXTREME CLIMATE EVENTS......................................................................95

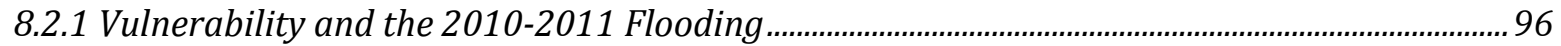

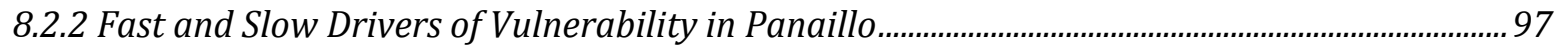

8.3 Future Food System Vulnerability: The Role of Climatic AND Non-Climatic FACTORS............. 100

8.3.1 Climate Change Projections for the Peruvian Amazon ........................................................... 100

8.3.2 Potential Socioeconomic Trajectories for the Peruvian Amazon .............................................. 102

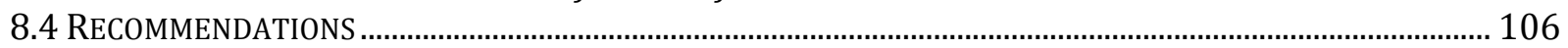

8.5 AREAS OF FUTURE RESEARCH........................................................................................................... 109

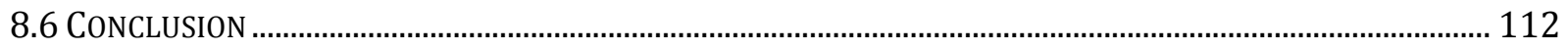

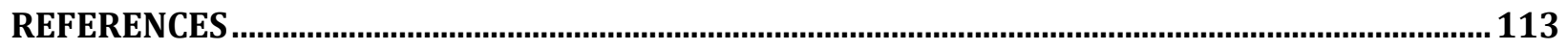

APPENDIX A - CHARACTERISTICS OF INTERVIEW RESPONDENTS ..........................................128

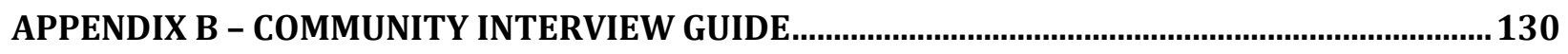

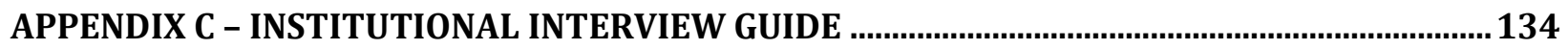




\section{List of Tables}

TABLE 1. OVERVIEW OF CLIMATE CHANGE IMPACTS ON FOOD SECURITY...................................................................................20

TABLE 2. COMMUNITY REPORTING ON DIMENSIONS OF HOUSEHOLD FOOD INSECURITY...............................................................41

TABLE 3. PERCEPTION OF HOUSEHOLD FOOD INSECURITY IN PANAILLO......................................................................................42

TABLE 4. RESPONDENT-ATTRIBUTED REASONS FOR HOUSEHOLD FOOD INSECURITY DIMENSIONS.................................................4

TABLE 5. COMMUNITY PERCEPTIONS OF HOUSEHOLDS VULNERABLE TO SEASONAL FLOODING.......................................................48

TABLE 6. ILLNESSES AND INJURIES THAT RESULT FROM SEASONAL FLOODING AS REPORTED BY INTERVIEW RESPONDENTS.........74

TABLE 7. MOTIVATION TO MIGRATE PERMANENTLY AND/OR TEMPORARILY AMONG COMMUNITY AND INSTITUTIONAL

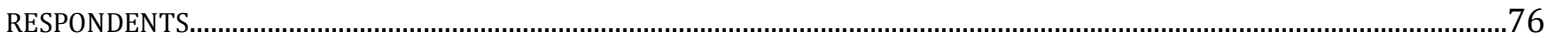

TABLE 8. EFFECTS THAT MAY TRIGGER ENVIRONMENTAL MIGRATION...........................................................................................93 


\section{List of Figures}

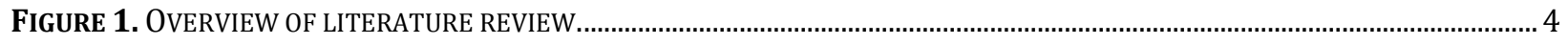

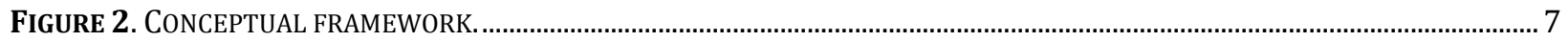

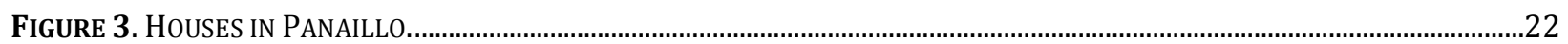

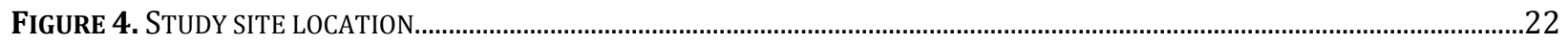

FigURE 5. VICTIMS FROM PRECIPITATION-RELATED EVENTS IN PERU BETWEEN 1970-2011_......................................................23

FigURE 6. POSTERS FROM PARTICIPATORY RAPID APPRAISAL FOCUS GROUP ACTIVITIES, INCLUDING

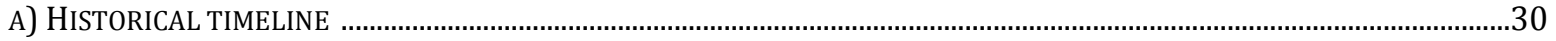

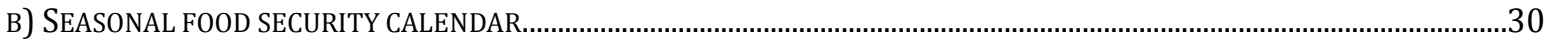

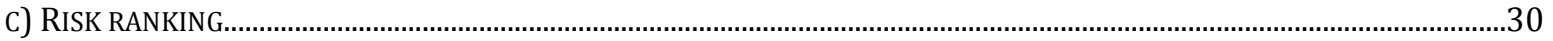

FIGURE 7. DISTAL DRIVERS OF PANAILLO'S FOOD SYSTEM VULNERABILITY. ...............................................................................45

FIGURE 8. INTERACTION OF MAJOR DRIVERS OF PANAILLO'S FOOD SYSTEM VULNERABILITY............................................................65

Figure 9. HYdRograPh OF MEAN DAILY FLOW RATES OF THE UCAYALI RIVER IN PUCALLPA. SOURCE: CARRANZA, 2012........83

FIGURE 10. HOUSES THAT WERE RECONSTRUCTED WITH METAL ROOFING NEXT TO A TRADITIONAL HOUSE WITH A ROOF MADE

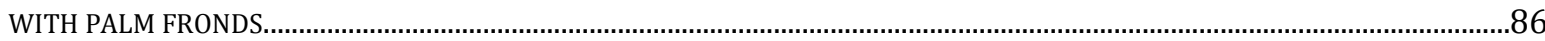




\section{CHAPTER 1. INTRODUCTION}

\subsection{Background}

According to the Intergovernmental Panel on Climate Change (IPCC), rainfall variability and related hydrological disasters are serious threats to agricultural production in developing countries (IPCC, 2012). Since projections of climate change indicate an increase in the frequency and intensity of climatic hazards like flooding and droughts, it is increasingly important to understand communities' adaptive capacity to extreme hydrological events (Verner, 2010). The impact of climatic hazards is place- and contextdependent (Verner, 2010; McSweeney \& Coomes, 2011). Climatic hazards interact with pre-existing socioeconomic and political conditions to make some individuals, households, groups and communities more vulnerable to climatic hazards than others (Ford et al., 2010a; O'Brien et al., 2007; Smit \& Wandel, 2006). Depending on the nature of the hydrological event and community context, a drought or flood may devastate a community, have minimal impact, or trigger positive change and innovation (Nyong et al., 2007; McSweeney \& Coomes, 2011).

Similarly, food security depends on both the biophysical and socioeconomic context in which the food system is embedded (Watts \& Bohle, 1993; Ford, 2009; Sen, 1981). The

food system encompasses the "dynamic interactions between and within biophysical and human environments which result in the production, processing, distribution, preparation and consumption of food" (Gregory, Ingram \& Brklacich, 2005: 2141). Extreme hydrological events may disrupt the food system by directly damaging food production and physical assets and by exacerbating pre-existing socioeconomic conditions (Kronik \& Verner, 2010).

Food security is intimately linked with health and climate in an Amazonian context, where livelihoods are more directly dependent on fragile environmental resources and communities have experienced flooding and droughts for thousands of years (Kronik \& Verner, 2010; Takasaki et al., 2010; Coomes et al., 2010). Amazonian communities have developed traditional adaptive mechanisms to negotiate this uncertainty and variability 
(Kronik \& Verner, 2010; Tomasella et al., 2013). For example, households in one floodprone community in the Peruvian Amazon increase their reliance on fishing in the floodplain as a safety net during the rainy season (Coomes et al., 2010). However, many indigenous Amazonian communities are currently experiencing major social and environmental changes, which could have profound effects on the food system and health by affecting the ways in which traditional adaptive mechanisms are practiced (Verner, 2010; Tomasella et al., 2013; Marengo, 2013; Gray et al., 2008; Finer et al., 2008). It is thus increasingly important to understand communities' current vulnerability and adaptive capacity to extreme hydrological events in order to address future health inequities and inform climate change policies.

\subsection{Research Aims and Objectives}

This thesis is part of the larger Indigenous Health Adaptation to Climate Change (IHACC) research program, a multi-national research project that uses a vulnerability approach to examine how climate affects the health of indigenous communities in the Peruvian Amazon, southwestern Uganda, and the Canadian Arctic. As a subproject of IHACC, this thesis seeks to characterize how indigenous communities in the Peruvian Amazon manage extreme hydrological events in order to maintain food security. In particular, the thesis aims to characterize the current vulnerability and adaptive capacity of the food system to a climatic hazard in Panaillo, a flood-prone indigenous community in the Peruvian Amazon. Specific objectives include:

1. Characterize the biophysical and socioeconomic drivers of the food system at the household and community level. In this objective, I seek to i) examine how the food system operates under normal conditions, as well as ii) characterize how climatic and non-climatic stresses propagate through the food system. I also hope to gain an understanding of how community members in Panaillo perceive the risks of climatic and non-climatic hazards.

2. Examine how socioeconomic and biophysical factors enable or hinder local adaptive capacity to climatic hazards over time. In this objective, I aim to i) identify common adaptive strategies undertaken before, during, and after the 
climatic event to maintain food security and food system services, and to ii) examine the effectiveness and availability of each adaptive strategy in the shortand long-term.

\subsection{Thesis Overview}

This thesis is comprised of nine chapters, beginning with a review of the relevant literature. The methodology is then described in Chapter 3, including a description of the case study and analogue approach that were used to guide the research and the participatory rural appraisal methods that were employed in fieldwork. Chapter 4 describes the current state of food security in Panaillo, followed by a more in-depth examination of the distal and proximal drivers of Panaillo's food system vulnerability in Chapters 5 and 6. To illustrate food system vulnerability to an extreme climatic event, the extreme 2010-2011 floods are examined in Chapter 7. A discussion of these results and their implications for future food system vulnerability is the subject of Chapter 8 , followed by concluding thoughts in Chapter 9. 


\section{CHAPTER 2. LITERATURE REVIEW}

This chapter will review the bodies of literature related to the vulnerability approach, food systems, and climatic events and climate change in the Amazon (Figure 1). The chapter begins by outlining the vulnerability approach, which serves as the conceptual framework for this thesis. It then reviews the topics of food security and food systems, and examines how the food system is vulnerable to climatic events. The chapter concludes with a brief overview of how climate change is expected to impact food systems. Each section will explicitly focus on food systems in Amazonia, the study site of this research.

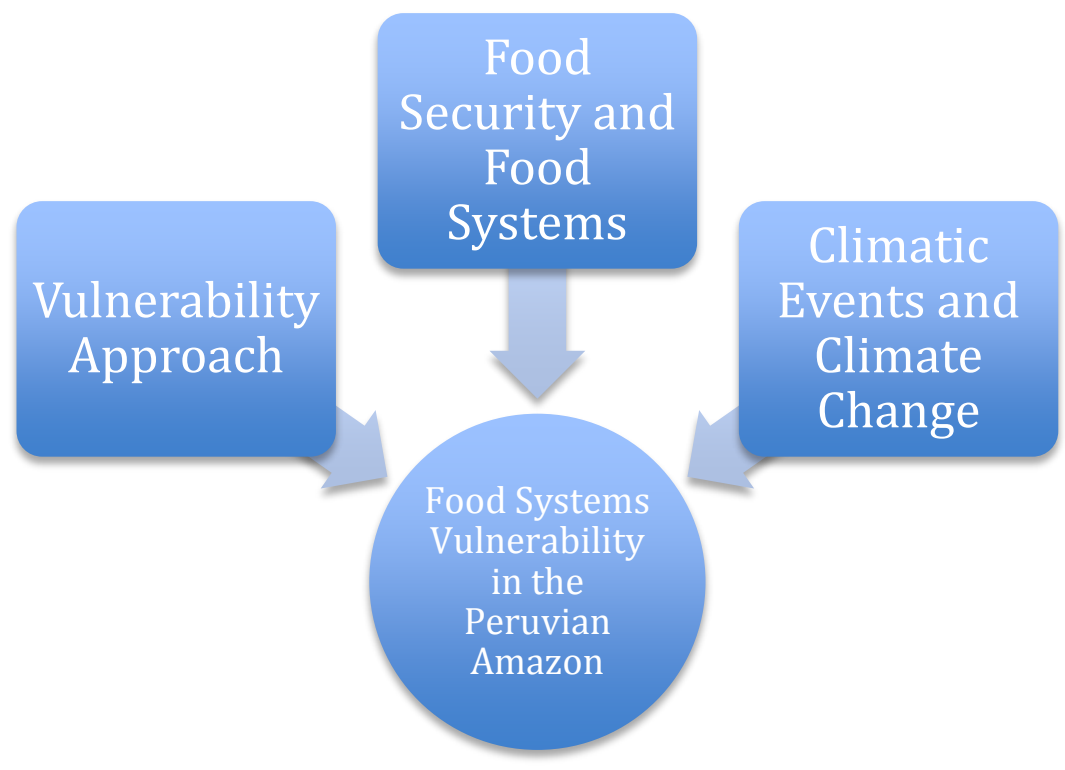

Figure 1. Overview of literature review.

\subsection{Vulnerability approach}

In order to address the multi-scalar, context-dependent, and dynamic nature of food security and adaptive strategies for climatic hazards, a vulnerability approach will be used as the conceptual framework for this thesis. Climatic hazards literature has increasingly recognized the role of socioeconomic conditions in producing natural disasters (Hewitt, 1983). Rather than try to re-establish pre-event conditions, disaster management and hazards literature increasingly focus on addressing underlying vulnerabilities (Reenberg et al., 2008). The vulnerability approach emerged from this literature, incorporating concepts from sustainable livelihoods, resilience, and political ecology in order to examine complex human-environmental systems (Ford et al., 2010b; Eakin \& Luers, 2006). As an evolving 
research paradigm, vulnerability research has increasingly shifted away from an outcomeled 'biophysical' approach to a 'contextual' or 'starting point' approach that recognizes how socioeconomic and cultural factors shape vulnerability in particular places ( $O^{\prime}$ Brien et al., 2007). The conceptual model that will be used in this research will reflect a contextual approach to vulnerability, seeking to understand how climatic hazards interact with socioeconomic, cultural and political conditions to make some individuals, households, groups and communities more vulnerable to climatic hazards than others ( $\mathrm{O}^{\prime} \mathrm{Brien}$ et al., 2007; Smit \& Wandel, 2006; Ford et al., 2010a; Yohe \& Tol, 2002).

Vulnerability is a dynamic concept that describes a system's "capacity to be wounded" (Ford et al., 2010a), and is both an outcome and a process, reflecting the potential for loss or the susceptibility to harm of a system in response to a change or stimuli (Smit et al., 2000; Smit \& Wandel, 2006; Adger, 2006). Vulnerability is a function of sensitivity, exposure, and adaptive capacity (Smit et al., 2000). Exposure refers to the nature of the stimuli (e.g., flood) and its characteristics (e.g., magnitude, spatial extent, frequency, duration, etc.). Sensitivity refers to the traits of the system itself, which determine how the exposure will manifest (e.g., livelihood diversification, biodiversity, etc.). Adaptive capacity addresses how the system manages, addresses, and adjusts to the conditions that result from this exposure-sensitivity, including the ability to take advantage of new opportunities (Ford \& Smit, 2004; Smit \& Wandel, 2006). Since adaptive capacity depends upon the natural, social, economic, political, and cultural context in which the system is embedded, the processes and conditions of exposure-sensitivity and adaptive capacity can overlap (Smit \& Wandel, 2006; Ford et al., 2006; Westerhoff \& Smit, 2009). Sensitivity, exposure and adaptive capacity thus illustrate how vulnerability results from a combination of internal and external processes, including the system's underlying susceptibility, as well as external risks, shocks and stresses (Bohle, Downing, \& Watts, 1994; Ribot, 2011).

Resources are often differentially distributed within a system, which can constrain or enable the accessibility and implementation of certain adaptive strategies (Bohle et al., 1994; Kelly \& Adger, 2000). Accordingly, contextual vulnerability research focuses on building adaptive capacity in order to address multiple underlying drivers of vulnerability, not just climate-related risks (Kelly \& Adger, 2000). Adaptive capacity can enhance or 
reduce vulnerability by mediating the relationship between exposure-sensitivty and adaptive strategies (Westerhoff \& Smit, 2009). However, adaptive capacity does not necessarily translate into adaptive strategies (Adger and Banrett, 2009; Westerhoff \& Smit, 2009; Smit \& Wandel, 2006). The social, economic, institutional and ecological context of the system determines access to assets and entitlements (Bohle et al., 1994; Kelly \& Adger, 2000; Eakin et al., 2009). The availability and effectiveness of adaptive strategies thus depends on the biophysical and socioeconomic context (Liswanti et al., 2011; Takasaki et al., 2010). Although physical and ecological factors influence adaptive capacity, sensitivity, and exposure, several authors have argued that social, cultural, and political factors are as important (if not more important) drivers of vulnerability than biophysical factors (Smit \& Wandel, 2006; O’Brien et al., 2007; Kelly \& Adger, 2000; Fussel \& Klein, 2006).

Vulnerability and its components are highly dynamic over time and space (Smit \& Wandel, 2006; Adger et al., 2009; Ford, et al 2013). The concepts of teleconnectedness and nested vulnerability illustrate the ways in which drivers of vulnerability constantly evolve and interact on multiple spatial scales (Eakin et al., 2009; Adger et al., 2009; Ford et al., 2013). Eakin et al. (2009) discuss the teleconnected and nested nature of vulnerability in her discussion of Mexican and Vietnamese coffee producers. Her case study demonstrates how global processes can shape opportunities and constraints at the local level, and how smallholder responses to global phenomenon can also influence larger scale processes. Adger et al. (2009) similarly conclude that these cross-scale interactions complicate vulnerability outcomes. Leichenko and O'Brien (2002), Eriksen et al. (2005), and Ford et al. (2013) similarly emphasize the importance of large-scale drivers of vulnerability, including 'slow' global processes such as economic liberalization and globalization. Consideration of both local and global scales is thus essential in vulnerability analysis. Accordingly, the conceptual framework for this thesis includes the local, regional and global context, as illustrated in Figure 2.

Due to the nested, teleconnected nature of vulnerability, system responses have the potential to alleviate or exacerbate the conditions that influence its own vulnerability via feedback loops (Kates et al., 2010; Eakin et al., 2009; Eriksen \& Silva, 2009; Eakin \& Luers, 


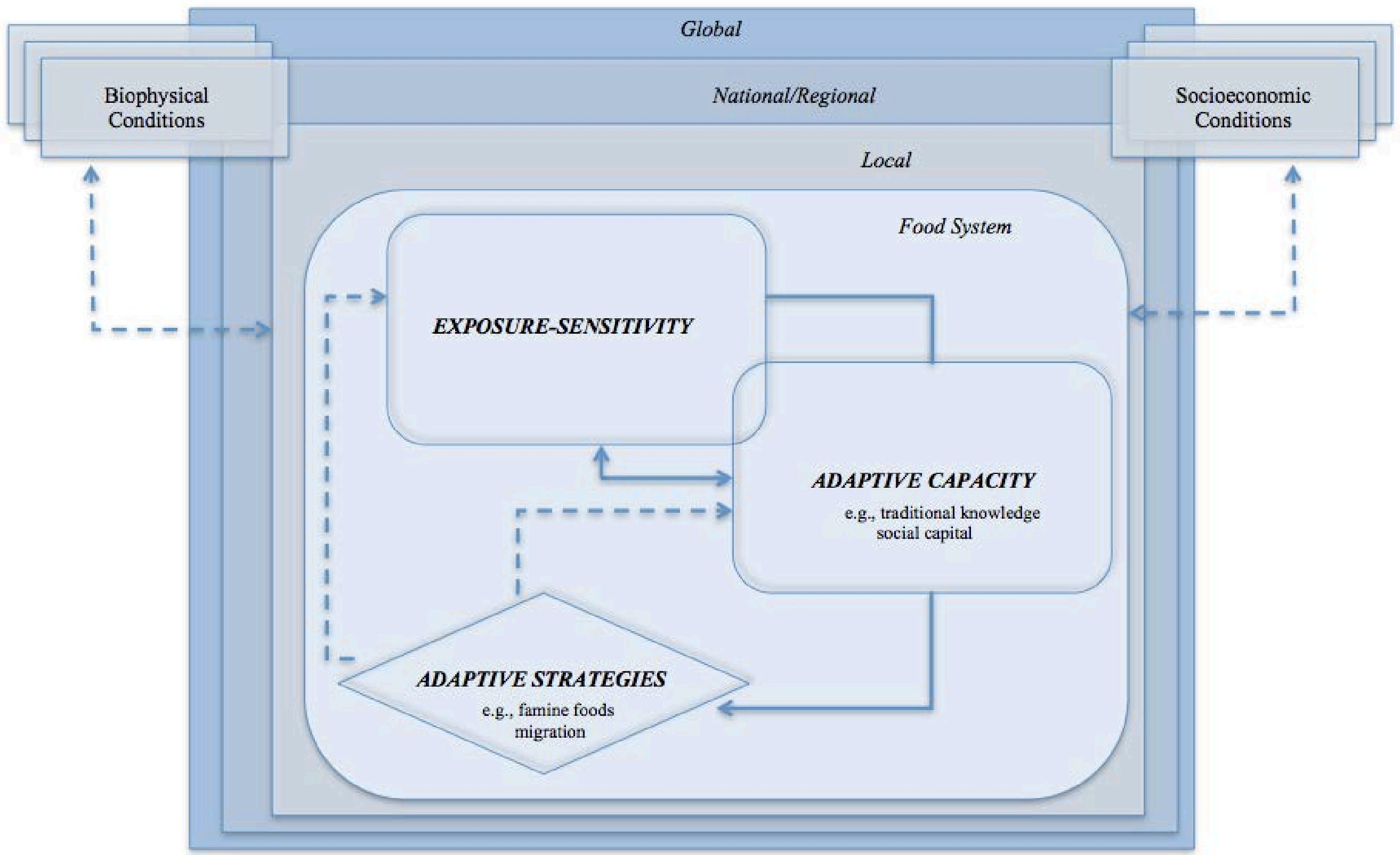

Figure 2. Conceptual framework (primarily based on Westerhoff \& Smit, 2009 and Ford, 2009). 
2006). Accordingly, short-term adaptive strategies can undermine long-term vulnerability (Fazey et al., 2011; Ford et al., 2013). For example, coastal settlements that are constructed as a result of flood protection mechanisms illustrate the "levee effect" in which infrastructural protection encourages maladaptive development (Travis, 2010; Kates et al., 2010). Lauer et al. (2012) uses the example of community in the Pacific Islands and the 2002 tsunami to discuss how adaptive capacity may not eliminate vulnerability, but rather shifts it to another time, place or type of disturbance. Eriksen et al. (2005) eloquently describe this context-dependent and dynamic nature of adaptive capacity after a climatic event when stating

A complex mesh of interactive processes creates an ever-evolving distribution of vulnerability, differentiated within the community, as households fail to identify, or succeed in identifying and implementing, effective responses to environmental stress, within a socio-economic and political context that is itself constantly changing (302).

Vulnerability thus depends upon multiple stressors interacting at multiple spatial and temporal scales (Smit \& Wandel, 2006).

\subsection{Food Security and Food Systems}

Food security has four main components: availability, accessibility, utilization and stability (FAO, 2008). Food availability refers to the physical amount, type, and quality of food that is produced, distributed, and exchanged (Ingram et al., 2010). Food production is influenced not only by biophysical conditions, such as climate, soil, and land suitability, but also socioeconomic factors, such as the use of inputs, land availability, and government agricultural policies (Ingram et al., 2010). Furthermore, the level of biodiversity in the agricultural system also influences the agro-ecosystem's susceptibility to pests and disease, thereby affecting food availability (Eriksen, 2008).

Although the literature has tended to focus on agricultural production and food availability, over three-quarters of malnourished children under five in developing countries live in countries with food surpluses (Ingram et al., 2010). It is now understood that food access and distribution are typically the major drivers of famines (Ingram et al., 2010; Devereux, 2007; Sen, 1981; Watts \& Bohle, 1993). Food access describes the ability to secure the legal, political, economic and social resources that are necessary to obtain 
food (FAO, 2011a). This accessibility encompasses food affordability, allocation and preferences, and is highly dependent on income, expenditures, markets, and prices (FAO, 2011a). Food access also pertains to the distribution of food within a household, which is especially important to consider in communities like Panaillo where strong gender roles predominate (Ali \& Niehof, 2007; Ingram et al., 2010).

The literature has increasingly noted the importance of diet quality and the use of food, especially with improved diagnostics of micronutrient deficiencies (Ingram et al., 2010). Food utilization concerns the ability to use and benefit from the food's value in a nutritional, socio-cultural, and safety sense. It recognizes the cultural importance of food for ceremonies, social rites, and customs (FAO, 2011a). Food utilization also examines dietary diversity and the nutritional quality of food, which can be constrained through food preparation, food storage, and cultural feeding practices (FAO, 2011a). Malnutrition from micronutrient deficiencies (e.g., iron deficiency, iodine deficiency) has a higher global prevalence than malnutrition resulting from inadequate caloric intake (Black et al., 2003).

The FAO (2008) also refers to a fourth dimension of food security: food stability. Food stability examines the availability, access, and quality of food over time within its socioeconomic and biophysical context (Ingram et al., 2010; FAO, 2011a). Food stability in areas prone to climatic hazards may fluctuate between seasons due to climatic variability, as well as political instability or market changes (Ingram et al., 2010). Food insecurity is considered "transitory" when food instability is temporary, for example, as a result of rapid changes in household income, domestic food production, food prices, or an environmental shock, such as a flood or drought (Devereux, 2006). Chronic food insecurity is a persistent state in which poverty and inadequate access to resources consistently impede food availability, access, and/or use (Devereux, 2006). Seasonal food insecurity occurs in areas with predictable, cyclical events that affect the food system (Devereux, 2006). Depending on the context in which these events occur, seasonal food security can resemble transitory and/or chronic food insecurity, which will be explored in greater depth in this thesis.

This thesis specifically focuses on the vulnerability of the food system. The food system encompasses all activities that are responsible for the production, processing, packaging, distribution, retailing, and consumption of food. Food system activities not only determine food security outcomes (e.g., availability, access, utilization), but also have social 
and environmental ramifications (Ingram et al., 2010). The food system is responsible for the livelihoods of 36 percent of the world's workforce (Ingram et al., 2010), including the majority of livelihoods for the residents of Panaillo, the study site of this thesis. The food system also provides social, physical, and political capital for society (Ingram et al., 2010). The food system itself is influenced by the socioeconomic and biophysical characteristics of the area, including demographic composition, available technology, socio-political and cultural traits, climate, availability of water and nutrients, biodiversity, attributes of proximate bodies of water, atmospheric composition, and land cover (Ingram et al., 2010). The food systems approach combines actor-based and systems-based approaches in order to examine the context-dependent, dynamic, multi-scalar nature of the food system (Misselhorn et al., 2012; Ingram et al., 2010).

\subsubsection{Food Security and the Food System in the Amazon}

In general, there are limited data on the food system in the Amazon Basin, the study site of this thesis, and most work has focused on the Brazilian Amazon (Ortiz et al., 2013). As the world's largest tropical rainforest, the Amazon provides a variety of important ecosystem services, including carbon sequestration, biodiversity, and regulation of water cycles, nutrient cycles, and climate patterns (Bergman, 1980). Most rural families depend directly and indirectly on ecosystem services for their food security (Ortiz et al., 2013). Agro-fishing livelihoods are widespread in the Amazon, and the Peruvian Amazon is a large producer of maize, rice, yuca, and, to a lesser extent, sugarcane, coffee, plantain, citrus fruits and some vegetables (Ortiz et al., 2013). Fish and bushmeat are the primarily sources of protein in the Amazon, and corn and yuca are considered to be the most important food sources for subsistence farmers in the area (Ortiz et al., 2013).

However, over one-third of the population living in Amazonia is classified as medium to seriously food insecure in 2004, mainly as a result of constrained food access, distribution and utilization (Ortiz et al., 2013). In Peru, 18.1 percent of children under five are chronically malnourished and 27.7 percent of the Peruvian population was acutely malnourished in 2012 (Santa Cruz et al., 2013). The Amazonian regions have higher food insecurity vulnerability in comparison to the national average, and Ucayali, the region where this fieldwork was carried out, also has the fifth highest infant mortality rate out of 
the 25 departments in Peru (Santa Cruz et al., 2013). Historically, nutrition programs in the country have been inappropriate for the given context and have failed to address the root causes of food insecurity, instead providing nutritional supplements (Aguiar et al., 2007).

\subsection{Food System Vulnerability to Climatic Events}

In this thesis, a climatic event refers to a climate-related stimulus that occurs in a relatively isolated incident (Smit et al., 2000). In the case of food system vulnerability, climate events often refer to extreme hydrological events, such as flooding and drought (Smit et al., 2000). These climatic events interact with non-climatic conditions to alter food system vulnerability. Climatic events are part of climate variability and may become a new climate norm if anomalous events recur and reflect changes in long-term mean conditions (Smit et al., 2000).

Food system vulnerability may result from a climatic hazard if any of the food system activities or assets is damaged in such a way that food security outcomes are not achieved (Ingram et al., 2010). Food system vulnerability outcomes include any failure of the food system to deliver ecological and social services. Therefore, food system vulnerability outcomes may include food insecurity, loss of livelihoods, volatile agricultural markets, damaged transportation infrastructure, and irreversible land degradation. Defining both food security and other food system services as potential outcomes of food system vulnerability creates a more holistic, nuanced understanding of the food system (Eriksen, 2008), especially in Panaillo where agro-fishing livelihoods are prominent.

Both food systems literature and conceptual models of vulnerability also highlight the feedback mechanisms that take place between the system and its socioeconomic and biophysical environment (Ingram et al., 2010; Watts \& Bohle, 1993). Similar to the vulnerability approach, the food systems approach also considers how multi-scalar biophysical and socioeconomic conditions influence the system of interest over time and space (Ingram et al., 2010). Food systems vulnerability can thus address the nested nature of food security drivers (Eakin et al., 2009). These similarities strengthen the integration of the food systems approach and the vulnerability approach in this thesis.

With regards to vulnerability to a climatic hazard, Ford (2009) notes that the exposure-sensitivity of a food system to climate change reflects both the nature of the 
climatic conditions and the characteristics of the food system. Accordingly, this research examines how the specific characteristics of a given climatic hazard (e.g., flood event) affects food security, as well as the socioeconomic and cultural factors that pre-condition the food system to be vulnerable to a climatic hazard. The impact of a climatic hazard on food system vulnerability will depend upon the magnitude, frequency, duration, severity, spatial dispersion, speed of onset, and timing in relation to other hazards and activities that affect the food system, such as planting (Ford, 2009; Lovendal \& Knowles, 2006).

However, flooding may not be a driver of food insecurity if there are sufficient deployable resources before, during, and after the event to effectively cope with the posthazard aftermath (Little et al., 2006; Motshalopheko et al., 2011; Mazzeo, 2011; Eriksen \& Silva, 2009). Households in drought- and flood-prone areas have developed a variety of strategies to maintain food security amidst a climatic events. Some authors distinguish 'adaptive' strategies from 'coping' strategies, depending on whether the action is carried out immediately and/or in direct response to a stressor (e.g., Campbell \& Beckford, 2009), whereas others refer to 'coping' strategies and 'adaptive' strategies interchangeably (Tschakert et al., 2010). Since 'adaptive' strategies are more commonly used in climate change adaptation literature (Smit \& Wandel, 2006) and the timescale and motive for a particular strategy can be difficult to discern, this thesis will exclusively refer to 'adaptive' strategies when describing how an entity copes with or manages a particular stress.

Adaptive strategies are often distinguished in the literature as being 'structural' or 'non-structural' (Lopez-Marrero, 2010; Coomes et al., 2010; Few, 2003). Structural strategies aim to reduce the impact of floodwaters on structures by using physical means to prevent floodwater spread and penetration (e.g., flood defenses, water levees, dikes) (Few, 2003). These strategies are often financially and environmentally costly and may increase vulnerability in the future if environmental conditions significantly change (LopezMarrero, 2010; Coomes et al., 2010). Non-structural adaptive strategies consist of social, cultural, economic, and technological strategies that reduce the short- and long-term impacts of the flood. These non-structural strategies may be autonomously or consciously undertaken, and may target flooding specifically or stress more generally (Few, 2003). Examples of non-structural strategies include zoning laws to prevent developments in high-risk zones, building codes, land-use planning, weather-related insurance, and public 
sensitization (FAO, 2011a; Tschakert et al., 2010; Lebel, 2012; Rasmussen et al., 2009).

The literature also categorizes adaptive strategies for climatic hazards as 'ex-ante' and 'ex-post'. 'Ex-ante' actions are carried out prior to the flood in order to mitigate and prepare for the flood in order to avoid or minimize flood impacts. For example, early warning systems and weather forecasting can enhance a community's ability to take appropriate preparatory actions for a flood (Eriksen \& Silva, 2009; Tschakert et al., 2010; Roncoli et al., 2001; Moran et al., 2006). Soil conservation techniques can reduce soil erosion and run-off, and may consist of the introduction of woody plants between crops, terracing, contour cropping, and improved watershed management (Eriksen \& Silva, 2009; Ngaira, 2009; Lebel, 2012; Altieri \& Koohafkan, 2008; Verner, 2010). Livelihood diversification can also buffer flood impacts by providing the household with alternative sources of food and income (Takasaki et al., 2010; Eriksen \& Silva, 2009; Tschakert et al., 2010; McSweeney, 2005; Alayon-Gamboa \& Ku-Vera, 2011). Other strategies that mitigate flood impacts include food storage, disturbance-tolerant seeds, integrated pest and pathogen management practices, and keeping livestock to sell (Few, 2003; Howden et al. 2007; Ingram et al., 2010; Misselhorn et al., 2012).

'Ex-post' adaptive strategies are carried out in the aftermath of the flood through immediate responses or in the later recovery period through rebuilding and rehabilitation (Lauer, 2012; McSweeney, 2005; Liswanti et al., 2010; Lopez-Marrero \& Tschakert, 2011). In a variety of case studies, authors discussed the importance of relying on social networks for food, remittances, and loans in the aftermath of a climatic hazard (McDowell \& Hess, 2012; Reenberg et al., 2008; Lopez-Marrero, 2010; McSweeney, 2005; Mercer et al., 2009; Ziervogel et al., 2006b). Migration is another common ex-post adaptive strategy in floodprone areas to avoid flood impacts and generate an alternative source of income (Hofmeijer et al., 2012; Lopez-Marrero, 2010; McSweeney, 2005; McSweeney \& Coomes, 2011). Food aid can also provide an important safety net for vulnerable areas, although several case studies have criticized food aid for its poor timing, inequitable distribution and inability to meet nutritional needs (Eriksen \& Silva, 2009; Lopez-Marrero, 2010; Devereux, 2007).

Studies have demonstrated how resource-poor households have less effective and/or fewer available adaptive strategies, and consequently suffer from constrained food 
security after the climatic event (Eriksen \& Silva, 2009; Sherman \& Ford, 2013; Speranza et al., 2008; Devereux, 2007; Alayon-Gamboa \& Ku-Vera, 2011). Other important determinants of post-hazard food security include the timing and distribution of aid, as well as the extent of climatic damage experienced by the household and the surrounding area (Little et al., 2006; Motshalopheko et al., 2011; Mazzeo, 2011; Eriksen \& Silva, 2009). Recent studies have also demonstrated how post-hazard food security is shaped by global processes, such as liberalization, globalization, and land use transitions (Eriksen \& Silva, 2009; del Ninno et al., 2003; Speranza et al., 2008). Therefore, adaptive strategies may be more or less effective for certain individuals, households, groups, or communities depending on household resources and the pre- and post-hazard context (Liswanti et al., 2011; McSweeney, 2005; Takasaki et al., 2010).

Few (2003:55) fittingly summarizes the importance of non-climatic factors in food system vulnerability by stating, "Seasonality per se is not the problem. It is the interaction of limited opportunities, disadvantage and weak fall-back positions that leads to negative outcomes". Given the importance of social factors in determining vulnerability, this thesis focuses on the relative role that flooding has on the food system in comparison to these non-climatic factors, as well as how flooding exacerbates or alleviates those non-climatic drivers of food insecurity.

\subsubsection{Food System Vulnerability to Climatic Events in the Amazon}

A variety of biophysical and socioeconomic factors have been attributed to food insecurity in the Peruvian Amazon in the recent literature. Several authors consider climate variability to be one of the greatest constraints to the Amazonian food system (Ortiz et al., 2013; UNDP \& BCPR, 2013). The UNDP Human Development Report on Peru reports that over two-thirds of the disasters that are registered in Peru are linked to climate phenomena and related events, and that 80 percent of climate-related disasters consist of intense raining and associated events, such as flooding and mudslides (Santa Cruz et al., 2013). Twelve percent of the Peruvian Amazon consists of floodplains, including the study site Panaillo. These floodplains are completely inundated and reshaped by erosion and deposition each year (Kvist \& Nebel, 2001).

Amazonian communities like Panaillo have developed traditional strategies to 
negotiate climatic hazards, including seasonal flooding (Kronik \& Verner, 2010; Tomasella et al., 2013). For example, swidden-agricultural practices and crop diversity have helped strengthen food production systems and maintained food security amidst climatic hazards in the Peruvian and Ecuadorian Amazon (Coomes, 2010; Perreault, 2005; Gray et al., 2008; Kvist \& Nebel, 2001; Gray et al., 2008). Since floodplains have enhanced fertility, floodplain agriculture also sustains most of the rural population in the area and transportation is predominantly done via river (Kvist \& Nebel, 2001).

Tomasella et al. (2013) found in their recent work in the Brazilian Amazon that communities traditionally grow crops on floodplains in the dry season that are mature enough for harvest before the onset of the rainy season. When the area is flooded, these households generate income through timber extraction, using the water canals that form in the floodplain for transportation (Tomasella et al., 2013). In this case, seasonal flooding is considered essential to livelihood well-being, rather than a threat to mitigate.

However, due to a combination of economic structures, public policies, shifting social networks, and environmental changes, food systems in the Amazon are undergoing rapid transitions and may be unable to secure food security in the future (Marengo et al., 2013; Hofmeijer et al., 2012; Gray et al., 2008; Goy \& Waltner-Toews, ). Major social factors influencing food security and rural livelihoods in the Amazon include the development of road infrastructure, river navigability, market accessibility, logging and deforestation, oil exploration and drilling, migration, and the strength of social networks (Appling \& Salisbury, 2013; Hofmeijer et al., 2012; Consorcio H\&O, 2005; Vuori, 2009; Takasaki et al., 2014; Minzenberg \& Wallace, 2012; Coomes, 2010). For example, many indigenous Amazonian households are now practicing more intensive, commercial agriculture, which is inherently less resilient to a climatic hazard (Gray et al., 2008). However, small producers in Peru struggle to negotiate fair market prices and cannot generate sufficient household income from agro-fishing livelihoods (Santa Cruz et al., 2013). Additionally, the commercialization of agriculture, fishing and forest products has further encouraged overextraction and resource depletion (Nebel, 2001; Kvist \& Nebel, 2001).

Land use change and the Amazon's integration into the global economy are considered to be major drivers of food system vulnerability in the Amazon (Ortiz et al., 2013; Santa Cruz et al., 2013; Aguiar et al., 2007; UNDP \& BCPR, 2013). Land use change in 
the Amazon mostly consists of deforestation and poor management of lands from slashand-burn agriculture, large-scale farming, and cattle-raising (Kleinwechter \& Lara, 2010; Ortiz et al., 2013). These changes have been documented to disrupt nutrient and water recycling, decrease forest productivity, increase the risk of forest fires, and affect the health of local flora and fauna (Ortiz et al., 2013; Davidson et al., 2012). Davidson et al. (2012) found that seasonality patterns have significantly altered in areas with high rates of deforestation. Recent land use changes have been driven by agricultural expansion and intensification, cattle ranching, demand for biofuels, illicit crop cultivation (i.e., coca), market integration, and road construction, all of which are fueled by international market demand, technology, transportation costs and politics (Ortiz et al., 2013; Sears \& PinedoVasquez, 2011; Santa Cruz et al., 2013; Boyd, 2008; Zambrano et al., 2010). The volatility of world food prices introduces an additional source of instability in the Amazonian food system for both consumers and producers (Santa Cruz et al., 2007; Perrault, 2005; Brondizio \& Moran, 2008; Espinosa, 2008).

Weak governance in Peru has also exacerbated food system vulnerability. Many resource extraction decisions are made inappropriately in Lima without the proper consultation of local stakeholders (Santa Cruz et al., 2013; Takahashi \& Meisner, 2013a). Furthermore, several decision-makers in Peru prioritize economic growth over other development initiatives (Takahashi \& Meisner, 2013a). Recent economic growth has not been matched with reductions in income inequality in spite of the pro-poor aims of recent decentralization efforts (Cueto et al., 2011). Wealthier regions currently receive up to three times greater public expenditure per capita than the country's poorest regions (CalvoGonzlez, 2010). This situation is exacerbated by widespread corruption, which was recently estimated to cost Peru 3.6 billion dollars annually (Comisión de alto nivel anticorrupción, 2013). It is also estimated that the poorest Peruvians spend 5 percent of their income for payments to officials in order to receive services (World Bank Peru, 2013). Vásquez et al. highlight how low institutional capacity leads to inadequate government services in remote indigenous communities in particular, stating that,

Great logistical difficulties, limited resources of institutions and the weak management skill of local institutions implies that state-sponsored activities - not only in an emergency situation - are implemented in the areas closer to provincial and local capitals and that the needs of people living in remote 
native communities and farmhouses are neglected (2012: 20).

\subsection{Food System Vulnerability and Climate Change}

The global food system is both a cause and a victim of climate change. In the past three hundred years, the food system has dramatically altered the Earth's atmospheric conditions, primarily through the release of carbon dioxide from clearing land for food production, methane from rice and livestock, and nitrogen dioxide from fertilizer (Smith \& Almaraz, 2004; Ingram et al., 2010). Agricultural systems may also pollute nearby ecosystems by releasing nitrites, nitrates, and chemicals into water streams (Ortiz et al., 2013).

However, climate change will also impact multiple aspects of the food system, including food availability, access, utilization and stability (see Table1). The manifestation of climate change impacts will vary across food systems (Ingram et al., 2010). With moderate warming, food production is expected to increase in temperate areas if the increased levels of atmospheric $\mathrm{CO}_{2}$ enhance plant growth, known as the "greenhouse fertilization effect" (FAO, 2011a). However, climate change is expected to have adverse effects on agriculture in the tropics and subtropics, where the majority of developing countries are located and where the fieldwork for this thesis was carried out (Leary et al., 2008). Although global food supply chains can moderate local or regional food shortages, developing countries may lack the financial capital to trade (FAO, 2011a). Furthermore, warming of over $3^{\circ} \mathrm{C}$ is expected to constrain agricultural production even in temperate areas (Adger et al., 2007).

Given the climate-sensitivity of agriculture, forestry and fisheries, livelihoods based on these activities will also be affected by climate change (Misselhorn et al., 2012). Developing countries are especially vulnerable to climate change since livelihoods and incomes are often highly dependent on climate-sensitive natural resources, and poverty and low levels of human and economic development constrain the ability to adapt to climate-related risks and take advantage of new opportunities (Heltberg et al., 2008; Bizikova et al., 2007; Altieri \& Nicholls, 2013). Similarly, indigenous populations are particularly vulnerable to climate change impacts on food security due to their political marginalization, dependence on natural resources for livelihoods, rapid socioeconomic and 
cultural transitions, and health inequality (Ford, 2012; Green, 2009). Extreme weather events, irregularities in seasonal patterns, and rising sea levels have already impacted livelihood assets and food distribution infrastructure, creating food emergencies around the world (FAO, 2011a).

\subsubsection{Food System Vulnerability and Climate Change in the Amazon}

According to mid-range greenhouse gas emission scenarios, temperatures in the Amazon are expected to rise by 1.8 to $5.1^{\circ} \mathrm{C}$ in the $21^{\text {st }}$ century (Malhi et al., 2008). Climate models from the Intergovernmental Panel of Climate Change (IPCC) project increases in the severity and frequency of the El Niño phenomenon, which could intensify seasonality in the Amazon (Malhi et al., 2008). Global warming is projected to result in reduced precipitation, increased drought, and intensified severity and frequency of forest fires in the Amazon (Cook et al., 2012; Santa Cruz et al., 2013; Cochrane \& Barber, 2009). For example, the main city in the Ucayali region, Pucallpa, experienced serious uncontrolled forest fires in agricultural plots during the 2005 drought (Santa Cruz et al., 2013).

According to the Food and Agriculture Organization (FAO), climate change will negatively impact food security in the Peruvian Amazon, including production, access, use and stability (Vegas de Cáceres, 2010). Several studies project lower crop yield, increased soil erosion, reduced water availability, and increased plagues and diseases in the Peruvian Amazon in response to changes in seasonality (Santa Cruz et al., 2013; Vegas de Cáceres, 2010). Lakes may dry up due to high temperatures, which could potentially induce significant losses in fish populations from hypoxia and eutrophication (Santa Cruz et al., 2013; Marengo et al., 2013). Climate change could thus have profound implications for agro-fishing livelihoods, biodiversity, water availability, and human health in the Peruvian Amazon (Vegas de Cáceres, 2010; Santa Cruz et al., 2013; Brondizio \& Moran, 2008).

However, like all climate change projections, significant uncertainties remain. The ability of tropical plants to withstand high temperatures remains unclear (Cook et al., 2012). Higher $\mathrm{CO} 2$ concentrations could increase plant growth (i.e., "greenhouse fertilization effect") and the efficiency of water use among vegetation (Cook et al., 2012). For example, Saleska et al. (2007) found that the chlorophyll content and leaf area index in the Amazon forest increased during the 2005 drought due to increased sunlight and the 
ability to use deep roots and hydrologic redistribution to maintain necessary water levels for growth. This study indicates that the Amazonian forests are potentially more resilient than ecosystem models assume, although Saleska et al. also emphasize that the Amazon is still highly vulnerable to deforestation and fires.

In spite of the current and future impacts of climate change on the food system, the scholarship on food security and climate change is limited to general studies. The literature primarily focuses on agricultural productivity, food availability, and resource access and availability, and has not focused on indigenous communities (Ford et al., 2012; LopezMarrero, 2010; Ford, 2009). Some literature has examined local adaptive strategies to droughts and flooding, yet these studies have placed limited emphasis on food security and risk perception (Lopez-Marrero, 2010; Lemos et al., 2004). No study has examined adaptive strategies for climatic events with a focus on food security and Amazonian communities, the subject of this thesis. This thesis will thus expand on these topics in its discussion of the Panaillo community food system in the Peruvian Amazon. 
Table 1. Overview of climate change impacts on food security.

\begin{tabular}{|c|c|}
\hline $\begin{array}{c}\text { Food } \\
\text { Security } \\
\text { Component }\end{array}$ & Potential Climate Change Impact \\
\hline $\begin{array}{c}\text { Food } \\
\text { Availability }\end{array}$ & $\begin{array}{l}\text { Production: } \\
\text { - } \quad \text { Differential impact on agricultural production } \\
\text { o } \quad \text { Temperate areas may experience higher production amidst moderate } \\
\text { warming, no benefit under warming above } 3^{\circ} \mathrm{C} \\
\text { o } \quad \text { Decreased production in tropical and subtropical areas } \\
\text { - Could surpass crop thresholds for rainfall, soil moisture, temperature and radiation } \\
\text { - } \quad \text { Changing distribution of wild foods } \\
\text { - Constrained water availability, leading to loss of crops, livestock and other productive } \\
\text { Storage, processing, distribution } \\
\text { - } \quad \text { Moist conditions could impede stable storage, especially for grains } \\
\text { - } \quad \text { Disrupted or destroyed transportation could inhibit access to food markets } \\
\text { - } \quad \text { Increased dependence on food imports } \\
\text { - Global food price volatility from supply fluctuations (i.e., surpluses and shortages at } \\
\text { local and global levels) could constrain exchange for both producers and consumers }\end{array}$ \\
\hline $\begin{array}{c}\text { Food } \\
\text { Access }\end{array}$ & $\begin{array}{l}\text { Allocation } \\
\text { - Reduced food availability for low income households may cause uneven intrahousehold } \\
\text { food distributions (dependent on social/political/cultural processes and access to } \\
\text { alternative livelihoods) } \\
\text { - Constrained public resources could inhibit public/charitable food distribution schemes } \\
\text { (i.e., food aid) } \\
\text { Affordability } \\
\text { - Reduced incomes from climate-sensitive livelihoods } \\
\text { - Increased food prices from short-term variations in national yields } \\
\text { Preference } \\
\text { - Changing availability and prices of preferred food (resulting in changing diets or } \\
\quad \text { increased expenditure on preferred food) }\end{array}$ \\
\hline $\begin{array}{c}\text { Food } \\
\text { Utilization }\end{array}$ & $\begin{array}{l}\text { Nutritional value } \\
\text { - Low diet diversity and low micronutrient intake due to inability to engage in small-scale } \\
\text { production, find wild foods, and/or purchase a diversity of foods } \\
\text { - Increased illness, which impedes the physiological utilization of foods } \\
\text { Social and cultural values of foods consumed } \\
\text { - The lack of availability of special foods could constrain traditional practices and } \\
\text { customs, potentially to the extent of abandoning these cultural traditions } \\
\text { Food safety } \\
\text { - Higher temperatures may increase deterioration of food quality } \\
\text { - Decreased water availability could impact food processing and preparation } \\
\text { - Changing livelihoods may make children responsible for food preparation, potentially } \\
\text { compromising hygiene practices }\end{array}$ \\
\hline $\begin{array}{c}\text { Food } \\
\text { Stability }\end{array}$ & $\begin{array}{l}\text { Stability of supply } \\
\text { - Extreme climatic events threaten continuity of food supply, especially the impact of } \\
\text { droughts/floods on rain-fed agricultural systems } \\
\text { Stability of access } \\
\text { - Global food price volatility may threaten agricultural livelihoods and food affordability } \\
\text { Food emergencies } \\
\text { - Increase in frequency and magnitude of food emergencies } \\
\text { - Difficulty storing sufficient grain reserves with higher temperatures and humidity } \\
\text { - Resource competition and challenges to rural livelihoods could induce migration }\end{array}$ \\
\hline
\end{tabular}

Source: FAO, 2011a 


\section{CHAPTER 3. RESEARCH APPROACH}

This chapter provides an overview of the research approach taken in this thesis. It describes the case study and analogue approach used in this research, as well as outlines the community-based participatory research methods that were used to carry out the fieldwork and the rationale for data collection and analysis.

\subsection{Case Study and Analogue Based Research Approaches}

\subsubsection{The Case Study of Panaillo}

Case studies are often employed in vulnerability research since they provide an in-depth, contextualized understanding that can be difficult to attain using other research methods (Ford et al., 2010b). Case studies lend themselves to the complexities of climate change vulnerability research, allowing for the examination of multiple stressors that change over time and space (Ford et al., 2010b; Adger, 1999). Several authors have identified a need to conduct more in-depth, community studies that consider the complex, dynamic circumstances in which these adaptive strategies are employed (Iwasaki, 2009; Verner, 2010; Kronik \& Verner, 2010). This study's use of a case study will thus allow for a more detailed, deeper understanding of the topic (Ford et al., 2010b).

The Shipibo community of Panaillo served as the case study for this thesis (Figure 3). The Shipibo are a riverine tribe that stems from the Panoan linguistic group (Behrens, 1986). The Panoans share ancestry with the Quechua and Aymara, and first entered the central Ucayali basin in 800 BC. The Shipibo have had sporadic contact with Europeans and missionaries since the mid $17^{\text {th }}$ century (Harris, 2005). The rubber boom in the 1880 s to 1920s significantly transformed the economic and social landscape of the Amazon Basin due to the rapid and extensive expansion of European colonialism (Chibnik, 1995). Many Shipibo were hired by Europeans to extract rubber during this time period (Bergman, 1980). In the 1940s, a road was constructed in order to connect Lima and Pucallpa and resource extraction activities and settlements increased in Pucallpa and along this road (Goy \& Waltner-Toews, 2005).

Panaillo is located on a riverbank in the Amazonian Lowlands of Peru on the Panaillo tributary of the Ucayali River (Figure 4). The Ucayali River flows northward 


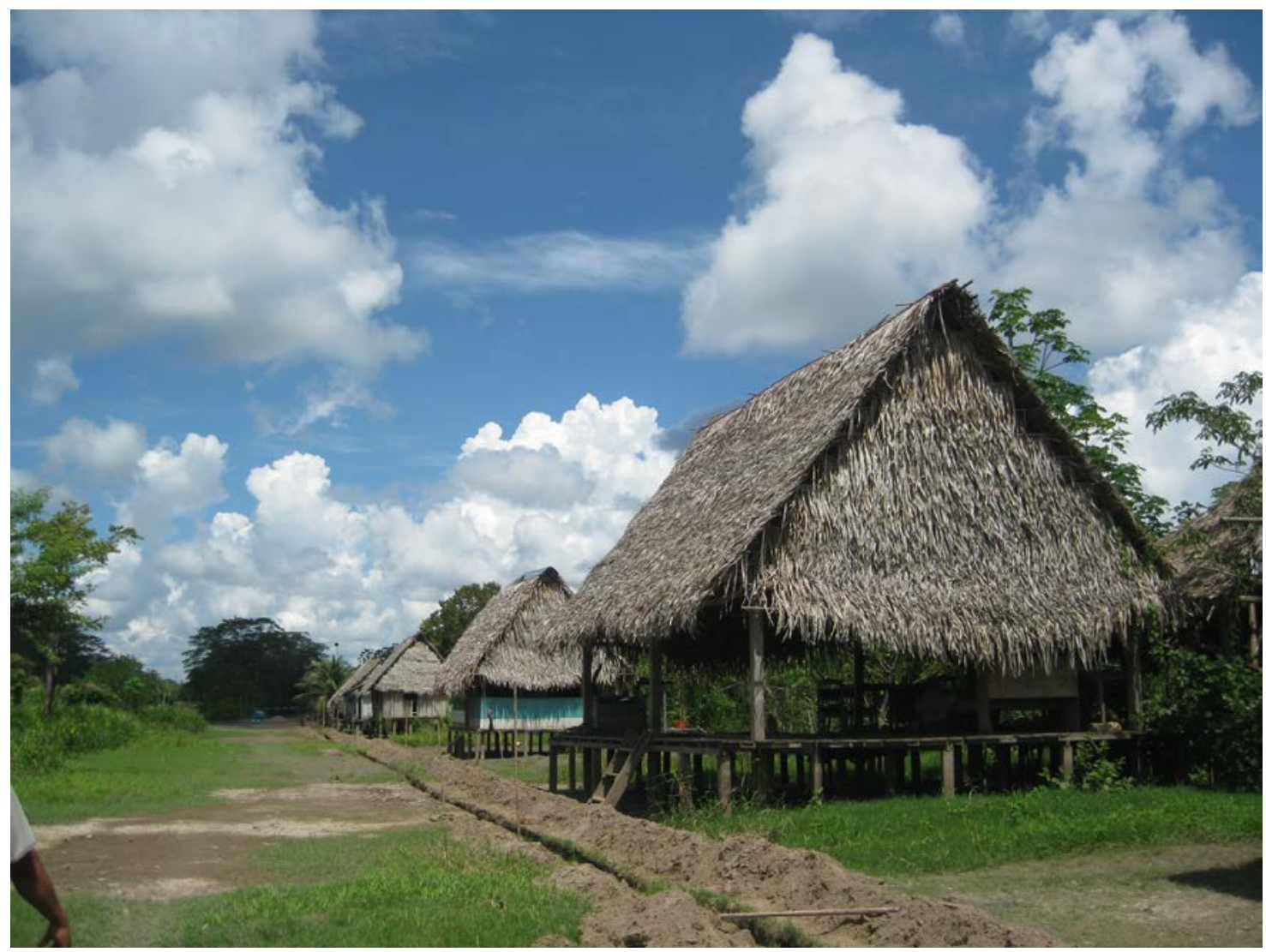

Figure 3. Houses in Panaillo (taken during fieldwork).

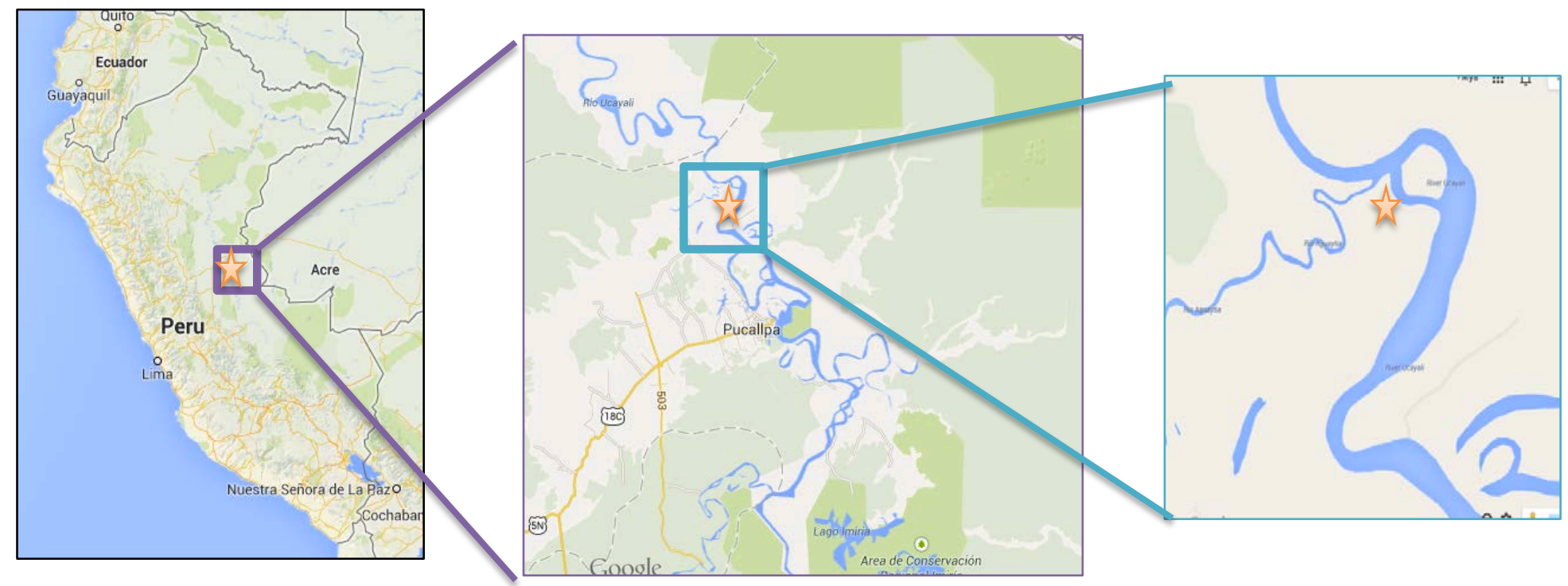

Figure 4. Study site location. The exact location of Panaillo is marked by the yellow star. Source: Google Maps. 
through the Ucayali region and is considered one of the main headwaters for the Amazon River (Abizaid, 2005). The Ucayali is characterized by a tropical climate and an annual flood cycle (Kvist \& Nebel, 2001). The rainy season is typically from January to March, a semi-dry season from April to May, a dry season from July to August, and a semi-rainy season from September to December (Carranza, 2013b). Due to the river's low gradient (approximately 5 centimeters per kilometer), the Ucayali is one of the largest actively meandering rivers in the world (Abizaid, 2005; Abad et al., 2012). During the rainy season, the river typically widens from $400 \mathrm{~m}$ to $2 \mathrm{~km}$ and rises $10.79 \mathrm{~m}$ from its low stage at Pucallpa, which is the capital city of the Ucayali and located $140 \mathrm{~m}$ above sea level (Bureau of Marine Transport from Ministry of Transportation and Communications - Ucayali, interview, 2013). As illustrated in Figure 5, the province of Coronel Portillo, where Panaillo is located, had one of the highest numbers of victims from precipitation-related events in Peru between 1970-2011 (Santa Cruz et al., 2013).

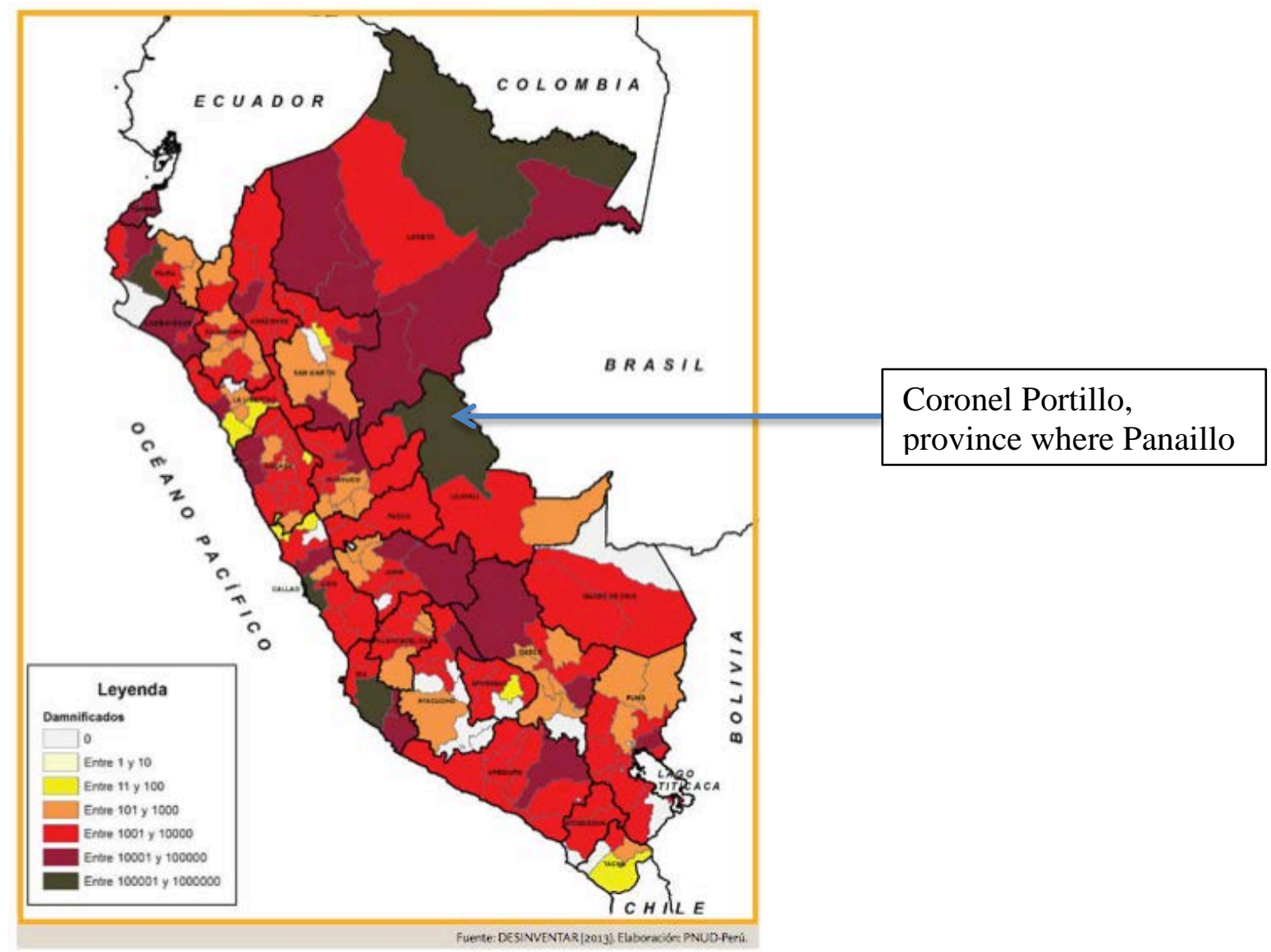

Figure 5. Victims from precipitation-related events in Peru between 1970-2011. Source: Santa Cruz et al., 2013 
The community of Panaillo was originally founded in the late $19^{\text {th }}$ century along the Ucayali river in the Contamana region. However, in the late 1940s, the community was forced to relocate when the Ucayali River changed course. The community temporarily relocated to Yarinacocha for six years, until moving in 1954 to a different location on theUcayali riverbank near the mouth of the Callería River and above the mouth of the Aguaytia River (Bergman, 1980). It was in this location that Ronald W. Bergman carried out a detailed ethnography of the community of Panaillo in 1971-2 (see Bergman, 1980). However, in 2004, the community was forced to move from this location when the Ucayali River changed course again. According to fieldwork, community members temporarily resided in Pucallpa for one year until the community was re-established in its current site. The community is now located below the mouth of the Aguaytia River and away from the Ucayali River on the small Panaillo tributary. However, many households never returned to Panaillo, and instead assumed permanent residence in Pucallpa (Hofmeijer, 2010). According to semi-structured interviews in this thesis research, Panaillo currently has a population of 220 people representing 22 households, indicating that about one-third of the community permanently left the community following the extreme flood event in 2004.

The Shipibo residents of Panaillo have maintained strong traditional beliefs and customs, including the use of the indigenous language (Bergman, 1980). The Shipibo have a matriarchal social organization with kin relationships based on the woman's family (Tournon, 2002). Women thus play an active part in community organization and resource management, though male heads of larger families have the most influence (Heise, 1999). According to common practice and traditional custom, Shipibo communities are relatively egalitarian (Tournon, 2002). Kinship and reciprocity are fundamental to Shipibo culture and the women tend to acculturate more selectively than the men (Bergman, 1980). For example, many women continue to wear traditional dress, whereas most men wear shirts and pants purchased in Pucallpa.

It is Shipibo custom to have settlements on the banks of rivers and lakes in the floodplains since these locations have easy access to aquatic life and fertile soils (Bergman, 1980). Houses in Panaillo are arranged in a single row along a single dirt street that faces the river. This is a traditional settlement pattern seen in many Amazonian communities (Bergman, 1980; Chibnik, 1994). Houses are mostly made from forest materials, and palm 
fronds are traditionally used for roofing. Three households have constructed houses using metal roofing and plastic to cover walls. Due to seasonal flooding, houses are elevated on stilts so that the floor is between one and 1.5 meters from the ground. A few fruit trees and plantain plants are located around houses, although community members explained that most of their trees and plantain plants were destroyed in the most recent flood. A backswamp runs along the back of the houses. Households use water from the backswamp and from Panaillo River for cooking and bathing.

The community has two schoolhouses and four schoolteachers who teach kindergarten and primary school. According to fieldwork observations, community members must travel to the city of Pucallpa to complete secondary education. The community also has one health post where community members can receive basic medical treatment. However, the health post is operated by a single nurse technician, who frequently travels to Pucallpa. When the health post is closed, community members with boat access can travel to the health center in the neighboring mestizo community of Tachitea.

Panaillo experiences geographic isolation, political and cultural marginalization, and is undergoing dramatic changes from economic development (Hofmeijer et al., 2013). The community has become increasingly integrated into the market economy following the construction of a road linking the community to the city of Pucallpa in 2009 (Hofmeijer et al., 2013). Panaillo is now accessible from Pucallpa by traveling 5-7 hours by boat or 2-4 hours by road, according to fieldwork experience. Pilot research for IHACC in Panaillo identified acculturative stress, marginalization, and the loss of traditional knowledge as pressing community concerns (Hofmeijer et al., 2013).

This thesis research revealed that most households are still highly dependent on subsistence agriculture and fishing. Subsistence activities typically supply the household with food throughout the dry season. However, household income has become increasingly important. Whereas Bergman noted in 1971 that income was mostly used to purchase clothing, as well as machetes, metal cooking pots, and medicines, this fieldwork highlighted that money is being frequently used to purchase processed foods, such as sugar, oil, sweets and crackers, which have been incorporated into the traditional diet. Many community members must also purchase traditional foods, such as plantain, in order to maintain 
appropriate food consumption levels in the off-season and when household income levels are low. Food is purchased from local convenience stores, the market in the neighboring town of Tacshitea, and the regional market in Pucallpa (Hofmeijer, 2010). Semi-structured interview respondents also reported that 17 households migrate seasonally to live in Pucallpa and the surrounding area during the rainy season. According to interview respondents, the population of Panaillo has been decreasing since the 2004 floods as a result of out-migration.

Whereas both men and women engage in agricultural activities, only men hunt, fish, and work in timber extraction and mostly women work in traditional handicrafts, according to fieldwork. In semi-structured interviews, all households reported selling agricultural products and traditional handicrafts, five households reported selling fish, and six households also reported selling timber in the winter. There are few alternative income-generating activities within the community, resulting in 11 households that reported having one or more family members who currently or previously worked outside of the community in low wage, temporary labor positions (e.g., large-scale agricultural plantations, oil/logging operations, and small businesses). Bergman (1980) similarly noted that there were limited income-generating opportunities for Panaillo residents.

\subsubsection{A Temporal and Spatial Analogues Approach}

Between 1954 and 1971, Bergman (1980) reports that Panaillo was flooded three times, with the most severe flooding occurring in 1965 when the community was covered with one meter of water. Since Panaillo relocated in 2004 to its current location, the community has flooded every year with between .75 and 1.5 meters of water, based on community memory and fieldwork observations of damage to housing. The intensity and frequency of this flooding is thus relatively new for Panaillo, making it an excellent case study for climate change adaptation.

Panaillo's relatively recent experience with more frequent and severe flooding episodes lends itself to a spatial and temporal analogue approach. Analogues are increasingly being used in climate change vulnerability research and are based upon the idea that knowledge about a particular subject can be used to provide insight into another subject with similar structure and organization (Ford et al, 2010b). Temporal analogues 
examine current and past experiences with climatic hazards in order to gain insight into future vulnerability to climate change (Glantz, 1991; McLeman \& Hunter, 2010; Brooks et al., 2009; Ford et al., 2010b). In this study, Panaillo's experiences with flooding over the recent past are used to better understand the community's current ability to manage hydrological variability and extremes, as well as to provide insights into how Panaillo's food system might manage climatic hazards in the future. The case study of Panaillo can also provide a spatial analogue for communities with similar characteristics that currently experience flooding or that might experience a new flood regime in the future with the onset of climate change (Ford et al., 2010b). Chapter 7 specifically examines the extreme flooding in 2010-2011, including the institutional and community responses to the extreme event. Since future climate change is expected to increase the frequency and severity of flooding events, the insights gained from understanding the 2010-2011 flooding and impacts are useful as a temporal analogue of the Peruvian system's current and future potential responses to extreme flooding.

Analogues are limited in that no two places/times are identical, and this thesis does not suggest that Panaillo's unique experience with flooding in the recent past can be necessarily generalized to other communities or other time periods. However, important issues and overarching themes can be drawn from a case-study analogue approach, and spatial and temporal analogues have proven to be useful in climate change vulnerability research in assessing and characterizing the drivers and circumstances that produce a particular outcome and in creating inference about future conditions (Hayman et al., 2012; Berrang-Ford, Ford, Paterson, 2011; Ford et al., 2010b; McLeman \& Hunter, 2010; Glantz, 1991).

\subsection{Methodology}

\subsubsection{Participatory Rural Appraisal Methods}

Fieldwork utilized Participatory Rural Appraisal (PRA) methods. PRA refers to a family of qualitative field research methods that enables researchers to obtain information from local people about local conditions in a cost-effective, timely, and culturally appropriate fashion (Chambers, 1994). PRA methods have been implemented previously in Panaillo, the other IHACC study communities, and other indigenous communities, in order to better 
engage with community members using more effective, culturally appropriate forms of communication (Hofmeijer, 2013; Lardeau et al., 2011; Sherman et al., 2012). These participatory methods have been shown to be effective in examining community coping mechanisms to climatic hazards in Latin America, Africa, and the Pacific Islands (Kronik \& Verner, 2010; Eriksen, 2005; Mercer, 2009; Tschakert et al., 2010).

PRA is part of a community-based participatory research (CBPR) approach in which the community assumes greater ownership over the research process (Green \& Mercer 2001). The community is considered an equal partner with the researchers throughout the research process, and community members directly benefit from the research's relevance, appropriateness and capacity-building in research activities (Castleden et al., 2012; Pearce et al. 2009).

Accordingly, the community actively collaborated at each stage of the research process, and research was guided by the ethical framework developed with other Peruvian IHACC communities (see Sherman et al., 2012). The IHACC research team consulted with the community in several previous research trips to appropriately inform the design of this research; including in work conducted by myself as an undergraduate in an independent study (see Sherman et al., 2012). This previous community work and a scoping trip in December 2013 were used to determine a relevant and desired research topic and appropriate methods. Community input was incorporated into a research proposal, which was presented in May 2013 first to community authorities and secondly to the communal assembly in order to obtain communal informed consent. Fieldwork was carried out in Pucallpa and Panaillo from May 3 - June 8, 2013 and from July 10 - 22, 2013, and in Lima from June 9 - July 9, 2013 and July 23 - August 10, 2013. The research obtained ethics approval from the Research Ethics Board at McGill University and the Institutional Ethics Committee at the Universidad Peruana Cayetano Heredia.

Individual informed consent was also obtained from all interview and focus group participants. Participants could choose to give informed consent verbally or by signing a written informed consent form, which were available in both the indigenous language (Shipibo) and Spanish. All focus groups and interviews were carried out in Spanish and/or Shipibo, in accordance with the participants' preference. I am fluent in Spanish and a male and female research assistant provided Spanish-Shipibo translation services for all 
interviews and focus groups. Since it was important to respect gender barriers, interviews and focus groups were assisted by the research assistant of the same gender. I was active in soliciting community feedback on the topic and method format throughout the course of fieldwork and this information informed the content of subsequent focus groups and semistructured interviews.

The data and participant list was kept confidential at all times and all interview transcripts were stripped of personal identifiers. Confidential identifiable data was only accessible to myself and was stored on a password-protected computer. Participants have been identified in this thesis according to an interview number, which was assigned during fieldwork. In order to maintain confidentiality, community interview respondents were only described in this thesis according to their gender and if they held a leadership position in the community, and institutional interviewees were only described according to the type of institution the interviewee represented (Appendix A).

\subsubsection{Participatory Rural Appraisal Focus Groups}

Three PRA focus groups were conducted in Panaillo (Figure 6). The focus groups lasted between 1-3 hours and 8-13 individuals participated in each, including men, women, community leaders, and elders. In accordance with local cultural norms, focus groups were carried out with separate groups of men and women in order to overcome the power relations that can form within the group participating in the workshop and to explore and compare the different perspectives that exist in the community (Davis, 2001; Mayoux, 2005; Kesby, 2000). Participatory rural appraisal activities were carried out in each focus group to help guide discussion. To allow for greater participation of each individual, each focus group was split into two smaller groups to complete the PRA activity. Each group presented their poster created through the activity to the entire group, and a discussion was then carried out with the entire group on the themes raised. The discussion of focus groups was tailored to reflect the important issues and concerns of the community. All Panaillo community members, including men, women and community leaders, were invited to participate in the focus groups at the communal assembly meetings and through multiple announcements on the community loudspeaker. 
a)

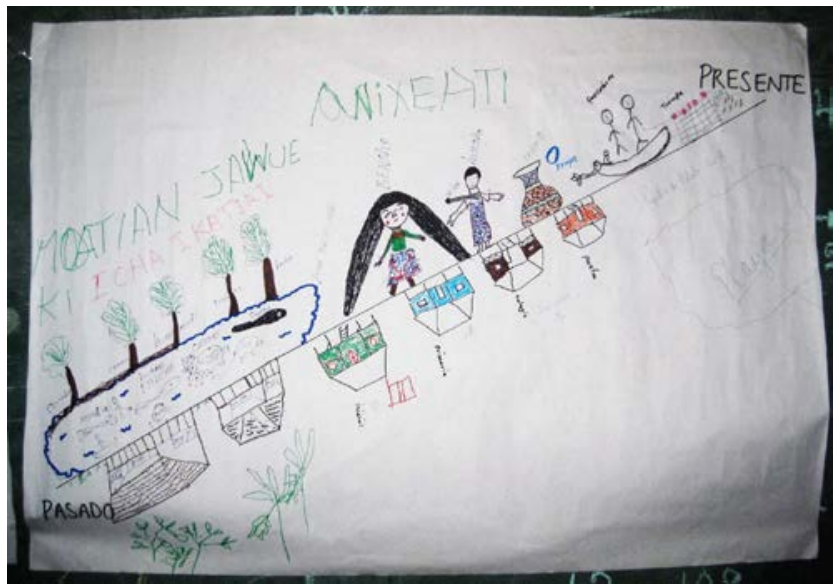

b)

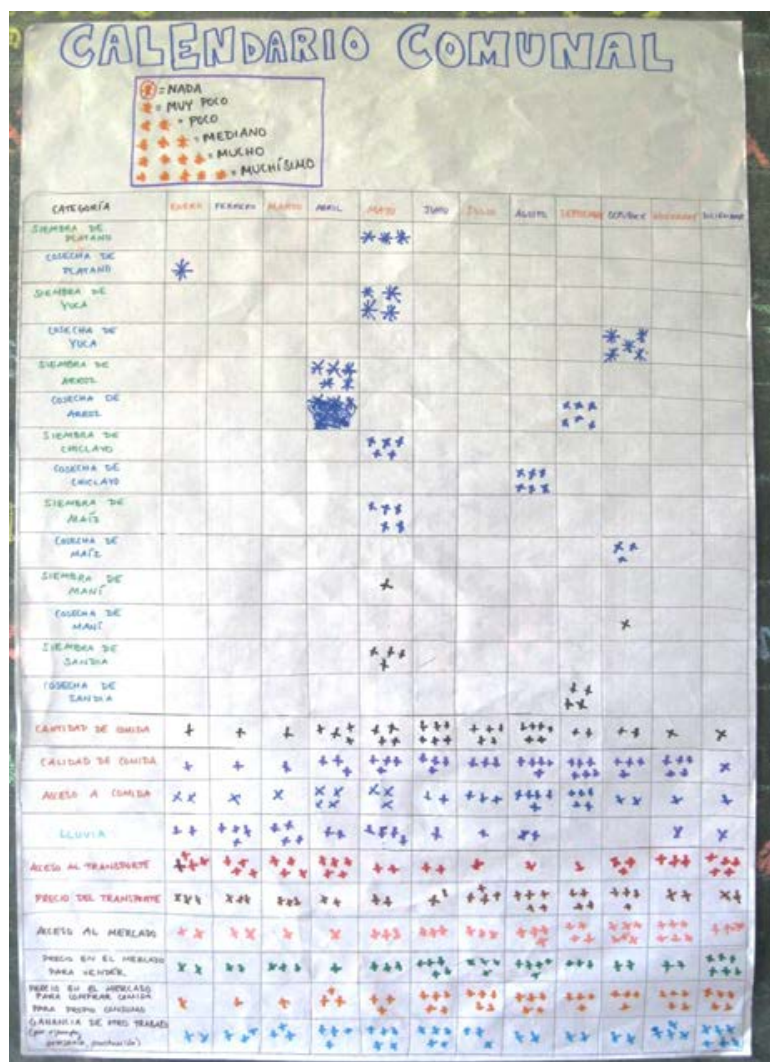

c)

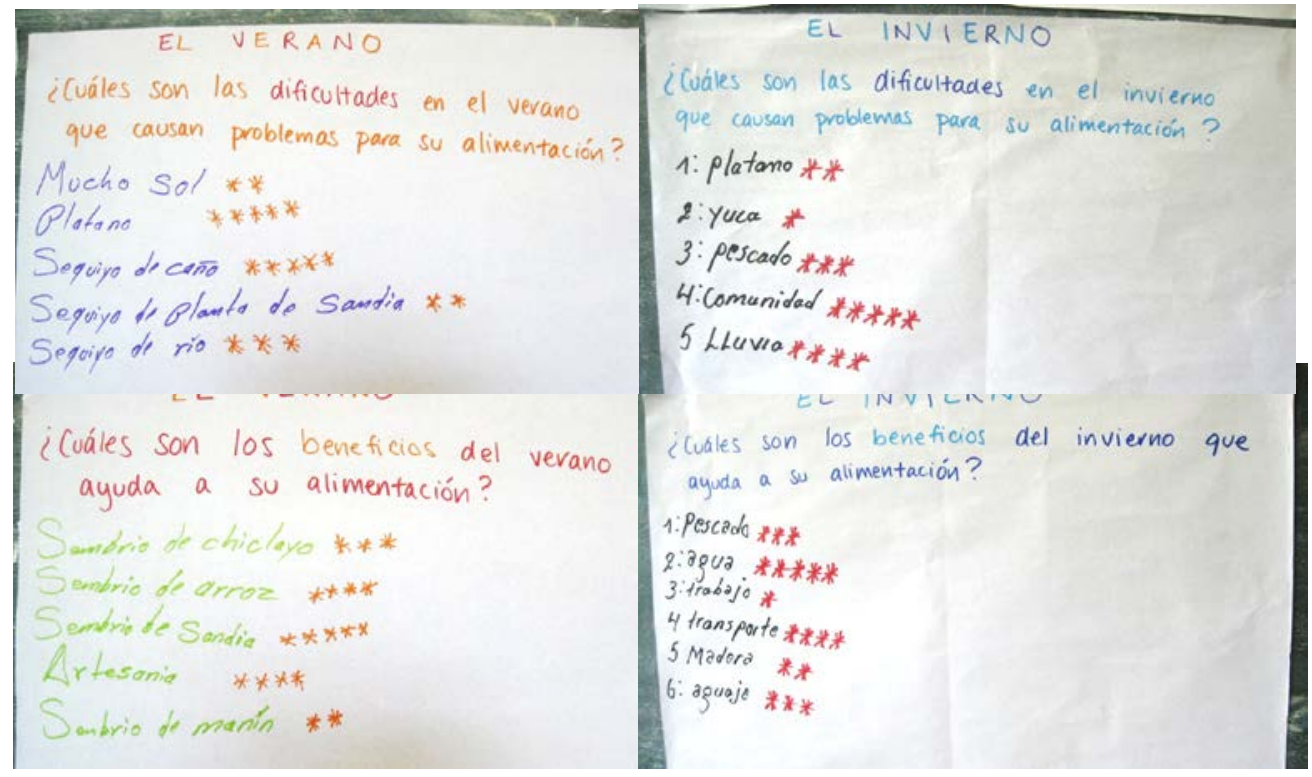

Figure 6. Posters from Participatory Rapid Appraisal Focus Group activities, including, a) Historical timeline, b) Seasonal food security calendar, and c) Risk ranking. 


\subsubsection{Community Context Introductory Focus Group}

A historical timeline activity was carried out to better understand community context and collective memory, including the community's history, livelihoods, available resources, social dynamics, and past experiences with climatic shocks. As the first research activity in the community, this focus group was used to better understand the general context of the community in order to better inform the issues discussed in later fieldwork. Participants were asked to recollect important social and environmental events in their lives or in the popular memory of the community in order to chart the community's history from a point in the past to the present. In this manner, participants created a historical timeline to explore food practices, resource availability, and important community events in the community's history. The results were interpreted with caution due to the bias of more recent events. The discussion of the diagram centered on the nature of the events and the adaptive strategies used in response to these events. The focus group specifically explored how post-hazard food security and adaptive strategies have changed over time (Mayoux, 2005; Davis, 2001).

\subsubsection{Seasonal Food Security Focus Group}

To explore how climatic hazards affect food security, a seasonal food security calendar activity was used as part of a focus group. In this activity, participants created a seasonal calendar that established relationships between seasonal events, special events, and the time of year (FAO, 2011b). Each focus group was provided a calendar with ten categories related to household food security, precipitation, transportation and food markets, and livelihoods, as well as fourteen categories related to the planting and harvest times for the seven principal crops (rice, cowpea, plantain, yuca, corn, peanuts, and watermelon). These categories were determined through consultations with community members and were in accordance with the FAO's recommendations for categories in seasonal calendar activities (FAO, 2011b). Participants were asked to evaluate each category for each month in accordance with its availability and/or abundance.

A special emphasis was placed on how agricultural and fishing cycles, resource availability, market access, livelihood viability, and household food security are affected by seasonal flooding. The group was also asked to identify a year with extreme flooding 
incidence, and both male and female focus groups chose to discuss the severe flooding in 2010-2011. Each category of the original seasonal calendar was then discussed to compare the similarities and differences between a normal flood year and the severe flood year of 2010-2011. This comparative exercise provided a sense of the impact of extreme climatic hazards on food security. The PRA activity also revealed how normal seasonality influences food security and livelihoods, as well as how extreme climatic hazards impact food security before, during, and after the incident. Seasonal calendars also provided the opportunity to discuss the various adaptive strategies that have been used in the community in response to climatic extremes, and to explore how these strategies change over time.

\subsubsection{Risk Ranking Focus Group}

To examine community perceptions of vulnerability drivers and adaptive strategies, risk ranking was employed. In the risk ranking activity, participants listed, compared and scored various options according to predetermined criteria (Tschakert, 2007). Ranking was employed in pilot research for IHACC to identify the climate-related health risks in Panaillo (Hofmeijer et al 2013). In my fieldwork research, participants were asked to list and rank what they consider to be the major difficulties and opportunities of maintaining household food security. The activity was repeated for the dry season and the rainy season. This activity thus helped to distinguish the seasonal risks to food security and identify the relative perceived risk of flooding for food security in comparison to non-climatic risks. Local risk perception influences the pre- and post-disaster strategies that are used to minimize disaster-related damage (Lemos et al., 2004). Discussion explored the relative impact each threat has on food security, how risks interact to enhance or reduce food security, the persistent effect of certain drivers of risk (e.g., if flooding affects food security in the dry season), and the availability and preferences to certain adaptive strategies for climatic hazards.

\subsubsection{Semi-structured Interviews}

All Panaillo community members, including men, women and community leaders, were invited to participate in the semi-structured interviews, and quota sampling techniques were used to interview at least one member of every household. Semi-structured 
interviews were thus carried out with 27 Panaillo residents, representing all 18 households that were present in the community at the time of fieldwork. Both male and female heads of household were interviewed, with the exception of three households, including two households in which the male household head was seeking temporary employment outside of the community and one household in which one household head declined to participate. Five households had only one head of household, including three single mothers and two single fathers. Fifteen interviews were also carried out with former Panaillo residents that had migrated to the city. A snowball sampling technique was employed for these interviews by drawing from the contacts of Panaillo community members and other migrants.

Thirty-two interviews were carried out with institutions working with Panaillo and/or related issues of food security and extreme climate events, including interviews with NGOs and institutions working at the community, local, regional, and national levels. Institutional contacts were invited to participate based on purposive sampling techniques in order to conduct interviews with the most interested, knowledgeable and appropriate individuals for the research topic. Interviews were carried out with personnel from nongovernmental and governmental institutions, including organizations working with health, agriculture, disaster risk management, education, research, and indigenous issues (see Appendix A). The number of interviews was based on theoretical saturation and all interviews and focus groups were completely voluntary. In accordance with local customs, research participants were provided a lunch and/or refreshment on the day of their participation.

The semi-structured interview guides for the community and institutional interviews are attached in Appendices B and C. Interview respondents are also described in Appendix A. The interview guide was pre-tested for content and context by academics, local research collaborators and community members. The confidential interviews were conducted in-person and individually, and lasted between 45 and 120 minutes. Seventy percent of participants gave permission for interviews to be audio-recorded $(n=52)$. Recorded interviews were transcribed verbatim and manually checked for transcription error. 


\subsubsection{Participant Observation/Experience}

Participant observation was also used to provide a more in-depth contextualized understanding of the information documented in the interviews and focus groups (Bennet, 2002). By participating in local routines and practices, I was able to culturally integrate and build rapport with community members. In addition to living with a host family throughout fieldwork in Panaillo, I also participated in agricultural activities, cooking, community celebrations, and social gatherings. Observations, impressions, and experiences were recorded in detail in a field notebook.

\subsubsection{Data Analysis}

All interviews, focus group notes, and participant observation notes were transcribed and analyzed using content analysis. Content analysis followed the Mayring approach to qualitative analysis, which uses a systematic approach guided by theory to analyze qualitative text. Specifically, deductive category application was used to create and apply the codebook (Mayring, 2004; Saldaña, 2009). The codebook contained explicit descriptions of each deductive category, inclusion and exclusion criteria for the text of each category, and examples of text that would be coded in a given category (Mayring, 2004). The detailed definition of each category was important to maintain the validity and reliability of the work (Mayring, 2004). Transcriptions were initially coded using the analytical framework for vulnerability (see Ford \& Smit, 2004; Smit et al., 2000). The codebook was then modified to incorporate the prominent themes that emerged in this preliminary analysis. Preliminary analysis was carried out while in the field, and results were presented to the community four weeks following the conclusion of community fieldwork in a validation workshop in order to clarify and confirm findings. Although perspective bias is a potential limitation of this study, several authors have recently noted the importance and validity of indigenous knowledge in global environmental change research (Smith \& Sharp, 2010; Weatherhead, Gearhead \& Barry, 2010; Orlove et al., 2010). Multiple sources of data (i.e., community interviews, institutional interviews, focus group discussions, participant observation, peer-reviewed literature, and grey literature) were also used to triangulate the data for this study. Frequency counts and percentages were sometimes used to describe the data, such as food security questions that were asked of 
each Panaillo and migrant participant (e.g., "in the past year, did you ever eat less than you felt you should because there wasn't enough food?"). It is indicated in the results section when the question was not asked to all of the 27 current Panaillo residents and all of the 15 migrants that were interviewed.

\subsubsection{Positionality}

It is important to acknowledge how the researcher's identity influences the research process. Working with indigenous issues especially requires carefully managing power relationships, in part due to the long history of research exploitation and western imperialism in indigenous communities (Smith, 1999). As a 23-year old, white, American, female Master's student at a Canadian university, my identity can imply a sense of privilege and power. During my fieldwork, it was impossible to not be seen as a wealthy outsider. I was constantly asked to support the community in various ways, ranging from providing lunch for a community celebration to seeking out scholarships for children to be able to access higher education. As a young graduate student, I did not want to confuse my intentions or motivation for working with the community in my thesis fieldwork, and I was also limited by my own financial means. However, community engagement is an important part of community-based participatory research, and the fieldwork approach taken in this thesis strongly emphasized the importance of developing and strengthening community relationships (Pearce et al., 2009; Castleden et al., 2012). It was thus important for rapportbuilding and community relations (as well as my personal desire) to be able to support the community in a meaningful sustainable manner.

As part of my community engagement strategy, throughout fieldwork I worked closely with the IHACC team and Panaillo community members to help promote their traditional handicrafts livelihood. For example, we provided transportation and accommodations to women from the community so that they could attend a capacitybuilding workshop in the nearby city of Yarinacocha. We also formally registered 22 women and girls in the state artisans registry, and increased communication between Panaillo artisans and the Regional Office of Commerce and Tourism in Ucayali (DIRCETUR). Per the community's request, I also helped the community navigate the legal system to try to recover funds that were donated in 2012. Thousands of dollars that were donated by an 
American NGO were stolen by a corrupt Shipibo NGO, but the legal case had been substantially delayed due to bribes and discrimination. Over the course of two months, I accompanied community members to courthouses to follow-up on the case, and observed on several occasions how my white skin and education made courthouse officials visibly uneasy and seemingly more inclined to advance the case. I also used my Spanish-English bilingualism to help increase the communication between the community, the American NGO, and the Peruvian court system.

These actions unavoidably influenced my relationship with community members and created certain power dynamics. All of these actions leveraged my privileged position as a white, educated outsider with relatively greater financial means. However, I ultimately think that these actions were essential for building strong community relations. Reciprocity is the foundation of Shipibo culture, and the community had supported me enormously in my work by participating in my research activities and being so hospitable and open with me during my stays in the community. It was important that I help to advocate for the community in return, and I was able to do so in a way that hopefully limited dependency and minimized power relations (since I was seen as a young student without many financial resources). I further built rapport by fully immersing myself in community life, for example, by learning Shipibo phrases and eating traditional foods.

My positionality as a foreigner shaped my research process in other ways. Research in Peru is structured by the bureaucratic and procedural culture found among Peruvian institutions. As such, researchers often struggle to attain interviews with institutional contacts, especially amidst time constraints and limited local connections. My status as a foreigner arguably gave me better access to institutional information since I was often able to by-pass this institutional culture and conduct interviews on-the-spot. My foreignness made this less formal approach more socially acceptable. Furthermore, the interviews that were carried out in the presence of another Peruvian seemed to be more restricted in their interview responses compared to the interviews that I conducted alone. In the presence of another Peruvian, institutional contacts tended to provide an idealized version of what their institution should be doing, rather than the reality. My age must have made me seem less intimidating, and my genuine eagerness to learn about the Peruvian system helped to build better rapport with interviewees. 
The Amazon also has several serious safety concerns for foreigners, ranging from lethal snakebites to infectious diseases to violent attacks from narco-traffickers. Visitors are particularly targeted for kidnapping and violent crime due to the conception that they have money, and women are at a higher risk for sexual assault. These safety concerns limited my independence and mobility during my fieldwork, both in Panaillo and the cities of Pucallpa and Lima. I needed to be accompanied by a research assistant for travel between Pucallpa and Panaillo, and it was important to carefully manage my relationships with community members, particularly men. Although I tried to establish myself as a daughter/sister figure within the community, alcoholism often exacerbated episodes of sexual harassment, and one such incident ultimately forced me to fire my first research assistant while in the community.

The positionality of research assistants is a critical influence in the research process (Temple, 2002). I initially began working with a Shipibo teacher from the city of Yarinacocha. Although he had lived most of his life in a rural Shipibo community, he was still an outsider to Panaillo. Being a teacher also gave him a more privileged status in the community, which potentially affected his relationships with less educated community members. His integration in the community was facilitated, however, by the fact that he shared the traditional language and customs. As a Shipibo shaman, he was also able to serve as my cultural interpreter to a great extent. However, his inappropriate conduct in the community under the influence of alcohol not only jeopardized my relationship with the community, but also placed my own well-being at risk, and I was forced to fire him. This event strongly shaped my relationship with community members. The blatant assertion of my power in firing my research assistant undoubtedly exacerbated power dynamics with many community members, especially the men, although the situation also strengthened my bond with community members, who defended my decision and increased their own protection of me for the remainder of my fieldwork. I had been working informally with a young man and young woman from the community since the start of my research, and following this incident, I began to work exclusively with these individuals as my research assistants. Community approval of my work increased substantially, especially among the women and elderly.

As demonstrated in this section, research with indigenous communities is filled with 
complexities. It is crucial that I am aware of how my own identity influences the way I maneuver these intricacies. It has thus been important to critically consider my positionality throughout my fieldwork and analysis, and how the researcher-community relationship has impacted both myself and Panaillo. 


\section{CHAPTER 4. RESULTS - HOUSEHOLD FOOD INSECURITY AMONG CURRENT AND FORMER PANAILLO RESIDENTS}

This chapter presents the current status of household food insecurity amongst current and former residents of Panaillo. It examines household food security according to food utilization, food quantity, food quality, and food stability. The results presented here are based on focus groups and interview responses to food security questions, which were adapted from the Latin American and Caribbean Household Food Security Measurement Scale (ELCSA). This overview provides the foundation for a more in-depth discussion of the drivers of food system vulnerability in the next two chapters.

\subsection{Food Utilization}

The typical Shipibo diet is largely based around fish. The Shipibo word for cooked food (piti) (Behrens, 1986) is used interchangeably with the word for consumable fish. When asked how Panaillo residents diversify their diet, three interview respondents and both male and female seasonal food security calendar focus groups responded with different fish species and ways of preparing fish. In migrant interviews, fish was less prominent in the diet. No migrant described diet variety in terms of fish and all migrants reported eating more chicken, red meats, breads, and vegetables.

In the traditional Shipibo diet, fish is eaten with a carbohydrate, preferably plantain. One male elder in Panaillo stated that: "The kitchen should never lack plantain. This is our custom from a very long time ago" (Interview \#1, 5/13/2013). Yuca, rice, and breadfruit might also be used to complement fish, although households must have financial and natural resources to obtain and consume these items.

When available, households also consume chicken, beans, some vegetables (e.g., regional sweet pepper, tomato), and some fruit (e.g., camu camu, mango). Current and former Panaillo residents typically eat 2-3 times per day, depending on the size of the meal and food availability. In Shipibo culture, it is typical to share a plate during the meal, and men often eat separately from women and children. Children are given priority access to household food. One male Panaillo respondent stated: "The kids always eat first because they are the ones that cannot bear the hunger" (Interview \#12, 5/21/2013). All current 
and former Panaillo residents interviewed also reported feeling worried about their household's food security, with 41 percent of Panaillo respondents $(n=11)$ and 53 percent of migrant respondents $(n=8)$ specifically reporting concern over the nutritional well-being of their children.

In spite of the prioritization of children's nutrition, 40 percent of children in Panaillo suffer from chronic malnutrition, 30 percent from acute malnutrition, and 53 percent from anemia, according to a worker from a provincial nutrition supplementation program in Panaillo (Programa Articulado Nutricional [PAN]). In 2012, Panaillo had the highest rates of pediatric malnutrition and anemia out of the 33 communities participating in PAN. One institutional interviewee who works for this nutrition program commented that: "When the children are over six months old, the mothers just teach them how to endure the hunger" (Interview \#47, 5/17/2013). Such high rates of malnutrition can be attributed to contaminated water, unhygienic food preparation, insufficient food quantities, low nutritional education levels, and the aforementioned low diet diversity, all of which were observed during fieldwork and reported by three health workers that work with Panaillo. According to a regional health worker for the Ucayali government, these food security determinants and high rates of malnutrition are common throughout the region and reflect high rates of poverty.

\subsection{Food Availability and Food Access in Panaillo Households}

As seen in Table 2, all households reported that at times their household did not have sufficient amounts of food. Four Panaillo respondents (representing two households) reported that they always found some way of maintaining food consumption levels, typically by increasing fishing efforts and/or purchasing food. The remaining 23 Panaillo residents reported reducing food consumption in the past year when fishing and/or buying food were not feasible. Reduced food consumption was attributed to the male household head not going fishing in 85 percent of Panaillo interviews ( $n=22)$. Forty-two percent of Panaillo respondents ( $n=11$ ) discussed how the household suffered from insufficient food when alternative ways of acquiring food were unavailable, such as food sharing $(n=4)$, consumption of agricultural products $(n=3)$, and using money to purchase food $(n=4)$. 
Table 2. Community reporting on dimensions of household food insecurity.

\begin{tabular}{|l|c|c|c|}
\hline $\begin{array}{l}\text { Dimension of Food } \\
\text { Insecurity }\end{array}$ & $\begin{array}{c}\text { Panaillo } \\
\text { Respondents } \\
\text { (n=27) }\end{array}$ & $\begin{array}{c}\text { Migrant } \\
\text { Respondents } \\
\text { (n=15) }\end{array}$ & $\begin{array}{c}\text { Average } \\
\text { (n=42) }\end{array}$ \\
\hline $\begin{array}{l}\text { Insufficient food } \\
\text { quantities }\end{array}$ & $100 \%(\mathrm{n}=27)$ & $100 \%(\mathrm{n}=15)$ & $100 \%(\mathrm{n}=42)$ \\
\hline $\begin{array}{l}\text { Insufficient food } \\
\text { quantities leading to } \\
\text { reduced food } \\
\text { consumption }\end{array}$ & $85 \%(\mathrm{n}=23)$ & $100 \%(\mathrm{n}=15)$ & $93 \%(\mathrm{n}=39)$ \\
\hline Poor food quality & $89 \%(\mathrm{n}=24)$ & $100 \%(\mathrm{n}=15)$ & $93 \%(\mathrm{n}=39)$ \\
\hline Skipping 1-2 meals & $77 \%(\mathrm{n}=21)$ & $87 \%(\mathrm{n}=13)$ & $81 \%(\mathrm{n}=34)$ \\
\hline $\begin{array}{l}\text { Eating less than } \\
\text { know should }\end{array}$ & $77 \%(\mathrm{n}=21)$ & $100 \%(\mathrm{n}=15)$ & $86 \%(\mathrm{n}=36)$ \\
\hline Feeling hungry & $85 \%(\mathrm{n}=23)$ & $80 \%(\mathrm{n}=12)$ & $83 \%(\mathrm{n}=35)$ \\
\hline
\end{tabular}

Since fishing is a male-dominated livelihood, women referred to their male family member not going fishing when discussing the role of fishing in household food insecurity. One female respondent illustrated this concept by stating,

We don't have enough food when my husband does not go fishing. When he goes fishing and can sell the fish, we buy sugar and rice, but now that he is sick, he cannot go fishing or buy us food (Interview \#17, 5/23/2013).

Women were also more likely to discuss non-fishing related reasons for insufficient household food levels, such as lack of financial resources ( $n=3$ women, 0 men) and foodsharing ( $\mathrm{n}=3$ women, 1 man). Similarly, when asked which households most struggled to maintain food security, all Panaillo respondents mentioned households that could not work or go fishing, including the elderly $(n=7)$ and single mothers and widows $(n=12)$ (see Table $3)$.

\subsection{Food Quality}

Eighty-nine percent of Panaillo residents $(n=24)$ and 100 percent of migrants $(n=15)$ that were interviewed reported issues with the quality of their food. Since plantain and fish form the staples of the Shipibo diet, problems with the quality of these specific foods were mentioned in most community interviews $(n=24)$ and in the male and female seasonal food security calendar focus groups. Five Panaillo interviewees also reported the consumption of rotten food. All five of these cases consisted of fish that fell into the trap early in the day 
Table 3. Perception of household food insecurity in Panaillo.

\begin{tabular}{|l|c|}
\hline \multicolumn{1}{|c|}{$\begin{array}{c}\text { Characteristics of Households that Struggle } \\
\text { with Food Insecurity }\end{array}$} & $\begin{array}{c}\text { Panaillo Respondents } \\
\text { that Mentioned } \\
\text { Household Characteristic } \\
\text { (n=27) }\end{array}$ \\
\hline $\begin{array}{l}\text { Those that cannot work in agro-fishing and/or income- } \\
\text { generating livelihoods }\end{array}$ & $44 \%(\mathrm{n}=12)$ \\
\hline Single mothers and widows & $44 \%(\mathrm{n}=12)$ \\
\hline Elderly & $26 \%(\mathrm{n}=7)$ \\
\hline No one & $11 \%(\mathrm{n}=4)$ \\
\hline Those without flood-resistant plantain & $4 \%(\mathrm{n}=1)$ \\
\hline Spouse away working & $4 \%(\mathrm{n}=1)$ \\
\hline No comment & $4 \%(\mathrm{n}=1)$ \\
\hline Doesn't know & $14 \%(\mathrm{n}=4)$ \\
\hline
\end{tabular}

and became rotten after lying in the sun for several hours. These respondents reported that fish that were more than slightly rotten were not consumed. Although field observations did not witness the consumption of rotten fish, there were several field observations of Panaillo community members consuming rotten fruits, vegetables, and bread. Since these foods are less prominent in the traditional Shipibo diet, these observations could be attributed to the local unfamiliarity with such foods. Among the 10 migrant respondents that were asked about the consumption of rotten food, 60 percent $(n=6)$ reported eating rotten fish as a result of purchasing rotten fish from market. Three migrants accidentally consumed rotten fish, whereas two migrant respondents reported not having enough money to buy higher quality fish.

\subsection{Food Stability}

Seventy-seven percent of Panaillo residents $(n=21)$ and 87 percent of migrants interviewed $(n=13)$ reported skipping 1-2 meals in the past year because of insufficient food in the household. Seventy-seven percent of Panaillo residents $(n=21)$ and 100 percent of migrants $(n=15)$ also reported having eaten less food than they thought they should have in the past year because they lacked food. In the past year, respondents in 85 percent of Panaillo interviews ( $n=23)$ and 80 percent of migrant interviews $(n=12)$ also reported feeling hungry but not eating anything because the household lacked food. The principal 
reasons for such food instability are presented in Table 4, which illustrates the role of fishing, work within and outside of the community, financial resources, harvest foods and flood conditions in maintaining household food security throughout the year. Lack of fishing was the most frequently mentioned reason for moments of household food insecurity among Panaillo residents. Male household members were reported to be unable to go fishing due to a combination of engaging in other paid work or agricultural activities, illness, and flood conditions.

Although only two Panaillo respondents attributed insufficient household food levels and skipping meals to flooding, the influence of flooding on food insecurity became increasingly prominent for issues of feeling hungry and eating less food than one should (see Table 4). Five community members explicitly mentioned flooding in reasons for eating less than one should, and six community members attributed their hunger to flooding. However, it is important to note that flooding has a strong indirect role on fishing, agricultural production, and income-generating opportunities within and outside of the community, as will be discussed in the next chapter.

\section{Chapter Summary}

Current and former Panaillo residents report significant challenges with household food utilization, quantity, quality, and stability. All current and former Panaillo residents interviewed reported being worried about their household's food security, especially for the children in the family. Between 77-100 percent of current and former Panaillo respondents reported feeling hungry, skipping meals, and eating less than they felt they should at various points in the last year. Households in Panaillo experience high levels of food insecurity primarily as a result of insufficient fish and harvest foods for household consumption and low levels of household income with which to purchase food. The following two chapters will elaborate on these issues by examining the drivers of food system vulnerability in Panaillo. 
Table 4. Respondent-attributed reasons for household food insecurity dimensions.

\begin{tabular}{|c|c|c|c|}
\hline $\begin{array}{l}\text { Reason reported for } \\
\text { household food } \\
\text { insecurity }\end{array}$ & Dimension of food insecurity reported to affect & $\begin{array}{l}\text { Panaillo Respondents } \\
\text { Attributing Reason to } \\
\text { Dimension of Food } \\
\text { Insecurity }\end{array}$ & $\begin{array}{c}\text { Migrant Respondents } \\
\text { Attributing Reason to } \\
\text { Dimension of Food } \\
\text { Insecurity }\end{array}$ \\
\hline \multirow{4}{*}{$\begin{array}{l}\text { Male family member } \\
\text { does not go fishing }\end{array}$} & $\begin{array}{l}\text { Insufficient food quantities resulting in reduced food consumption } \\
\text { (n=23 Panaillo; } 15 \text { Migrant) }\end{array}$ & $96 \%(n=22)$ & $0 \%(n=0)$ \\
\hline & Skipping 1-2 meals (n=21 Panaillo, 13 Migrant) & $86 \%(n=18)$ & $0 \%(n=0)$ \\
\hline & Eating less than know should ( $\mathrm{n}=21$ Panaillo, 15 Migrant) & $86 \%(n=18)$ & $0 \%(n=0)$ \\
\hline & Feeling hungry ( $\mathrm{n}=23$ Panaillo, 12 Migrant) & $87 \%(n=20)$ & $0 \%(n=0)$ \\
\hline \multirow{4}{*}{$\begin{array}{l}\text { Male family member } \\
\text { away working }\end{array}$} & $\begin{array}{l}\text { Insufficient food quantities resulting in reduced food consumption } \\
\text { (n=23 Panaillo; } 15 \text { Migrant) }\end{array}$ & $22 \%(n=5)$ & $7 \%(n=1)$ \\
\hline & Skipping 1-2 meals (n=21 Panaillo, 13 Migrant) & $19 \%(n=4)$ & $0 \%(\mathrm{n}=0)$ \\
\hline & Eating less than know should ( $\mathrm{n}=21$ Panaillo, 15 Migrant) & $19 \%(n=4)$ & $7 \%(\mathrm{n}=1)$ \\
\hline & Feeling hungry (n=23 Panaillo, 12 Migrant) & $17 \%(n=4)$ & $8 \%(n=1)$ \\
\hline \multirow{4}{*}{$\begin{array}{l}\text { Male family member } \\
\text { occupied with local } \\
\text { work (e.g., } \\
\text { agriculture, } \\
\text { commercial fishing) }\end{array}$} & $\begin{array}{l}\text { Insufficient food quantities resulting in reduced food consumption } \\
\text { (n=23 Panaillo; } 15 \text { Migrant) }\end{array}$ & $17 \%(n=4)$ & $0 \%(n=0)$ \\
\hline & Skipping 1-2 meals (n=21 Panaillo, 13 Migrant) & $10 \%(\mathrm{n}=2)$ & $0 \%(\mathrm{n}=0)$ \\
\hline & Eating less than know should ( $\mathrm{n}=21$ Panaillo, 15 Migrant) & $5 \%(n=1)$ & $0 \%(n=0)$ \\
\hline & Feeling hungry (n=23 Panaillo, 12 Migrant) & $9 \%(n=2)$ & $0 \%(n=0)$ \\
\hline \multirow{4}{*}{$\begin{array}{l}\text { Low financial } \\
\text { resources }\end{array}$} & $\begin{array}{l}\text { Insufficient food quantities resulting in reduced food consumption } \\
\text { (n=23 Panaillo; } 15 \text { Migrant) }\end{array}$ & $26 \%(n=6)$ & $100 \%(n=15)$ \\
\hline & Skipping 1-2 meals ( $\mathrm{n}=21$ Panaillo, 13 Migrant) & $29 \%(n=6)$ & $100 \%(n=15)$ \\
\hline & Eating less than know should (n=21 Panaillo, 15 Migrant) & $43 \%(n=9)$ & $100 \%(n=15)$ \\
\hline & Feeling hungry ( $\mathrm{n}=23$ Panaillo, 12 Migrant) & $43 \%(n=10)$ & $100 \%(n=12)$ \\
\hline \multirow{4}{*}{ Lack of harvest foods } & $\begin{array}{l}\text { Insufficient food quantities resulting in reduced food consumption } \\
\text { (n=23 Panaillo; } 15 \text { Migrant) }\end{array}$ & $13 \%(n=3)$ & $0 \%(n=0)$ \\
\hline & Skipping 1-2 meals (n=21 Panaillo, 13 Migrant) & $14 \%(n=3)$ & $0 \%(n=0)$ \\
\hline & Eating less than know should (n=21 Panaillo, 15 Migrant) & $19 \%(n=4)$ & $0 \%(\mathrm{n}=0)$ \\
\hline & Feeling hungry (n=23 Panaillo, 12 Migrant) & $17 \%(n=4)$ & $0 \%(\mathrm{n}=0)$ \\
\hline \multirow{4}{*}{$\begin{array}{c}\text { Flood conditions } \\
\text { explicitly mentioned }\end{array}$} & $\begin{array}{l}\text { Insufficient food quantities resulting in reduced food consumption } \\
\text { (n=23 Panaillo; } 15 \text { Migrant) }\end{array}$ & $9 \%(n=2)$ & $0 \%(n=0)$ \\
\hline & Skipping 1-2 meals ( $\mathrm{n}=21$ Panaillo, 13 Migrant) & $10 \%(n=2)$ & $0 \%(n=0)$ \\
\hline & Eating less than know should ( $\mathrm{n}=21$ Panaillo, 15 Migrant) & $19 \%(n=4)$ & $7 \%(n=1)$ \\
\hline & Feeling hungry ( $\mathrm{n}=23$ Panaillo, 12 Migrant) & $22 \%(n=5)$ & $8 \%(\mathrm{n}=1)$ \\
\hline
\end{tabular}




\section{CHAPTER 5. RESULTS - DISTAL DRIVERS OF FOOD SYSTEM VULNERABILITY}

This chapter examines the food system vulnerability of Panaillo through four major themes: climate and climatic events, economic development, low institutional capacity, and the assimilation social model of Peru (see Figure 7). These themes have profound effects on the food system and health by affecting the ways in which livelihoods and adaptive strategies are practiced. Examining the distal drivers of the food system captures the broader determining factors of food system vulnerability. The focus of this chapter thus reflects the importance of large-scale factors in shaping the context of food security and vulnerability (Ford et al., 2013; Chapin et al., 2004). The chapter is structured by the principles of the vulnerability framework presented in Chapter 3, although terms like sensitivity-exposure and adaptive capacity are not explicitly used.

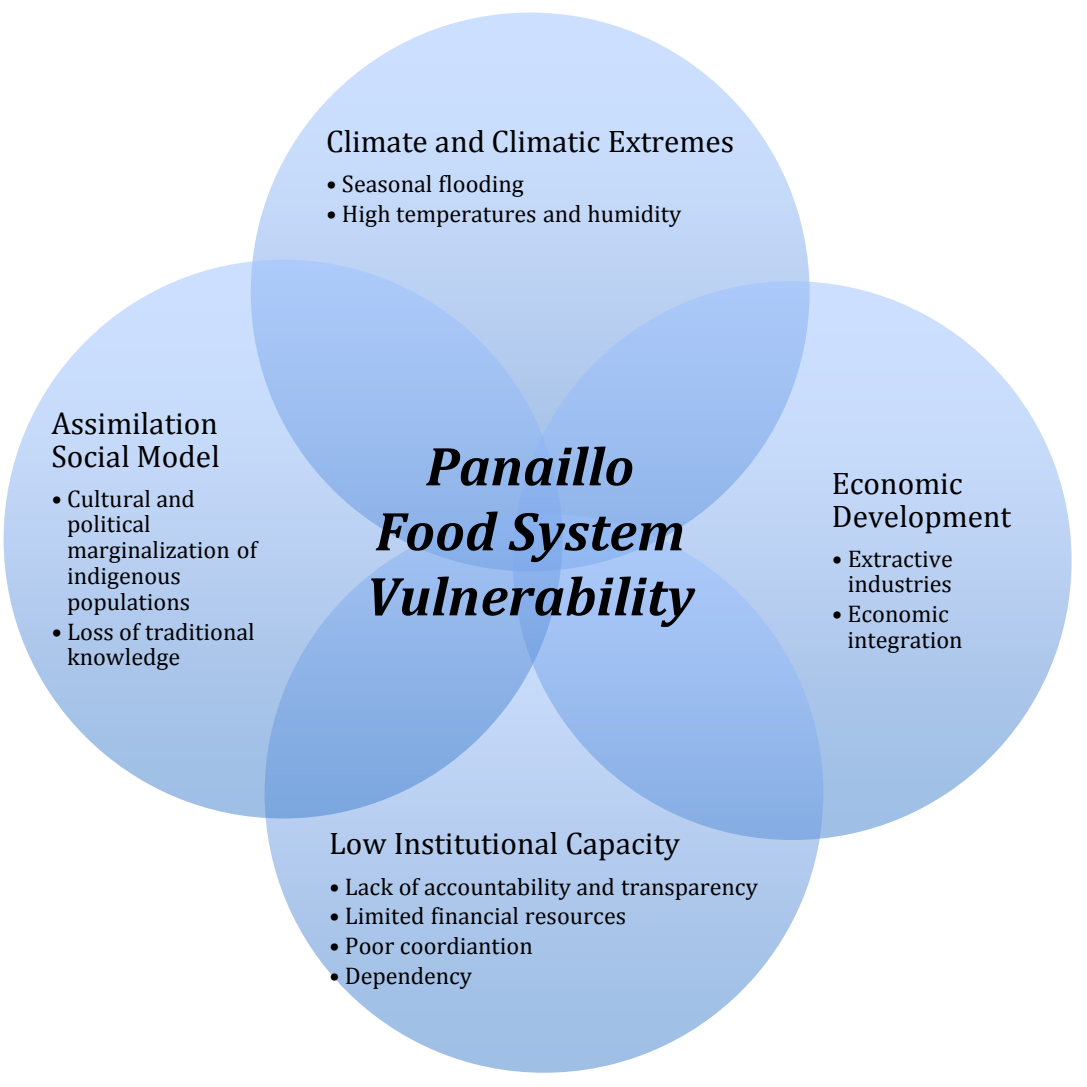

Figure 7. Distal drivers of Panaillo's food system vulnerability. 


\subsection{Climate and Climatic Events}

\subsubsection{Seasonal Flooding in Panaillo}

The Panaillo River begins to rise with the onset of the rainy season in November. Flooding typically begins in January in the same lower areas of Panaillo each year, and was reported by most Panaillo respondents $(78 \%, \mathrm{n}=21)$ to become completely flooded within one week. Flooding typically lasts 2-3 months, with peak flood levels in February or March. Earlier rains can result in earlier flood onset, as seen in 2012-2013 (Carranza, 2013a). The flood in 2012-2013 also had a later peak than usual due to less intense rains, which led to a slower progressive rise of the Ucayali River (Carranza, 2013a).

Flood management is addressed through the National System of Disaster Risk Management (SINAGERD), which operates through the National Center for Disaster Risk Estimation, Prevention and Reduction (CENEPRED) and the National Institute of Civil Defense (INDECI). These institutions oversee local, provincial, and regional Civil Defense offices, which operate in a decentralized and mostly autonomous manner. Each office manages its own budget to address disasters, including the flooding that occurs in Ucayali each year (Interview \#63,6/17/2013). If the district is unable to cope with flood damage, they declare a state of emergency and receive support from the province. Similarly, the province/region can declare a state of emergency if the flood damage exceeds the area's coping capacity and federal support is required. In order to ensure that such declarations only occur for an actual emergency, sanctions apply if a state of emergency is declared when the government's designated budget should have been able to manage the climatic event (Interview \#63, 6/17/2013). For example, the floods in 2010-2011 and 2011-2012 were both given a 'red alert', indicating flood conditions of highest risk. In these years, the Ucayali region declared a state of emergency in order to solicit national flood relief support. The flood in 2012-2013 was less severe than in preceding years, and the entire region did not declare a state of emergency, although three districts in Coronel Portillo and the province of Padre Abad did.

\subsubsection{Flooding Impacts on Panaillo's Food System}

Flooding creates both challenges and opportunities for Panaillo residents and their 
livelihoods. One male Panaillo respondent commented: "The flood is like tradition here. It has its consequences, it [has] advantages and disadvantages" (Interview \#3, 5/10/2013). Similarly, Bergman stated: "Each year there is a flood, and all life adjusts to it. It comes not as a disaster, but as a season" (1980: 53). However, Panaillo community members generally have a negative perception of seasonal flooding. One-quarter of Panaillo respondents $(n=7)$ and one-third of migrant respondents $(n=5)$ stated that the flood has no benefits. Conversely, 60 percent of migrants interviewed $(n=9)$ stated that the flood had no consequences in the city of Yarinacocha. The city only floods occasionally during severe flood years, and migrant households do not depend on homegrown foods for household food security. One migrant respondent commented: "We don't feel anything here. The water rises in the community and you see it rising close up. In the city, we're on higher ground and we only notice the flood when we go to ports" (Interview \#33,6/3/2013).

All of the difficulties listed in the risk ranking focus group for the dry and rainy seasons were directly or indirectly related to hydrological conditions, including difficulty with agricultural conditions and fish availability. Some households were identified by current and former Panaillo residents to have relatively greater difficulty in coping with the flood, including those that must depend on other family members for sources of food and income (e.g., elderly, widows, single mother, orphans) and those that are unable to work in agro-fishing or income-generating livelihoods (Table 5). These traits resemble the community perceptions of households that are vulnerable to food insecurity (see Table 3). When asked about the difficulties created by the flood, 74 percent of community members $(n=31)$ described how flooding inhibits agricultural production. According to interviews with the Ministry of Agriculture, only the camu camu berry (Myrciaria dubia) can survive severe flooding. Camu camu requires high quantities of water for growth, and can be submerged for up to five months. Plants with longer growth cycles, such as plantain, cannot be cultivated in Panaillo unless the flood is of lesser intensity and shorter duration. Some households still cultivate crops such as plantain, yuca and corn in the forested areas near Panaillo. However, the flood typically kills these crops before they reach maturation, with the exception of a 3-month yuca cultivar. Accordingly, plantain scarcity was the most frequently mentioned and highest scoring difficulty for both rainy and dry seasons in the risk ranking focus group. One migrant respondent stated: "There are no crops. The flood 
leaves us with nothing. It's an empty plain. Nothing. Nothing. If there's something it's only trees that aren't edible. It's very difficult to live this way" (Interview \#38, 7/15/2013).

Living in a flood-prone area becomes advantageous for Panaillo residents when river levels lower and households are able to plant fast-growing cultivars on the fertile riverbeds. Households plant rice, cowpea, peanuts, and watermelon in May and harvest these crops in August until the onset of the flood in December. This cultivation is responsible for the majority of harvest foods for household consumption and income in

Table 5. Community perceptions of households vulnerable to seasonal flooding.

\begin{tabular}{|l|c|c|c|}
\hline $\begin{array}{l}\text { Types of Households } \\
\text { Reported to Have the } \\
\text { Most Difficulty with } \\
\text { the Seasonal Flood }\end{array}$ & $\begin{array}{c}\text { Panaillo } \\
\text { Respondents } \\
(\mathbf{n}=27)\end{array}$ & $\begin{array}{c}\text { Migrant Respondents } \\
(\mathbf{n}=\mathbf{1 5})\end{array}$ & $\begin{array}{c}\text { Total } \\
\text { Respondents } \\
\text { (n=42) }\end{array}$ \\
\hline Elderly & $26 \%(\mathrm{n}=7)$ & $40 \%(\mathrm{n}=6)$ & $31 \%(\mathrm{n}=13)$ \\
\hline $\begin{array}{l}\text { Unable to work in } \\
\text { agro- } \\
\text { fishing/income- } \\
\text { generating } \\
\text { livelihoods }\end{array}$ & $15 \%(\mathrm{n}=4)$ & $27 \%(\mathrm{n}=4)$ & $19 \%(\mathrm{n}=8)$ \\
\hline $\begin{array}{l}\text { Those that stay in } \\
\text { Panaillo during the } \\
\text { flood }\end{array}$ & $19 \%(\mathrm{n}=5)$ & $13 \%(\mathrm{n}=2)$ & $17 \%(\mathrm{n}=7)$ \\
\hline All suffer equally & $19 \%(\mathrm{n}=5)$ & $13 \%(\mathrm{n}=2)$ & $17 \%(\mathrm{n}=7)$ \\
\hline $\begin{array}{l}\text { Widows, single } \\
\text { mothers, and } \\
\text { orphans }\end{array}$ & $15 \%(\mathrm{n}=4)$ & $13 \%(\mathrm{n}=2)$ & $14 \%(\mathrm{n}=6)$ \\
\hline $\begin{array}{l}\text { Those without a } \\
\text { harvest }\end{array}$ & $7 \%(\mathrm{n}=2)$ & $13 \%(\mathrm{n}=2)$ & $10 \%(\mathrm{n}=4)$ \\
\hline $\begin{array}{l}\text { Those that migrate } \\
\text { to the city for the } \\
\text { winter }\end{array}$ & $11 \%(\mathrm{n}=3)$ & $0 \%(\mathrm{n}=0)$ & $7 \%(\mathrm{n}=3)$ \\
\hline $\begin{array}{l}\text { Those with an old } \\
\text { house }\end{array}$ & $4 \%(\mathrm{n}=1)$ & $0 \%(\mathrm{n}=0)$ & $2 \%(\mathrm{n}=1)$ \\
\hline $\begin{array}{l}\text { Families with many } \\
\text { children }\end{array}$ & $0 \%(\mathrm{n}=0)$ & $7 \%(\mathrm{n}=1)$ & $2 \%(\mathrm{n}=1)$ \\
\hline $\begin{array}{l}\text { Those who live in } \\
\text { lower areas (of the } \\
\text { city) }\end{array}$ & $0 \%(\mathrm{n}=0)$ & $7 \%(\mathrm{n}=1)$ & $2 \%(\mathrm{n}=1)$ \\
\hline Doesn't know & $11 \%(\mathrm{n}=3)$ & $20 \%(\mathrm{n}=3)$ & $14 \%(\mathrm{n}=6)$ \\
\hline
\end{tabular}


Panaillo. In the risk ranking focus group, rice production on mudflats was the highestscoring and most frequently mentioned benefit of the dry season, and over one-third of community members $(\mathrm{n}=15)$ listed fertile riverbeds as a benefit of flooding. However, crops take several months to reach maturation; as one migrant explained: "You plant, you invest and you have to wait to see your money" (Interview \#32, 5/26/2013). Panaillo residents thus rely mainly on fish and purchased food until harvest crops are ready. Nonetheless, this form of agriculture is always risky, even amidst normal seasonal flooding (Chibnik, 1994).

The hydrological cycle also has a strong influence on fishing livelihoods. Community interviews ( $\mathrm{n}=12)$ and participants in the seasonal food security focus group noted how the high volume of water and strong currents from the seasonal flooding make fishing difficult. Bergman (1980) similarly noted how the formation of whirlpools in the rainy season impeded fishing and boat transport. Nets and spears also become less viable fishing tools in the rainy season due to the larger quantity of water and fish may migrate to other areas due to increased sediment and debris in a given area. However, flooding also replenishes local fish stocks since the high water levels enable fish to leave their lake habitats and to migrate downstream in the recession of floodwaters. The flood conditions also play an important role in the reproductive cycle of seasonal fish, which spawn at the start of the flood season (Ruffino \& Isaac, 1995). Furthermore, fish become easier to catch during the mijano, the period of fish abundance when water levels lower and fish become trapped in new lakes (Junk, Bayley \& Sparks, 1989; Santa Cruz et al., 2013; Kvist \& Nebel, 2001). The abundance and variety of fish during the mijano were discussed in over 30 percent of community interviews $(n=13)$ and the seasonal food security focus group.

However, fish abundance has minimal overlap with the abundance of harvest foods, meaning that most Panaillo residents lack either the fish or the carbohydrate complement. Once plants are finally mature, fish populations decline as they become overharvested and die in drying lakes. One Panaillo respondent stated: "Now you have to choose between plantain or fish because they're not abundant at the same time" (Interview \#4, 5/10/2013). In a study with the Shipibo community of Nuevo Éden, Behrens (1986) notes that 
malnutrition increases in the dry season since community members do not have access to protein-rich foods like fish, even though carbohydrate sources, such as plantain, are plentiful.

Flooding also impacts alternative income-generating livelihoods. One-third of Panaillo respondents $(n=9)$ and over half of migrant respondents $(n=8)$ mentioned difficulty working as a consequence of flooding. For example, two respondents discussed the difficulty finding wage labor on large agricultural plantations during the rainy season since farms in lower areas cease production due to flooding. Four Panaillo respondents also discussed the difficulty of making traditional handicrafts when the floor is covered with water. Since agro-fishing livelihoods are not as viable in the flood season, this lack of income-generating work has significant repercussions on household income and food, as indicated by female participants in the risk ranking focus group. Accordingly, 37 percent of Panaillo respondents $(n=10)$ mentioned having the highest diet diversity in the dry season, especially after the harvest. Certain livelihoods benefit from the flood conditions. Men in the risk ranking focus group discussed being able to extract timber more easily in the flooded conditions due to the high water levels and rapid access to trees by boat. Similarly, Goy and Waltner-Toews (2005) found that food scarcity is greatest during the rainy season.

Travel by boat is also easier and faster in the rainy season than in the dry season, when river levels drop significantly. Participants in the risk ranking focus group considered transportation to be the most significant benefit of the flood. However, strong waves, wind, and currents can limit mobility during the rainy season, as indicated in three Panaillo interviews and reiterated in the risk ranking focus group. Furthermore, since canoes replace walking in the months of the flood, mobility can be highly constrained if a boat is unavailable. Similarly, inadequate bridges and poor urban infrastructure were reported by two migrant interviews to limit mobility in the city.

\subsection{Economic Development}

Economic development has dramatically changed the landscape and livelihoods of the Peruvian Amazon. Over the past twenty years, Peru has emerged as one of the fastest growing and most stable economies in Latin America (IMF, 2013; United Nations, 2014). Peru's economy almost doubled in size between 2002-2012, marking the country's highest 
10-year growth rate in its history (Vera \& Wong, 2013). Extractive industries, including mining, logging, and oil exploration, have significantly contributed to Peru's rapid economic growth (Pantigoso, 2014). Panaillo is located in the heartland of Peru's logging industry (Sears \& Pinedo-Vasquez, 2011). Over the past few years, the logging industry in the nearby city of Pucallpa has grown substantially and illegal logging is thought to make up 80-95 percent of that industry (Cossío et al., 2014; Sears \& Pinedo Vasquez, 2011). The high international demand for Amazonian timber has combined with increasing pressures to clear land for agriculture and has resulted in massive deforestation throughout the region (Kleinwechter \& Lara, 2010). Peru is also a leading exporter of copper, gold and silver, and oil blocks can be found in over two-thirds of the Peruvian Amazon (Finer et al., 2008). Mining and oil operations have been spreading throughout the Peruvian Amazon in the past few decades, and are located mostly in the northern Loreto, Cusco and Madre de Dios regions, although one petroleum operation is beginning upstream of Panaillo in Alto Ucayali according to two Panaillo interview respondents and 7 institutional respondents.

Since Panaillo residents depend on both financial and natural resources for their food, the resource extraction and market integration that have resulted from Peru's economic development have important implications for the food system. Community members directly participate in extractive industries through temporary jobs $(n=4)$. In addition, six residents directly sell timber, five residents sell fish, and all Panaillo households sell agricultural products. Six Panaillo respondents and two migrant respondents also reported working on large agricultural plantations as temporary wage laborers. Participants in the historical timeline focus group noted the increase of commercial fishing in the area and how fishermen are now using different types of equipment (e.g., large nets, poison) to capture larger quantities of fish.

Panaillo residents have also become increasingly dependent on financial resources to meet household needs. Approximately one-third of Panaillo respondents mentioned money as part of their reason for eating less than they thought they should $(n=9)$ and/or feeling hungry $(n=10)$. Ninety-three percent of Panaillo residents $(n=25)$ and 100 percent of migrants also indicated that lack of financial resources made it difficult to incorporate vegetables into the diet due to the high cost of seeds and/or high cost of vegetables in the market. Households are increasingly buying staple food items, like plantain and fish, in 
addition to manufactured goods and processed foods.

Migrant interviewees demonstrated a stronger dependence on financial resources for household food stability than Panaillo residents. All migrant interviewees ( $n=15)$ mentioned limited financial resources as the exclusive reason for missing meals, eating less than they should, and feeling hungry. Although no Panaillo male respondent exclusively attributed any of these food security dimensions to lack of financial resources, one-fifth of Panaillo female respondents $(\mathrm{n}=3)$ considered low financial resources as the exclusive reason for skipping meals. This finding reiterates how women in Panaillo have a relatively higher dependence on alternative strategies for food acquisition, since fishing is a maledominated livelihood activity.

Most Panaillo respondents $(n=25)$ reported needing to sell their agricultural crop immediately after the harvest out of financial desperation. However, the Ucayali markets are entirely driven by supply and demand. The vast majority of Panaillo respondents thus sell their crops at a time when market prices are lowest and supply is highest. One migrant respondent explained: “Out of necessity we are selling. It's not possible to wait for the price" (Interview \#31, 5/26/2013). Three Panaillo respondents also reported being unable to delay selling agricultural products until later in the season due to poor storage capabilities. Only two households $(n=3)$ reported being able to delay selling until the end of the harvest season to sell at a better price. Food prices increase substantially in the late harvest and rainy season, since supply is reduced from many lowland areas and residents in flooded areas depend more on purchased foods. The majority of community members $(n=25)$ discussed struggling to afford food in the rainy season due to these higher food prices, increased reliance on buying foods, and limited income.

Panaillo residents also have limited access to fair prices due to their lack of market contacts. While recalling her experiences selling agricultural products, one migrant respondent stated: "This is the problem of the indigenous communities here- there is nowhere to bring the product and there are no stable markets" (Interview \#32, $5 / 26 / 2013$ ). Although five respondents sold to the same person in the market each time, these contacts did not improve the price or stability of the transaction, and were sought out mostly to solicit loans. Similarly, all interview respondents that work in traditional handicrafts $(n=24)$ reported struggling to sell their products at a fair price. Over half of 
these respondents $(n=14)$ sold their handicrafts to small tourist shops, whereas the rest $(n=10)$ sold their work to random passersby, including the occasional tourist and intermediaries who resold the work.

Market access for sale and purchase is further constrained by the lack of affordable, reliable transportation. When Bergman (1980) carried out his fieldwork in 1971-2, four households in Panaillo owned a boat. Today only two households in Panaillo own a boat. The other 16 households must borrow the boat from these households or from other friends outside of the community. One elderly Panaillo resident discussed how his agricultural plot on the riverbed is far from the community, yet waiting to borrow a boat often delays planting. Waiting for transportation can also delay the sale of agricultural products. All river transportation is private, and almost half of community respondents $(n=18)$ reported being refused transport by collective boats because they did not want to carry such a heavy load or the boats were full. Private collective boats also charge more for passengers with additional weight. One Panaillo respondent commented that: "We ultimately work for the fleteros (men who collect transport charges). They earn more than us. If I bring 500 kilos, for every 100 kilos they charge 60-80 soles [ USD \$21-29]. We earn less than half" (Interview \#12, 5/21/2013). Accordingly, one-third of current and former Panaillo residents interviewed $(n=14)$ complained of the high cost of transport in collective boats for both travel and transporting goods.

Financial resources are not only needed to sell and purchase foods, but have also become increasingly important for livelihood activities. Although five men in the community sell fish, only two have an ice chest. Without an ice chest, the fish will rot by the time it reaches the market in Yarinacocha, and so these fishermen are forced to sell their fish catches cheaply to the neighbors with ice chests and/or to the local market in Taschitea. For subsistence and commercial fishing, a fish trap is also an essential piece of equipment. However, as mentioned in the historical timeline focus group, some households cannot afford this USD\$18-21 piece of equipment, and struggle to catch as many fish using a spear or harpoon. For timber extraction, households need money to purchase a saw, rent a boat, and pay for gasoline, workers, and food for the work party. Similarly, traditional handicrafts require purchased materials, including cloth, string, and needles. One Panaillo respondent commented: "You need money in order to work" (Interview \#36, 7/13/2013). 


\subsection{Low Institutional Capacity}

Peru has undergone rapid and extensive decentralization since 2002 with the aim of reducing regional inequalities and improving services and living conditions (CalvoGonzalez, 2010). Major criticisms of the decentralization process include weak intergovernmental coordination, fragmentation between local levels preventing economies of scale, lack of skills and resources at the sub-national level, and personal interests influencing the implementation of decentralization (Calvo-Gonzalez, 2010). The challenges stemming from the decentralization process have strongly shaped the Panaillo food system through the policies and programs that were produced in this socio-political environment. Low institutional resources, poor planning and coordination, dependency, and financial mismanagement were all shown in this research to inhibit effective, reliable implementation of services in Panaillo, including flood management and nutrition programs.

Over one-third of institutional respondents $(n=13)$ discussed how local institutions are constrained in their ability to carry out activities due to limited financial resources. The 12 institutions discussed in these interviews represent three nongovernmental organizations and nine governmental institutions at the district $(n=4)$, regional $(n=4)$ and national $(n=1)$ levels. In six interviews, respondents attributed insufficient financial resources to poor administrative skills, including planning, coordination, project management, and accounting. One institutional respondent highlighted this issue among indigenous organizations in particular, stating that: "The weakness of indigenous organizations is that they don't present a budget and they don't spend the budget they have either" (Interview \#51, 5/28/2013).

The national school-feeding program, Qali Warma, similarly illustrates institutional challenges with poor distribution of resources. Qali Warma provides breakfast to all impoverished districts in the country, as well as lunch to communities in 'extremely poor' districts. Although Panaillo is an 'extremely poor' community, Panaillo is only eligible for breakfast since Yarinacocha is considered a 'poor' district and Qali Warma provides meals according to district poverty levels. Qali Warma also bases its food provision for each school on 2010 statistics, which is problematic for areas with growing student populations, 
like Panaillo. Qali Warma's also received significant public criticism in Peruvian newspapers this past year when it repeatedly supplied rotten foods to schools, causing hundreds of cases of food poisoning (El Comercio, 2013b).

Institutional interviewees $(n=5)$ also discussed poor resource management in the district and regional Civil Defense offices. The Civil Defense at the regional and local levels became responsible for creating and managing their own budget once INDECI began to decentralize in 2011. However, five institutional respondents discussed how the local Civil Defense in Yarinacocha (Panaillo's district) did not properly design the budget to cover their jurisdiction's needs during the flood season. A respondent from Yarinacocha's Civil Defense office reported that sufficient funds were not available in 2012-2013 to employ more than two field workers to cover the entire district and funds were insufficient to provide more than two weeks of food aid to households. However, the office also reported purchasing an excessive amount of plastic material in that same year. Limited resources and low administrative skills in the Yarinacocha Civil Defense thus constrain the timely and sufficient allocation of flood relief in the area.

Inaccurate institutional information exacerbates funding issues. For example, Panaillo's electoral district changed five years ago from Callería to Yarinacocha and Panaillo should currently benefit from services and programs designated for communities in the Yarinacocha district. However, a respondent from the Callería Civil Defense stated that they continue to provide flood relief to Panaillo since they believe Yarinacocha is unlikely to do so. The absence of district services can be partly attributed to remaining confusion over Panaillo's jurisdiction. For example, an agriculture extension worker for the Yarinacocha district at the Ministry of Agriculture was unaware that Panaillo was part of their district's jurisdiction and that Panaillo should thus be included in program activities. Another institutional respondent from the Ministry of Agriculture asserted that Panaillo was only politically part of Yarinacocha, and that it administratively belonged to Callería. As a result of this misunderstanding, Panaillo cannot consistently rely on Yarinacocha services.

The minimal presence of government services and flood relief in communities is compounded by the lack of preventative culture in Peru, and more specifically in Panaillo (Latrubesse, 2009; Urby, McEntire \& Peters, 2011). Over 40 percent of institutional 
respondents $(n=13)$ criticized Panaillo and other flood-prone communities in the area for becoming dependent on flood relief support. Similarly, in community interviews, only one community member emphasized the importance of taking preventative actions, whereas six community members stated the desire for more relief support during the aftermath of a flood. According to three institutional respondents, the community's dependence on flood relief and social programs has inhibited long-term solutions to avoid flood damage each year. One institutional respondent commented that,

All of these programs do handouts and deteriorate [the indigenous peoples'] own forms of life because [indigenous communities] are waiting for the money or the food and they aren't seeing how to produce their own food, how to maintain their own strong economy (Interview \#72, 8/1/2013).

Dependency issues are also evident in the government itself, which relies on international organizations and NGOs to ensure that basic services reach its marginalized populations. For example, the Ucayali Health Strategy for Indigenous Communities receives little funding from the regional government for its programmed activities, and instead relies heavily on international aid organizations and NGOs. In Panaillo, the generosity of a Swiss NGO led to the construction of the first primary school. According to another institutional interview respondent, dependence and day-to-day thinking reinforce each other and ultimately obstruct sustainable development and preventative action (Interview \#52, 5/28/2013).

Institutional capacity is further weakened by the high rates of turnover among leaders. Fieldwork observations revealed that leadership positions in Panaillo do not have any economic benefit for the individual and often require that individuals minimize other livelihood activities in order to devote the necessary time and resources to the position. As a result, many authority figures serve only one term and many do not even complete their 2-year term. Similar trends are apparent at the district and regional levels. Five institutional interviewees noted that progress is stifled by the frequent change in authorities and the lack of knowledge transfer between them. For example, the Civil Defense is led by the mayor at the district level and the president of the region at the regional level. These positions change every four years and the former leader is not required to leave any information or documents in the office for the newly-elected official. 
Furthermore, the mayor and president of the region receive no explicit training in disaster management and also have many other responsibilities. One respondent commented that: "Because of high turnover, [the mayor] doesn't know what to do when there's a disaster" (Interview \#65, 7/8/2013). Two institutional interviewees considered the lack of institutional memory to be the greatest weakness of the disaster management system in Peru.

Poor institutional coordination further inhibits the holistic approach that is needed to prevent flood damage and reduce household food crises. In an interview with the Ucayali Civil Defense, the respondent discussed the institutional fragmentation that has emerged in the past decade, stating,

Our law only allows us to look at what is emergencies. What relates to poverty has another office that's in charge of these things. One matter is emergency, and another is poverty, another is invasions, those don't belong to us (Interview \#44, 5/17/2013).

Five interviewees also discussed how political affiliations stifle effective collaboration between offices. One respondent explains that,

Communication between institutions is still at a very low level. The problem is that different politics exist amongst the mayors and regional presidents, so when the mayor of one district is part of the same party as the regional president, there's fluid and immediate communication. But if the mayor is from a different party, the problems begin. We hope to overcome this because there isn't a political flag or creed in the case of a disaster. We are all equals (Interview \#53, 5/30/2013).

Poor communication has also constrained preventative action in disaster management. The National Center of Disaster Risk Estimation, Prevention and Reduction (CENEPRED) is the responsible institution for preventative aspects of disaster management. CENEPRED has only one office in Lima and does not work directly with the regional and local Civil Defense, but rather acts as a consultant to each president of the region. One CENEPRED interview respondent commented that,

Since we're just starting out, the [regional presidents and mayors] need to call us, but some of them still don't know we exist. They're saying, 'Where are we?' and 'Who are we?' because we don't have much capacity to assist everyone (Interview \#64, 6/24/2013). 
Although this interview respondent stated that CENEPRED's limited financial and human resources was the institution's greatest weakness, the respondent also stated the desire to remain a small institution since "the idea of us is not to reach all of Peru, but rather to provide the technical tools and guidelines that will permit us all to develop in an appropriate manner" (Interview \#64, 6/24/2013).

According to an INDECI interviewee, CENEPRED's low presence is a purposeful effort to evade responsibility. This respondent asserts that the Civil Defense, mayors and regional presidents will turn to INDECI for issues pertaining to CENEPRED since INDECI has an office and staff available on location (Interview \#63,6/17/2013). Another respondent stated that CENEPRED has taken advantage of its political connections with the national president, Ollanta Humala, in order to benefit from legal ambiguities and shift some of its responsibilities to INDECI. This respondent explained that: "They [CENEPRED] are now taking advantage of this disorder but some day another government will demand that they fulfill their responsibilities" (Interview \#63, 6/17/2013). Consequently, the preventative aspect of disaster management becomes limited to the preparation, response and rehabilitation covered by INDECI.

Political favors and the politicization of services have become widespread in Peru, as discussed in 25 percent of institutional interviews $(n=8)$ and observed in fieldwork. As a result of this environment, regular citizens often leverage their political power around elections in order to receive services. A former chief of Panaillo explained in an interview that Panaillo changed from Callería to Yarinacocha as part of an arrangement with a Yarinacocha mayoral candidate. In exchange for votes, Panaillo was promised a road linking the community to the city. Although the road was built the next year, one migrant respondent highlights the precarious nature of these agreements in stating,

In Panaillo, the government and Civil Defense hardly ever go to Panaillo, and when they do, they give very little. They don't give Panaillo much importance. Sometimes they go when they want votes, but when they're already in their chair in the office, they forget about the communities (Interview \#32, $5 / 26 / 2013)$.

These issues of accountability and political bias are prominent in Peru. In a recent survey, 70 percent of Peruvians were tolerant of corruption, including willingness to pay a bribe or turn a blind eye to officials who extend favors to friends and family (World Bank 
Peru, 2013). Throughout fieldwork, there were several protests in both Ucayali and Lima criticizing the government's low transparency and corruption. In Panaillo, several community members were not paid for their work in the construction of the community's water pump, and other migrant respondents were not paid for their security services during national holidays. At an institutional level, one INDECI respondent described the need for increased vigilance over mayoral allocation of resources. The respondent explained that: "Many times a mayor might be friends with a particular community, invent a disaster, and give money that ultimately goes to a party. Other times, the funds stay in the mayor's office and never make it to the community" (Interview \#63, 6/17/2013). This sort of corruption cripples government services and programs that could otherwise benefit Panaillo's food system and increase its adaptive capacity to seasonal flooding.

\subsection{Assimilation Social Model}

Whereas climatic events, economic development, and low institutional capacity are relevant for all communities in the area, Panaillo and other indigenous communities must also contend with a national social model that ultimately promotes cultural assimilation. The 1993 Peruvian Constitution recognizes the right for ethnic and cultural identity and Peru has ratified the Institutional Labor Organization's Convention 169, which outlines basic indigenous rights (Valdivia, Benavides \& Torero, 2007). Nonetheless, the United States' 2008 Peru Country Report on Human Rights Practice reported social, economic and political marginalization of indigenous peoples, illegal discrimination in restaurants and clubs, and difficulty exercising basic rights due to lacking identity documents, language barriers and inadequate infrastructure in indigenous communities (Bureau of Democracy, Human Rights, and Labor, 2009).

Over the past few decades, Peru began to advocate for interculturalidad, an idea based on cultural exchange and fostering communication between different groups with different customs (Coronel Cáceres, Zavala Soto, \& Estrada Vitorino, 2008). Interculturalidad theoretically extends the notion of multiculturalism and pluriculturalism by encouraging groups to not only respectfully coexist, but to also interact with each other in an equitable manner (Coronel Cáceres et al., 2008). In spite of the State's promotion of interculturalidad, Figueroa and Barrón (2005: 6) assert that indigenous populations in Peru 
continue to be treated as "second-rate citizens". Carmona and Cristóbal (2009) assert that concepts like interculturalidad counteract indigenous rights since they often result in policies and programs that promote the integration of indigenous peoples into a western system. Valdivia et al. (2007) similarly highlight how the rhetoric of interculturalidad creates a dualism between that western culture and indigenous culture, and that the state's policy towards indigenous peoples is ultimately based on acculturation and assimilation.

In this research, institutional interview respondents listed the State's lack of recognition of the indigenous system $(n=6)$, the dominance of the western system $(n=6)$, and the creation of dependency within social programming $(n=5)$ as obstructions to interculturalidad in Peru. Although most of these institutional interviews (60\%; n=4) were conducted with indigenous organizations, over 40 percent $(n=3)$ of the interviews were conducted with government employees working in health, agriculture and education. According to six institutional interview respondents, the Peruvian State has not provided the conditions needed for a genuine exchange between the western and indigenous worlds and has favored the western system. One institutional interview respondent explained that,

Our approach is still very western. The Peruvian government has adopted a discourse of inclusion into the economic model. They aren't saying that 'I'll give you support for your model, your culture, your perspective, your life plan.' No. Instead, they say 'I won't include your system and I'll include you under the image of welfare' (Interview \#72, 8/1/2013).

Five other respondents were similarly discontent about the manner in which indigenous communities were being 'included' in the State, asserting that social programming is being used to foster dependency, rather than autonomy.

Six interview respondents expressed concerns over the way indigenous communities needed to assimilate into western culture in some way in order to participate in social programming. For example, the school-feeding program Qali Warma distributes processed foods like pasta noodles and tuna fish, rather than more local, traditional foods, like rice and regional beans (Interview \#72, 8/1/2013). Bilingual education represents one of the greatest advancements in interculturalidad in Peru, according to three institutional interview respondents. However, participants in the historical timeline focus group discussed how schools used to ban traditional Shipibo dress and continue to largely teach in the Spanish language and use a western curriculum. Accordingly, a Shipibo 
schoolteacher in Panaillo asserted that: "The western culture is dominating and killing our culture" (Interview \#2, 5/10/2013).

In this study, Peru's assimilation social model was further illustrated by the marginalization and westernization of Panaillo and other indigenous communities. Panaillo experiences high levels of discrimination and political marginalization. Community members discussed personal experiences of discrimination in health posts, schools, and the job market in six interviews and the historical timeline focus group. Six institutional interviews similarly noted the pervasiveness of cultural discrimination in Peru and how it has led to insufficient funds for programs related to indigenous issues. There were also discriminatory remarks from four institutional interview respondents themselves, including the use of derogatory stereotypes regarding Shipibo work ethic.

Two institutional respondents discussed how widespread cultural discrimination fosters institutional norms that further marginalize indigenous communities. For example, a national identification card is required to receive government services, yet many community members in Panaillo and other indigenous communities struggle to acquire this card due to language and financial barriers. Five institutional interview respondents also commented that Panaillo has difficulty effectively soliciting government services, despite making several formal requests and submitting the necessary documents.

The loss of traditional knowledge and increase of western practices have also impacted traditional agricultural knowledge and food-sharing in Panaillo. Although Panaillo has two traditional healers, few rely exclusively on traditional medicines and the majority of Panaillo residents also seek out western medical treatments. Traditional knowledge on agriculture is also widespread, including using environmental cues to time planting activities. However, one of the youngest interviewees could not answer any question related to traditional agricultural knowledge. Similarly, Behrens (1989) observed that Shipibo communities increasingly ignored traditional agricultural knowledge when they began cash cropping rice. Concern over the lack of intergenerational knowledge transfer was also emphasized in the historical timeline focus group, previous Panaillo fieldwork (Hofmeijer et al., 2012), institutional interviews ( $n=6$ ), and interviews with Panaillo residents $(n=4)$. One institutional interview respondent stated that younger generations have traditional knowledge, but do not put their knowledge into practice, 
stating that: "They don't give traditional knowledge any importance, they give more importance to technology" (Interview \#68, 7/19/2013). Participants in the historical timeline and seasonal food security focus groups also mentioned the deterioration of the traditional social support system in Panaillo. Two incidents of theft in the community were reported in the seasonal food security focus group and 11 community members reported a heightened fear of burglars and increased sense of insecurity after the construction of the road in 2010.

Participants in the historical timeline focus group asserted that cultural changes have been most pronounced in the past ten years when marriage with non-indigenous people increased, migration for school or work became more common, and the construction of a road further integrated the community into the market economy. According to 12 Panaillo respondents, the main benefit of the construction of the road in 2010 was the increased ease with which they could buy or sell from the market. However, market integration has also influenced the traditional diet, as previously mentioned. Three institutional interviews also reported that indigenous communities are increasing eating processed foods, but without the nutritional education to ensure a healthy, balanced diet. In this way, the assimilation social model in Peru compromises the Panaillo food system by fostering an environment where indigenous communities must alter tradition in order to maintain food security.

\section{Chapter Summary}

Flooding brings many opportunities to the Panaillo food system, including the creation of fertile riverbeds for agriculture, the replenishment of fish stocks, improved transportation options and easier timber extraction. However, community members generally have a negative perception of seasonal flooding, mostly due to the challenges it brings to livelihoods. Economic development further exacerbates these challenges by increasing household dependence on financial resources for food, livelihood equipment and transportation. Panaillo residents struggle to generate sufficient income since community members lack market contacts, do not own a means of transport, and need to sell their crops immediately after the harvest when prices are lowest. Relief support from local institutions is ineffective as a result of limited institutional resources, poor planning, high 
turnover, dependency, and corruption. Indigenous communities are particularly vulnerable in this context due to the predominant social model in Peru, which promotes cultural assimilation. Although Peru embraces the concept of interculturalidad, this research highlights the dominance of the western system, cultural discrimination, political marginalization, and the loss of traditional knowledge and practices. The manifestation of the assimilation social model, climatic variability, economic development and low institutional capacity in the Panaillo food system will be further discussed in the following chapter. 


\section{CHAPTER 6. RESULTS - PROXIMAL DRIVERS OF FOOD SYSTEM VULNERABILITY}

This chapter examines the interactive effect of climate variability, economic development, low institutional capacity, and the assimilation social model in Peru. It shows how these four themes manifest in Panaillo through resource degradation, changing ecosystem dynamics, shifting climate regimes, and limited resources and services reaching indigenous communities (Figure 8). The repercussions of this environment on traditional livelihoods and strategies are then examined. The chapter concludes with a discussion of temporary and permanent migration as an emerging adaptive strategy for Panaillo residents.

\subsection{Resource Degradation and Changing Ecosystem Dynamics}

A recent study found that corruption in the Brazilian Amazon was a key variable in explaining high levels of deforestation (Mendes \& Junior, 2012). Similarly, in this research area, the growth of extractive industries in the Peruvian Amazon amidst low institutional capacity has contributed to widespread resource degradation throughout the area (Goy \& Waltner-Toews, 2005; Finer \& Orta-Martínez, 2010;). Most illegal logging in the Pucallpa area is done through illegal concessions, in which community members sell timber directly to companies (Cossío et al., 2014). In Panaillo, such practices have resulted in increased scarcity of high-quality timber that can be sold in the market and three community respondents reported being unable to engage in timber extraction this year as a result. Seven interview respondents also attributed declines in fish and animal populations to deforestation, since logging has introduced debris and toxins into the water, directly destroyed the habitats of many animals, and used loud machinery that causes animals to flee the area. Other studies have also documented the decline of animal and fish species as a result of extractive practices (Finer \& Orta-Martínez, 2010; Hern, 1992).

Oil exploration and mining are more concentrated in other regions, such as Madre de Dios (Finer \& Orta-Martínez, 2010). However, four community respondents and four institutional interviewees expressed concern over river contamination and erosion that have resulted from oil and mining operations located both upstream and downstream from Panaillo. One institutional respondent discussed contamination from illegal mining located 


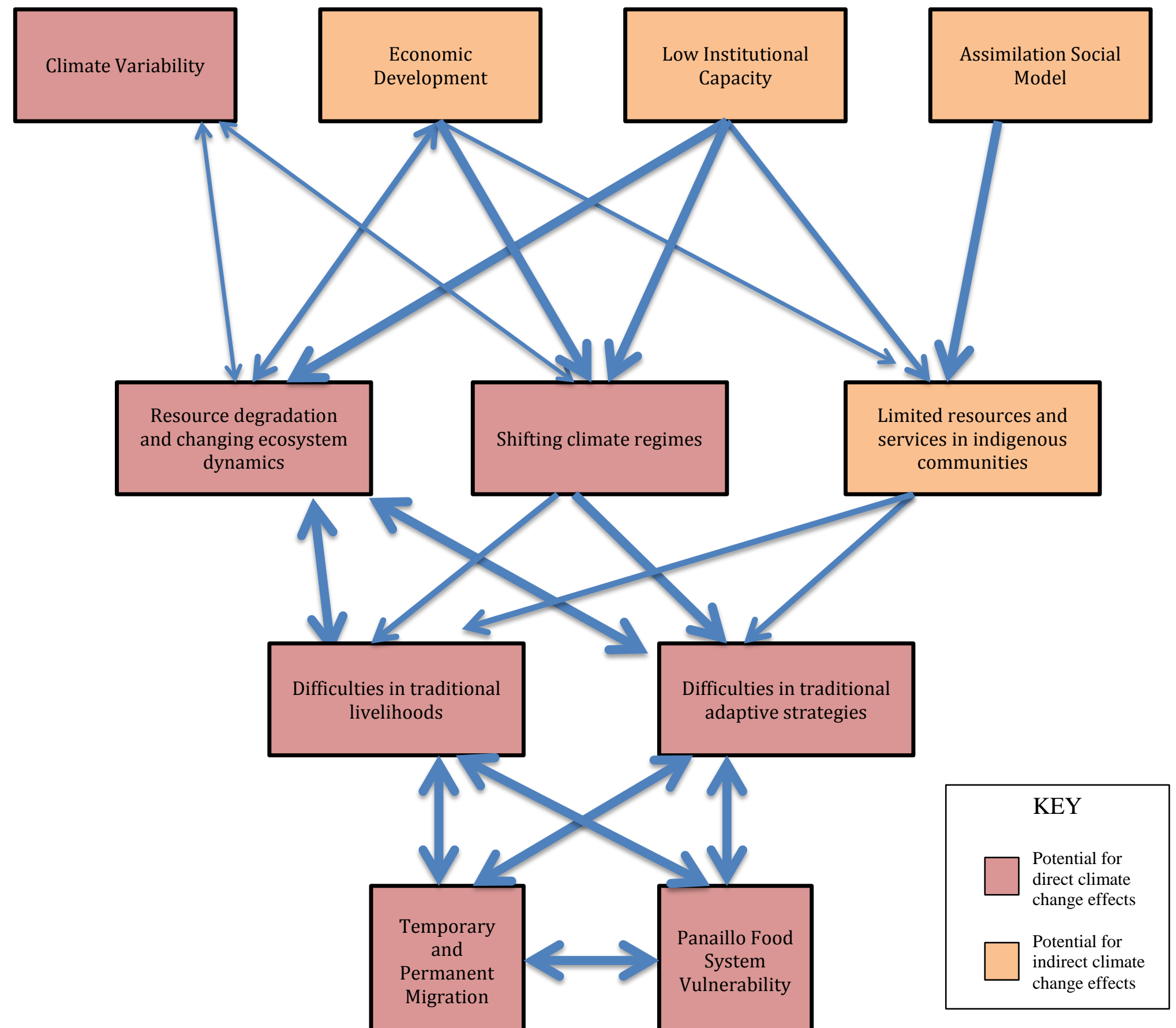

Note: Arrow thickness indicates strength of influence. Double-sided arrow indicates feedback loop.

Figure 8. Interaction of major drivers of Panaillo's food system vulnerability. 
in the Aguajal River basin in southern Ucayali, stating that,

There aren't any more fish because of the gold and metal mines that are there, and because of all of the chemicals and acids, the fish populations have completely disappeared from the river, the fish that were the principal source of food for the people that live in this basin (Interview \#46, $5 / 17 / 2013)$.

Fish populations are also threatened by illegal fishing practices and over-extraction, as mentioned in 10 community interviews and seven institutional interviews. Declines in fish populations in the Amazon as a result of over-extraction have been documented for several decades (Bergman, 1980; Hern, 1992). The historical timeline focus group described how traditional fishing methods (e.g., spears) did not capture as many fish, and that large nets and poisons have been increasingly used in the past decade. Community members reported that local fishermen use illegal nets and poisons to extract large quantities of fish of all sizes and species. Barbasco is derived from the roots of the plant Lonchocarpus nicou and is widely-used in the Peruvian Amazon as a poison for fishing. The poison stuns the fish, allowing for the capture of a large quantity of fish of varying maturity levels (Smith, 2001; Sirén, 2006). According to one respondent, the laws to sanction such practices are ineffective, since minor infractions often go unsanctioned, especially when committed by small-scale fishermen. Another respondent noted the lack of control mechanisms to effectively monitor the area, stating that,

A million laws can be passed, but the problem is in the implementation... The law comes out- the rules, the size restrictions- but the institutions don't have the logistics and the ability to enforce or control it... It's a dead law (Interview \#70, 7/22/2013).

Accordingly, 45 percent of community interviewees $(n=19)$ and over one-third of institutional respondents $(\mathrm{n}=11)$ discussed changes in fish and animal populations in the recent past. One-third of community interviewees $(n=14)$ reported lower fish catches, poorer fish quality, and lower fish diversity in comparison to fifteen years ago. The decline in fish populations has severe repercussions for the Shipibo cultural identity, which is strongly linked to fish. One community member stated: "Now there's only small fish and our children don't grow up knowing the paiche" (Interview \#4, 5/10/2013). Several studies have similarly attributed changes in ecosystem dynamics in the Amazon Basin to agricultural expansion, deforestation, mining and oil exploration, urbanization, 
and, to a lesser extent, human-induced climate change (Santa Cruz et al., 2013; Davidson et al., 2012; Vegas de Cáceres, 2010; Kvist \& Nebel, 2001; UNDP \& BCPR, 2013; Futemma \& Brondízio, 2003; Finer \& Orta-Martínez, 2010). Although there is limited information on species distribution, ecological roles, and resilience to climate fluctuations in the Amazon (Milliken et al., 2010), biodiversity losses have been widely reported; studies have examined declines in populations of fish (Santa Cruz et al., 2013; Garcia et al., 2009; Kvist et al., 2001a), woody forest plants (Santa Cruz et al., 2013; Kvist et al., 2001b), and animals (Santa Cruz et al., 2013; Finer \& Orta-Martínez, 2010) in the Amazon. Ucayali residents have also reported lower crop yield as a result of changes in climate (Vegas de Cáceres, 2010).

\subsection{Shifting Climate Regimes}

In this research, over 30 percent of community members $(n=13)$ and 38 percent of institutional interview respondents $(n=12)$ reported changes in climate, including less predictable rains, hotter temperatures in the dry season, and more frequent and severe flooding events. These interview respondents noted how unpredictable rains have complicated agricultural production, and one community member commented that,

It's been the dry season for two weeks here, but every afternoon it rains, rains, rains, and you can't work or cultivate or work around the house. There have only been three days in the summer without rain. Last year wasn't like this. Everything has changed (Interview \#4, 5/10/2013).

Fourteen interview respondents also reported changes in river dynamics, including changes in river flow patterns $(n=5)$, more extreme flood events $(n=8)$, flooding in new areas $(n=3)$, and lower river levels overall $(n=2)$. One community member commented that,

Before there weren't big floods. When I was 12 years old, the water didn't rise like this. In the rainy season, the water came, but it didn't drown the community, it didn't cover the houses. Now it's different... Now we flood every year and now we can't plant our plantain. There have been so many changes but I don't know why (Interview \#12, 5/21/2013).

A schoolteacher in Panaillo similarly commented that: "Now there's the fear that the river is dangerous and that it is eroding and Panaillo will disappear again" (Interview \#57, 6/2/2013). Similar changes in climate have been perceived by other inhabitants of Ucayali, who reported experiencing a hotter climate, increased forest fires, and difficulty with 
transportation as a result of low river levels (Vegas de Cáceres, 2010). Regional climate changes in the Amazon Basin have also been reported recent publications (Marengo et al., 2012; Espinoza Villar, 2009).

\subsection{Limited Resources and Services Reaching Indigenous Communities}

Government support becomes crucial in this shifting environment, yet this research highlights how low institutional capacity, the assimilation social model and economic development have fostered a bias against indigenous populations in multiple government sectors. For example, whereas many of the health strategies in the Ucayali Ministry of Health receive government funding, the health strategy for indigenous communities had never received government funding at the time of fieldwork. Instead, program activities depended on other funded projects and donations from international NGOs. Another NGO interviewee reiterated that,

The regional government doesn't pay much attention to the indigenous communities. The indigenous communities are not so important to them because the government works politically... Since they don't have DNI [national identification card], they don't serve the government, not even to think about them (Interview \#56, 5/31/2013).

Six institutional interviews also reported that Peru's push for economic growth has resulted in favoring certain sectors, organizations and communities on the basis of economic profitability. For example, an interviewee from a disaster management institution stated that the state is unlikely to invest in communities along the Ucayali River because it could result in economic loss should the river flow change (Interview \#64, 6/24/2013).

Consequently, indigenous areas like Panaillo receive limited resources and services. Eleven interview respondents reported that Panaillo and other indigenous communities lack access to consistent, culturally appropriate, quality healthcare. The community nurse technician complained that the health post was constantly lacking necessary medical equipment and medications. Incidents of discrimination were also observed during fieldwork at the community, district, and regional health posts. Goy and Waltner-Toews (2005) similarly note that health professionals often do not speak the Shipibo language and reportedly do not have positive interactions with rural Shipibo patients due to underlying 
ethnic tensions.

Similarly, low-quality education in rural areas was reported in one-third of community interviews ( $n=14)$ and 25 percent of institutional interviews $(n=8)$. It is estimated that 260-500 teaching hours are lost each year in Ucayali as a result of heavy rains and flooding (Vasquez et al., 2012). Classes are also canceled due to teacher absences. Throughout fieldwork, teachers left the community for extended periods of time without explanation or repercussion. Although most community members desire higher quality education, interviewees discussed how community members lack financial resources to pay tuition fees $(\mathrm{n}=10)$ and how scholarships designated for indigenous students are subject to corruption and cronyism $(\mathrm{n}=9)$.

Finally, government services were reported to be generally lacking in rural and/or indigenous areas, as discussed in all focus groups and over 30 percent of interviews $(n=23)$. Respondents attributed the lack of services to the communities' physical isolation, low accessibility, discrimination, corruption, and/or the lack of economic incentive for governments to work with these communities. Government employees that were interviewed acknowledged these issues, and 10 respondents emphasized that current efforts are being made to improve the situation, such as creating contextualized capacitybuilding programs for artisanal livelihoods.

\subsection{Difficulties in Traditional Adaptive Strategies}

The aforementioned biophysical and socioeconomic stresses have contributed to various challenges for the adaptive strategies traditionally used for seasonal flooding. Since the flood inhibits yearlong production, food preservation is an important strategy to maintain food security during the rainy season. Salted or smoked fish can be consumed weeks to several months after the time of capture. However, the seasonal food security focus group discussed how fish often rot when the lakes dry up since households lack the ability to carry large quantities of fish back to the house, do not have the time and salt to properly preserve the fish, and/or do not own the necessary equipment to sell fish.

Yuca is also commonly preserved in the form of fariña, and can last approximately 2 months. However, fariña production requires having a surplus of yuca and adequate time to dry the yuca. Panaillo households commonly reported being unable to make fariña when 
they lack labor and planting materials for agricultural production ( $n=19)$. Fariña production was also impossible in a given year when the flood onset occurred before the yuca harvest $(\mathrm{n}=11)$ and/or when the flood conditions prevented the necessary drying and processing of yuca that is needed in fariña production ( $n=13)$. Bergman (1980) describes observing women hurriedly harvesting yuca while standing in ankle-deep water. When flood conditions are conducive to fariña production, one community member reported making excess fariña to sell to neighbors. This latter example illustrates how some community members have higher adaptive capacity than others since they are able to take advantage of the situation and benefit from local conditions. In contrast, younger households may be increasingly vulnerable to flood events due to the decline of intergenerational traditional knowledge transfer. The knowledge needed for fariña production is no longer being transferred consistently to younger generations, as illustrated by one Panaillo respondents who was never taught how to make fariña (Interview \#29, 5/25/2013).

Food storage is another crucial strategy that Panaillo residents use to maintain food security in the rainy season. All Panaillo residents reported storing harvest foods and seeds, ranging from 30-200 kg rice and 10-50 kg cowpea, depending on the agricultural production level, how much the household sells, household size, and if the household migrates to the city during the rainy season. The main constraints to effectively storing harvest foods and seeds include lacking a proper storage container $(n=7)$, pests (i.e., rats, insects, fungus) ( $n=7)$, and insufficient drying of the seeds ( $n=4)$. Over 95 percent of community respondents commented that stored food was insufficient to cover household needs for the entire winter. According to 14 current Panaillo residents, the average household typically exhausts food stores 4.5 months after the flood onset in mid-April. Since harvest foods are not available for another four months, this transitional period requires families to purchase foods and/or seek out alternative foods.

The risk ranking focus group highlighted the alternative food sources that are consumed by Panaillo residents in the rainy season. During the flood, Panaillo households hunt and/or raise monkeys as an alternative protein source to fish and beans. Breadfruit is also commonly consumed during the onset of the dry season. Although breadfruit provides a carbohydrate source when other harvest crops are unavailable, Panaillo residents 
reported reducing breadfruit consumption in recent years. Five interviewees discussed how the breadfruit tree close to the village has been overharvested and residents did not want to travel long distances for the food. Breadfruit consumption also declined when flood-resistant plantain species became more available, according to the seasonal food security focus group and four Panaillo interviews. While not entirely flood-resistant, campeón (Spanish for 'champion') and sapo plantain plants are able to survive up to one week in water due to their stronger and deeper roots. However, the fruit will die or become stunted during this water submergence. According to community members, the fruit from these plantain plants are also less palatable than normal plantain species. The main benefit of these species over normal plantain is that the plant will be able to continue to produce fruit after the flooding period, whereas normal plantain plants do not survive the flooding, even if flooding lasts less than one week.

When income is low and the aforementioned food sources are limited, food-sharing is critical to maintain household food security. Extended families usually share one kitchen and eat together from a few common plates. Food may also be sent to other families, or families may be invited to eat with a host family (Behrens, 1992). This arrangement is meant to smooth over temporary food shortages as well as avoid food spoilage (Behrens, 1992). However, Behrens noted in 1992 that food-sharing practices were becoming less common in Shipibo communities as a result of market integration. In this research, the risk ranking focus group and 13 interviews highlighted existing food-sharing networks in the community. One Panaillo elder explained that: "Food tastes better when it is shared" (Interview \#18, 5/23/2013). However, according to Panaillo interview respondents, foodsharing networks have also declined as a result of insufficient household food quantities $(\mathrm{n}=5)$, as well as cultural changes $(\mathrm{n}=7)$. While discussing food scarcity in the rainy season, one respondent commented that: "Those that don't [store food and produce fariña] will die of hunger. In these times, no one gives to their neighbors, but when there is an abundance of fish, they invite others and share" (Interview \#9, 5/19/2013). A former schoolteacher discussed how cultural changes have impacted food-sharing practices, asserting that traditionally: "You would give me plantain and I would give you fish. In the conquest of the Western education system, they took that all away" (Interview \#66, 7/15/2013).

Although intercultural multilingual education has been actively promoted in Peru, 
several recently studies have similarly criticized this system and its implementation. Aikman (2012) describes how intercultural schooling in the Peruvian Amazon can further marginalize indigenous communities by reinforcing the 'otherness' of indigenous communities and labeling the community as 'indigenous', which is a term that still connotes backwardness and inferiority in many parts of Peru. According to Aikman, what is needed is "a political and transformative response to the intercultural lives they lead, not a technical adaptation of the educational status quo" (2012: 248). Other authors highlight how intercultural bilingual education in Peru exists in less than half of rural schools, teachers do not receive sufficient technical and financial support and curricula often lack cultural and sociopolitical content (Cueto et al., 2012; Sumida Huaman, 2014; Ames, 2012; Maurial \& Suxo, 2011).

\subsection{Difficulties in Traditional Livelihoods}

Over half of community members interviewed $(n=24)$ were not at maximum agricultural production for both climatic and non-climatic reasons. Each year, the type of soil and size of the riverbeds varies, as does the timing of the riverbeds' emergence after the river level lowers. One-third of Panaillo respondents $(n=9)$ reported that this variability impedes agricultural production. For example, during fieldwork, households did not have sufficient seeds for cowpea since the riverbed in the preceding year was most suitable for rice production and households saved mainly rice seeds. The timing of planting and harvest in relation to seasonality is also important. Strong precipitation after planting can disrupt agricultural production by washing away the seeds or rotting them (Seasonal food security focus group). Delayed planting also inhibits production since the soil dries out more, conditions are hotter for the workers, and the harvest season is shorter due to the flood onset. Early flood onset frequently ruins crops, as reported in one-quarter of community interviews and all three focus groups.

However, non-climatic factors also constrain agricultural production. Lacking seeds was the most frequently reported constraint to planting, which was mentioned by 17 community members and 7 institutional interviewees. Community members lacked seeds as a result of eating their own seeds in the rainy season $(n=5$, historical timeline focus group), insufficient production in preceding years $(n=1)$, and poor storage of seeds $(n=1)$. 
Community members also discussed not having sufficient workers to plant all of their seeds in a timely manner $(n=9)$, and to harvest the entire crop $(n=18)$. One Panaillo respondent commented that: "Everyone has their own harvest here so sometimes we leave our harvest to rot on the sandbar, mainly because we lack workers" (Interview \#36, $7 / 13 / 2013)$. Other community respondents $(n=8)$ discussed how low financial resources prevented a household from being able to hire workers to assist in the harvest. This was particularly important among female Panaillo respondents, who reported being less able to plant and harvest without a male family member ( $n=3$, historical timeline focus group). Panaillo respondents had to stop harvesting prematurely due to other household responsibilities $(n=4)$, the unbearable heat in the fields $(n=4)$, and employment $(n=1)$. Nine interview respondents and participants in the historical timeline focus group also experienced difficulty in tending crops and controlling pests while working outside of the community.

Traditional fishing livelihoods have also dramatically changed with the integration of fishing practices into the market economy. Two female Panaillo respondents reported eating low-quality fish because their male family member sells the higher quality fish. Fishing equipment is needed to sell fish, as well as to take advantage of fish abundance when the river levels lower at the end of the rainy season. The seasonal food security focus groups discussed how fish rot every year in the lakes because residents lack the equipment, labor, and time needed to extract and preserve all of the available fish. The participants in the historical timeline focus group also discussed how younger generations no longer know how to make a canoe or use a harpoon for fishing. They instead rely on manufactured equipment or partake in other income-generating livelihoods.

The decline of subsistence agro-fishing livelihoods has increased reliance on income-generating livelihoods, yet there are often limited opportunities to earn cash for Panaillo residents. The previous sections have described various constraints to selling agricultural and fishing products in Panaillo. Additionally, female participants in the historical timeline focus group discussed how the natural materials needed for traditional handicrafts are increasingly scarce due to over-extraction. Less predictable weather further inhibits traditional handicrafts since the preparation of materials requires hot, sunny conditions to dry seeds, cloth, bark, and other materials. Four community members also 
reported being unable to extract timber for sale since they do not own a power saw.

Illness and injury constrain both agro-fishing and income-generating livelihoods. The most frequently mentioned consequence of flooding was the illnesses and injuries that result from decreased temperatures, contaminated water, humidity and submergence in water, malnutrition and lowered immune defenses (see Table 6). Forty-four percent of Panaillo respondents listed the floodwater's proximity to the house as a benefit of the flood, since it made washing, cooking, and bathing easier. However, without proper latrines and waste disposal systems, water becomes easily contaminated in the community and disease rates are high. Contaminated water in Panaillo was mentioned in 15 percent of Panaillo interviews $(n=4)$ and 40 percent of migrant interviews $(n=6)$ as a consequence of flooding.

Table 6. Illnesses and injuries that result from seasonal flooding as reported by interview respondents.

\begin{tabular}{|l|c|c|}
\hline \multicolumn{1}{|c|}{ Illness/injury } & $\begin{array}{c}\text { Panaillo respondents } \\
(\boldsymbol{n}=\mathbf{2 7})\end{array}$ & $\begin{array}{c}\text { Migrant respondents } \\
(\mathbf{n}=\mathbf{1 5})\end{array}$ \\
\hline Diarrhea & $89 \%(\mathrm{n}=24)$ & $60 \%(\mathrm{n}=9)$ \\
\hline Vomiting & $30 \%(\mathrm{n}=8)$ & $26 \%(\mathrm{n}=7)$ \\
\hline Fever & $22 \%(\mathrm{n}=6)$ & $19 \%(\mathrm{n}=5)$ \\
\hline Headache & $11 \%(\mathrm{n}=3)$ & $7 \%(\mathrm{n}=1)$ \\
\hline Snake bites & $7 \%(\mathrm{n}=2)$ & $13 \%(\mathrm{n}=2)$ \\
\hline Influenza & $4 \%(\mathrm{n}=1)$ & $7 \%(\mathrm{n}=1)$ \\
\hline Dengue & $0 \%(\mathrm{n}=0)$ & $13 \%(\mathrm{n}=2)$ \\
\hline Joint problems & $4 \%(\mathrm{n}=1)$ & $7 \%(\mathrm{n}=1)$ \\
\hline Fungal infections & $4 \%(\mathrm{n}=1)$ & $0 \%(\mathrm{n}=0)$ \\
\hline
\end{tabular}

Poor health and injury inhibited community members from engaging in agriculture, fishing, traditional handicrafts, and/or timber extraction in one-third of community interviews (n=14). For example, one migrant could no longer work in timber extraction due to worsening arthritis. According to three Panaillo residents, at least one Panaillo adult is unable to work due to illness or injury at a given time during the dry season. The number of sick or injured adults unable to work was reported to double in the flood season. Community members with a medical condition have limited alternative employment options since their formal education is minimal and employers are increasingly conducting medical exams during job recruitment. 


\subsection{Migration}

The biophysical and socioeconomic constraints on agro-fishing livelihoods and traditional adaptive strategies have coincided with increasing levels of migration to urban centers. Only five households stay in Panaillo throughout the rainy season. All younger households leave Panaillo each year during the flood, whereas two of the three elderly households in Panaillo stay in the community. Panaillo residents stated that the principal motivation for temporary migration was to pursue income-generating livelihoods $(n=12)$ and/or to avoid flood conditions $(n=11)$. Panaillo migrants permanently migrated for education and job opportunities in the city ( $n=13)$, to live with family in the city due to illness, injury, and old age ( $n=7)$, and/or to avoid flood conditions in Panaillo ( $n=4)$. Institutions attributed increasing levels of migration to education and job opportunities in cities $(n=7)$, flooding in rural areas $(n=4)$, the lack of government services in rural communities $(n=2)$, as well as the reduced availability of natural resources $(n=2) . \quad$ As illustrated in Table 7, employment and education were the most frequently mentioned motivators for migration in this area. Nine community members discussed how employment opportunities within Panaillo tend to be sparse, temporary, and low-income. However, half of community members $(n=21)$ had difficulty finding employment outside of Panaillo, especially in work with job security. In semi-structured interviews, nine Panaillo residents mentioned working as laborers for large-scale agricultural plantations, such as those producing palm oil, tomato, and coffee. Other Panaillo interview respondents reported working in oil and logging companies $(n=4)$, construction work $(n=2)$, restaurants $(n=1)$, cleaning services $(n=1)$, teaching $(n=1)$, coca eradication campaigns $(n=1)$ and drug trafficking $(n=1)$. Ten community members reported lacking the qualifications needed for desirable jobs, which include positions in informal trading, government, schools, law, and other highly skilled occupations. The lack of qualifications for these positions showcases the importance of education and skills-development. Two migrants interviewed were unable to complete their studies due to lack of financial resources, in spite of education being their chief motivation for migrating to the city. Five community respondents also discussed the importance of having social contacts to help secure a job. 
Table 7. Motivation to migrate permanently and/or temporarily among community and institutional respondents.

\begin{tabular}{|l|c|c|c|}
\hline Migration Motivation & $\begin{array}{c}\text { Panaillo } \\
\text { Interview } \\
\text { Respondents } \\
(\mathbf{n}=27)\end{array}$ & $\begin{array}{c}\text { Migrant Interview } \\
\text { Respondents } \\
(\mathbf{n = 1 5 )}\end{array}$ & $\begin{array}{c}\text { Institutional } \\
\text { Interview } \\
\text { Respondents } \\
\text { (n=32) }\end{array}$ \\
\hline $\begin{array}{l}\text { Education and job } \\
\text { opportunities }\end{array}$ & $44 \%(\mathrm{n}=12)$ & $87 \%(\mathrm{n}=13)$ & $22 \%(\mathrm{n}=7)$ \\
\hline Avoid flood condition & $41 \%(\mathrm{n}=11)$ & $27 \%(\mathrm{n}=4)$ & $13 \%(\mathrm{n}=4)$ \\
\hline $\begin{array}{l}\text { Live with family in } \\
\text { city due to illness, } \\
\text { injury or old age }\end{array}$ & $0 \%(\mathrm{n}=0)$ & $47 \%(\mathrm{n}=7)$ & $0 \%(\mathrm{n}=0)$ \\
\hline $\begin{array}{l}\text { Lack of government } \\
\text { services in rural } \\
\text { communities }\end{array}$ & $0 \%(\mathrm{n}=0)$ & $0 \%(\mathrm{n}=0)$ & $6 \%(\mathrm{n}=2)$ \\
\hline $\begin{array}{l}\text { Decline in natural } \\
\text { resource availability }\end{array}$ & $0 \%(\mathrm{n}=0)$ & $0 \%(\mathrm{n}=0)$ & $6 \%(\mathrm{n}=2)$ \\
\hline
\end{tabular}

Institutional respondents generally believe that the quality of life for a migrant in the city is not better than life in rural areas. One institutional respondent explained that: "Migration doesn't improve their lives. Migration promotes poverty belts" (Interview \#73, 8/1/2013). Another institutional respondent similarly noted,

Their lives don't get much better after they migrate to the city because they don't have a place to work. If they don't work, how are they going to live? What are they going to eat? So the people start to become malnourished... And when the men want to do some work and know how to do it, they won't employ them here because they don't have a DNI [national identification card] (Interview \#56, 5/31/2013).

As a result, unemployment and job exploitation is common among migrants from indigenous communities. Six interview respondents discussed the poor working conditions and unfair pay that temporary and permanent migrants must accept. One male Panaillo respondent explained that: "On large plantations, they pay the cow 100 soles [ USD \$30] per day, but they only pay us four or six soles [ USD \$1.40-2.15] per day" (Interview \#12, 5/21/2013). Another Panaillo resident who temporarily migrates for jobs asserted that: "It's as if you were a slave" (Interview \#3, 7/12/2013). 
Panaillo respondents also stated that money $(n=13)$ and/or family connections $(n=16)$ were needed in order to successfully migrate. Nevertheless, 93 percent of migrant respondents $(\mathrm{n}=14)$ mentioned continuing to struggle with money after migration due to inconsistent income sources and high dependence on financial resources for household food. All of these migrant respondents emphasized the advantage of being able to produce their own food in Panaillo, for example, stating: "There you just had to grab your harpoon, hunt your fish, and soon you'd be eating. Here you can't do that. Here there's no harpoon; everything is just with money. It's a tremendous shock" (Interview \#5, 5/13/2013). Another migrant respondent commented: “In the community, everything is free, you don't have to pay for electricity, water, transportation, your kids' studies, but here you have to think about buying. Everything is an expense" (Interview \#32, 5/26/2013). Accordingly, 10 community members reported consuming more chicken in the city, due to the expensive nature of fish, the more preferable and traditional Shipibo food.

Urban migration has many ways of altering and disrupting Shipibo tradition. Many community members in the historical timeline focus group expressed their preoccupation with leaving their traditional way of life by migrating to the city. Eight community interviewees also discussed how migrants without strong family ties in the city could no longer access the strong social network that characterizes Shipibo communities. Five community interviewees similarly explained that food-sharing is not as common in Shipibo migrant communities. According to a female migrant: "Life is better in Panaillo because there are fish that are free, close, and abundant. You have all of your family there and when you lack food, everyone shares with each other. Here no. Here it is all economical" (Interview \#34, 6/3/2013). Four migrants did report some form of food-sharing, including one elderly migrant whose children give her food. However, this elderly migrant highlighted the instability of her food-sharing network by explaining that: "My kids sometimes go far away to work and there's nothing for me to eat in my house" (Interview \#30, 5/26/2013).

The separation of families that results from migration also has important implications for Panaillo's food system and community structure. Male participants in the risk ranking focus group listed the loss of community as the most significant difficulty in the rainy season. Eleven community members also discussed how temporary migration 
separates family members, which has serious ramifications for the food security of individuals that rely on a male family member for fishing (e.g., women, children, elderly). Over 25 percent of Panaillo women interviewed $(n=4)$ and 20 percent of migrant women interviewed $(n=3)$ were separated from their spouses during fieldwork. In Panaillo interviews, temporary migration of a household member was stated as the cause of decreased food quantity ( $n=5)$, skipping meals $(n=4)$, eating less than one should $(n=4)$, and feeling hungry but not eating $(n=4)$. Households are especially dependent on household fishermen and hunters in the rainy season since the owners of the local store in Panaillo migrate to the city temporarily and access to purchased food is reduced. Furthermore, remittances from migrant households to current residents in Panaillo are uncommon.

In light of this, migration of a spouse or children often instigates the migration of other family members, as mentioned in six community interviews. At the time of fieldwork, three elderly households from Panaillo had recently moved to the city to live in closer proximity to their children. Three Panaillo interviewees discussed the difficulties experienced by the elderly in Panaillo, since many of their children have migrated to the city and are unable to provide for their parents. Participants in the historical timeline focus group believed that the abandonment of elderly parents reflects the westernization that is happening among younger generations. Accordingly, when asked which type of household was most vulnerable to flooding, 26 percent of Panaillo respondents $(n=7)$ and 40 percent of migrant respondents $(n=7)$ mentioned the elderly (see Table 5).

Government programming is also disrupted by high levels of population movement, as mentioned in five institutional interviews. For example, flood relief budgets are based on the number of people that are found in the community at the time of the most recent visit. However, community members that migrate temporarily during the flood will sporadically return to Panaillo, depending on job availability, financial resources, and household needs. Since the population is in constant flux during the rainy season, flood relief may overshoot or underestimate the current needs of the community at the time of a Civil Defense visit. Furthermore, the community members that might be able to better negotiate and solicit necessary government services are often not present in the community. During fieldwork, two authority figures permanently migrated away from Panaillo in the middle of their 
term, and the communal assembly frequently complained about the extended absences of two other authority figures. Furthermore, the majority of community members with higher education and skills have permanently migrated to the city. As one migrant explains,

The majority of those that have studied in the city live here [in the city], those that are already professionals. But they hardly ever think about their community Panaillo... It's one of the problems of Panaillo- that it's the professionals that have left there (Interview \#32, 5/26/2013).

\section{Chapter Summary}

This chapter illustrates how climate variability, economic development, low institutional capacity, and the assimilation social model in Peru interact to increase food system vulnerability in Panaillo. Extractive practices have not been sufficiently regulated and widespread resource degradation has reduced the available materials for traditional livelihoods, as well as diminished flora and fauna populations. Community members are already experiencing significant changes in climate. The impacts of this shifting environment are felt even more strongly in the community due to the low levels of government support and resources that reach Panaillo and other indigenous communities.

Traditional livelihoods and adaptive strategies are further threatened by limited household resources, increased integration into the market economy, and the loss of traditional knowledge. Although temporary and permanent migration have emerged as solutions to these issues, this research highlights the difficulties migrants experience in the city, including limited employment options, low financial resources, and the loss of traditional lifestyles. Migration was also shown to affect the community structure of Panaillo and to hinder the delivery of critical government services and resources. The next chapter will further discuss these issues by examining the dynamic response of food system vulnerability to extreme flooding. 


\section{CHAPTER 7. RESULTS - FOOD SYSTEM VULNERABILITY TO EXTREME FLOOD EVENTS}

This chapter focuses on the extreme flood event of 2010-2011 as a temporal analogue to examine how extreme flooding influences the vulnerability of the Panaillo food system. As mentioned in Chapter 3, temporal analogues are commonly employed in climate change adaptation research in order to improve the understanding of current responses to climate extremes and to make inferences for the future (Ford et al., 2010b; Glanz, 1991; Tol, Fankhauser, Smith, 1998; Hallegatte, Hourcade, Ambrosi, 2007; Ford et al., 2006; Duncan, 1992). By examining institutional and community responses to a specific historical event, temporal analogue approaches can highlight how climate risks are managed, the ways socioeconomic and biophysical stressors shape post-hazard vulnerability, and dynamic nature of vulnerability over time and space (Ford et al., 2010b). For example, Tol et al. (1998) used a temporal analogue approach to affirm that adaptation to climate change would not be as smooth as spatial analogues studies indicate or as random as arbitrary adaptation studies suggest. Although temporal analogues cannot exactly replicate future conditions, they are still useful to examine societal interactions with current climate variability and to provide an empirical baseline for assessing future vulnerability and opportunity for adaptation (Ford et al., 2010b; Ford et al., 2006; McLeman \& Hunter, 2010; Giles \& Perry, 1998).

Several temporal analogue studies have focused specifically on vulnerability and extreme climatic events (Giles \& Perry, 1998; McLeman \& Hunter, 2010; Adger et al., 2012; White \& Etkin, 1998; Trenberth \& Fasullo, 2012; Erlat \& Türkes, 2012) due to the increase in frequency of climate extremes (Trenberth \& Fasullo, 2012; Erlat \& Türkes, 2012; Espinoza et al., 2009), the projection that 'extreme' events may become more 'normal' and severe with the onset of climate change (Adger et al., 2007; Giles \& Perry, 1998), and the potential for extreme events to markedly increase vulnerability and/or motivate adaptation actions (Adger, 1999; Travis \& Huisenga, 2013). Extreme climatic events have been shown to increase or decrease vulnerability (e.g., Adger et al., 2007, Fazey et al., 2011; Travis \& Huisenga, 2013). Frequent and severe climatic events may trigger positive changes in adaptive strategies, leading to increased resilience for future climatic events, for 
example, by planting hazard-resistant seeds or increasing livelihood diversification (Adger et al., 2007). Several studies have documented how extreme events may lead to a "window of opportunity" by catalyzing profound social, economic, policy and legal changes due to the vulnerabilities that are exposed as a result of the climatic event (Kates et al., 2010; Travis, 2012; McSweeney \& Coomes, 2011). Whether these transformational changes occur is dependent upon the frequency and severity of the extreme event and the decisionmaking context (Yohe \& Tol, 2002; Kates et al., 2010). As Arnell et al. (1984: 179) note: “All major changes are associated with major events, but not all events induce (or even demand) change".

Extreme events may also lead to reduced vulnerability since household resources are depleted in the climatic event and recovery is more difficult (Ford et al., 2013; Travis, 2010; Fazey et al., 2011; Travis \& Huisenga, 2013). Adaptive strategies used for the extreme event also have the potential to foster maladaptation, especially when profound changes following a climatic hazard encourage a false sense of security or foster dependency on unreliable institutions and limited resources (Kates et al., 2010; Travis, 2010; Arnell et al., 1984). For example, coastal settlements that are constructed as a result of flood protection mechanisms illustrate the "levee effect" in which infrastructural protection encourages maladaptive development (Travis, 2010). Maladaptive strategies also developed in the Pacific Islands when households stopped cultivating famine foods after the introduction of food aid, despite the unreliable and poorly-timed distribution of this external food relief (Campbell, 2006). It is thus important to critically analyze the effectiveness of adaptive strategies at varying spatial and temporal scales.

This chapter explores these themes through the extreme flood event in 2010-2011. The chapter begins by characterizing community perceptions of extreme flooding and then specifically examines the 2010-2011 extreme flood, including its impact on livelihoods, adaptive strategies, and the institutional response to the event. Although many institutions were seemingly more resilient following the 2010-2011 floods, Panaillo's food system vulnerability may be further compromised in the long-term as a result of community-level responses. 


\subsection{Community Perceptions of Extreme Flooding}

During semi-structured interviews and the seasonal food security focus group, current and former Panaillo residents were asked to distinguish the traits of an extreme flood from a normal seasonal flood, including whether the flooding differed in speed of onset, duration, and height. Community members characterized extreme flooding as rising faster (48\%, $n=20)$, lasting longer $(79 \% n=33)$, and rising higher ( $88 \%, n=37)$. Although the Peruvian alert system for flooding is mainly based on the how much the river rises above sea level, 21 percent of community members $(n=9)$ considered the flood duration to be the most important distinguishing feature of an extreme flood in comparison to normal floods. Relatedly, when asked to describe the distinguishable traits of an extreme flood year, community respondents tended to describe extreme flooding in terms of its consequences on community life, rather than the physical traits of the actual flood. Over 80 percent of community members $(n=35)$ characterized extreme flood years by the relatively greater damage it incurred. The most frequently mentioned characteristic of an extreme flood in community interviews was that floodwaters cover the house floor $(n=32)$. Community members also described how extreme flooding incurs greater crop loss ( $\mathrm{n}=11)$, causes more illness $(n=7)$, weakens the structural foundation of houses $(n=3)$, destroys agricultural seeds for the next year $(n=1)$, increases fish scarcity $(n=1)$, heightens the threat of snakes entering the house $(n=1)$, and increases livestock deaths $(n=1)$.

\subsection{Overview of the 2010-2011 Floods in Ucayali}

The extreme flooding in 2010-2011 was the most frequently mentioned extreme flood event among interview respondents. Prior to the 2010-2011 rainy season, the Peruvian Amazon was characterized by a severe drought, which unprecedentedly transitioned into one of the highest river discharges recorded in the area in April 2011 (Espinoza et al., 2012; See Figure 9). In the month of February 2011, $473 \mathrm{~mm}$ of rain fell in Ucayali, exceeding the February average of $279 \mathrm{~mm}$ (Vásquez et al., 2012). On February $22^{\text {nd }}$ alone, $101 \mathrm{~mm}$ of rain fell in the region (Vásquez et al., 2012). The Ucayali River reached a historical level of $147.46 \mathrm{~m}$ above sea level on March 5, 2011, which was the highest level recorded since 1980 when the Ucayali Coast Guard began to take annual measurements 
(Vásquez et al., 2012). Although 23 regions reported emergencies in response to the 20102011 floods, Ucayali was one of the most affected regions (Vásquez et al., 2012). In 20102011, Ucayali reported 6,706 injuries, 59,021 affected people, 22,500 houses damaged or destroyed, damage to 30 bridges and $400 \mathrm{~km}$ of roads, and the loss of 30,000 animals and 40,000 hectares of agricultural land (Vásquez et al., 2012). The regional government declared a state of emergency on February 25, 2011, and a federally-declared state of emergency in the region was pronounced on April 25, 2011.

\section{Pucallpa Hydrological Station - Ucayali River Mean Daily Flow Rate}

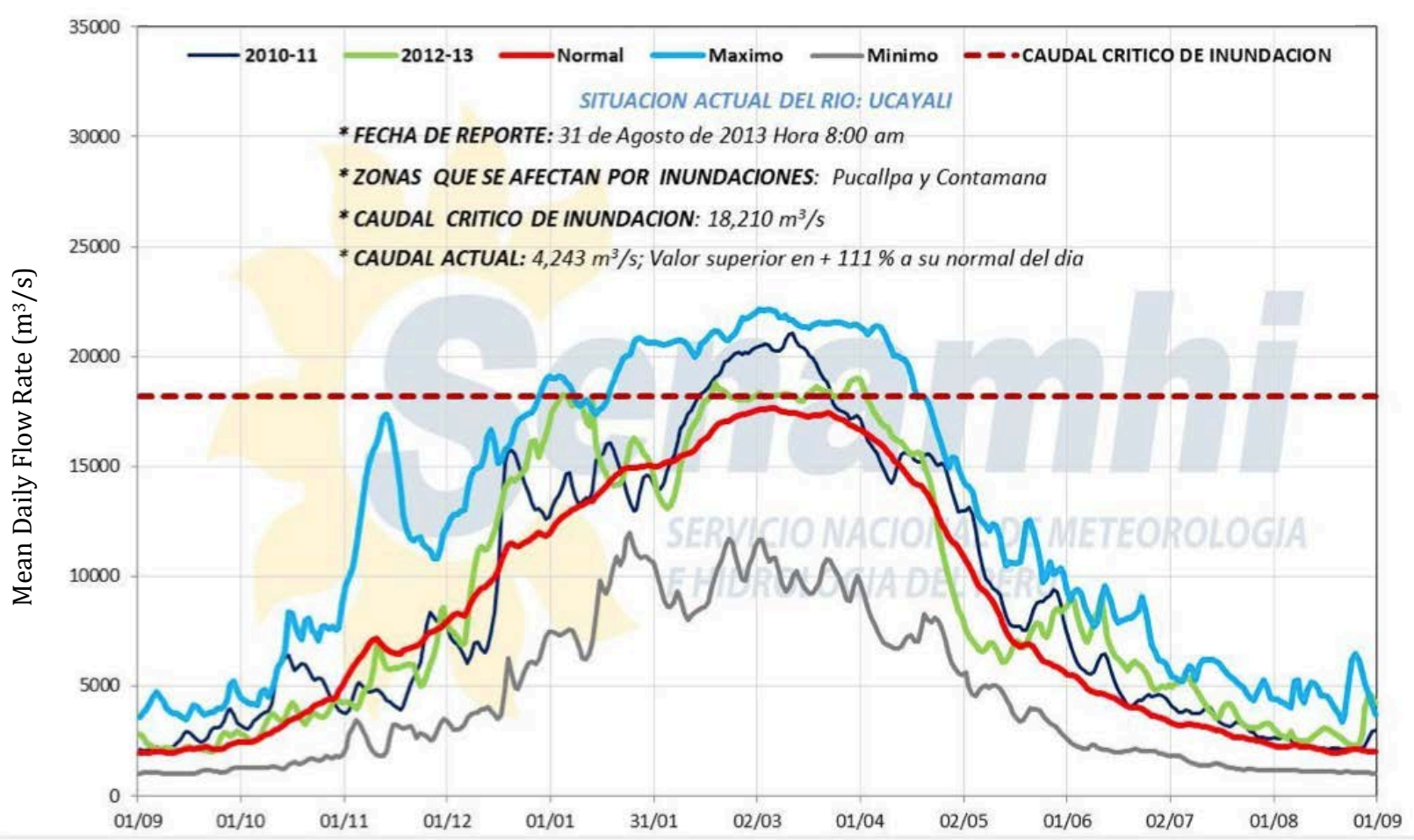

Figure 9. Hydrograph of mean daily flow rates of the Ucayali River in Pucallpa. Monthly measurements have been taken since 1980. Data was not available for 1985/86 and 1992/93. The dotted red line depicts the critical flow rate for flooding. The red line depicts average flow rate. The blue line depicts the maximum flow rate and the grey line depicts minimum flow rate. The blue line depicts the flow rate during the 2010-2011 hydrological year and the green line depicts the flow rate during the 2012-2013 hydrological year. Source: Carranza, 2012. 


\subsection{Impact of the 2010-2011 Flooding on Livelihoods}

The extreme flooding in 2010-2011 reportedly improved fishing and agricultural conditions in the short-term. The seasonal food security focus group and seven interviewees described how the extreme flood created more expansive riverbeds for agriculture, as well as enhanced soil fertility and removed debris from these riverbeds. Rice production in Panaillo particularly benefited from the post-flood conditions in 2011 since the flood created more expansive mudflats for rice cultivation. However, according to the seasonal food security focus group, Panaillo residents could not take advantage of the improved agricultural conditions due to the same financial and environmental constraints that inhibited agro-fishing livelihoods during normal flood years (see Chapters $5 \& 6$ ). Participants explained that the increased agricultural potential of the riverbeds was wasted since residents still did not have sufficient seeds to take advantage of the larger planting area and also lacked the laborers and/or money to hire additional workers for the harvest. The extended duration of the 2010-2011 flood also significantly shortened the harvest season and many crops were not yet mature by the time the next floodwaters arrived in November 2011. Although rice production was higher in 2011, saturation of local markets with rice product lowered its price and households struggled to generate as much income as normal years.

Fish populations were also reported by two institutional interviewees to increase after strong flood years (Interview \#67, 7/16/2013; Interview \#70, 7/22/2013). Participants in the seasonal food security focus group similarly reported having improved fish quality after the 2010-2011 flooding as a result of a more pronounced mijano and greater fish abundance. However, community members could only sell fish for a low price due to market saturation. The extreme flood event also led to erosion in some areas, causing fish to asphyxiate as a result of increased sedimentation. Focus group participants also complained that fish catches were lower after the 2010-2011 flooding because the Ucayali river flow shifted during the flood and the new flow partially prevented fish from entering the Panaillo tributary.

Furthermore, participants in the seasonal food security focus group commented that the extreme flood damaged household assets and limited the working conditions for 
agriculture, fishing, and traditional handicrafts during the rainy season. Income and homegrown food were thus needed in even greater quantities to aid recovery from the 2010-2011 flooding. However, community members continued to struggle to find external employment, especially since many companies' operations also needed to recover from flood damage.

\subsection{Impact of the 2010-2011 Flooding on Adaptive Strategies}

Many traditional strategies for seasonal flooding were rendered unusable in the 2010-2011 floods according to community interviews and the seasonal food security focus group. For example, focus group participants discussed how the long duration of the 2010-2011 floods delayed planting and thus shortened the harvest season. The shorter harvest season significantly reduced the window of time in which the yuca could be dried and the fariña prepared. Focus group participants also mentioned how food scarcity led to the decline of food-sharing networks in 2010-2011, and theft became more common. For instance, a neighboring community reportedly stole some of Panaillo's watermelon crops in September 2011.

According to six Panaillo respondents, households increasingly cultivated floodresistant plantain species (i.e., campeon and sapo) after seeing the need for a more floodresistant species. Two respondents began to cultivate flood-resistant plantain after the 2010-2011 flooding in particular. However, the 2010-2011 flooding wiped out all of the flood-resistant plantain species that the community had planted. As reported in Chapter 6, campeón and sapo plantain can only withstand one week of water submergence, and fruit yield is impaired by the cloudy conditions and the submergence of roots. Accordingly, the seasonal food security focus group mentioned needing to increase dependence on breadfruit during the 2010-2011 flooding since plantain was unavailable.

Furthermore, the extreme flood conditions in 2010-2011 necessitated additional measures to protect housing. Community respondents mentioned constructing a raised platform to be placed over the submerged floor $(n=13)$, placing wooden poles in strategic locations to support the house structure $(n=6)$, and securing belongings to the house $(n=3)$. Over one-fifth of community respondents $(n=9)$ reported that houses collapsed during extreme floods as a result of strong winds and erosion. Some residents reconstructed their 
houses using stronger materials. In 2011, one Panaillo resident used a stronger tin material for his house's roof since the traditional palm fronds used for roofs are increasingly scarce in the area (see Figure 10).

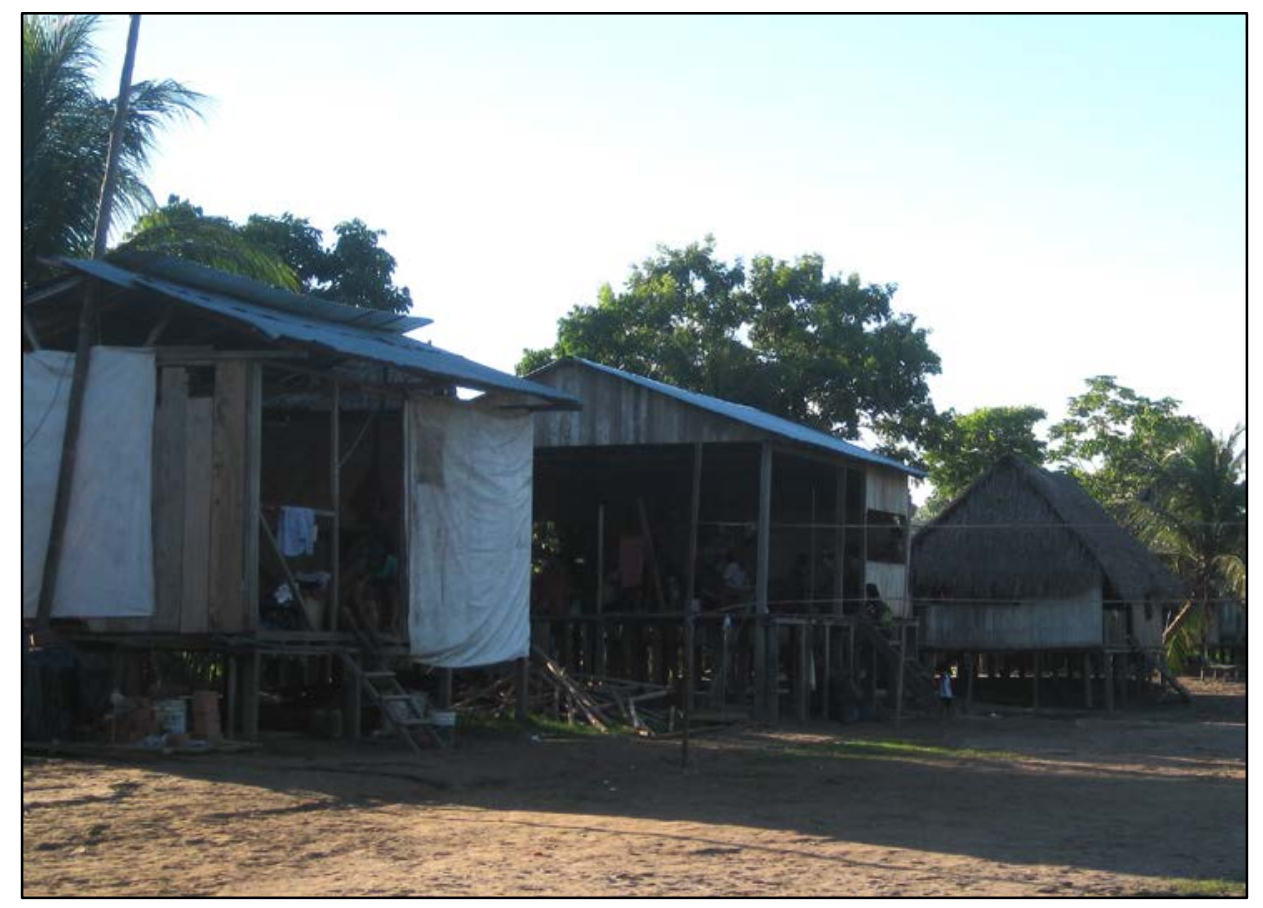

Figure 10. Houses that were reconstructed with metal roofing (right, center) next to a traditional house with a roof made with palm fronds (left).

Eight community members reported that the 2011-2012 flooding was easier to manage as a result of these structural changes and increased preparedness from the experience in 2010-2011. However, households also increasingly turned to migration in response to severe flood events, as discussed in 19 interviews. One community health worker in Panaillo explained,

Now they leave their homes for the city because [they] think that the flood will be strong... it's changed a lot recently because in these past few years there have been big floods in comparison to other years, and because of this the population has left (Interview \#43, 5/3/2013).

Five community members reported going to the city in 2011-2012 for the rainy season since the 2010-2011 flood conditions were so difficult in the community. Four community members also stated that their decision to migrate to the city each rainy season is determined by whether or not the floor of the house will be covered with water, suggesting 
that temporary migration increases in extreme flood years. McLeman and Hunter (2010) similarly noted increases in migration in response to extreme climate events, such as Hurricane Mitch in Central America and Hurricane Katrina in New Orleans. The authors reiterate that the tendency to migrate following a climatic event is differentially distributed among households; those with fewer household resources are more likely to permanently relocate. Similarly, Panaillo residents with the ability to make more permanent structural changes to housing following the extreme event were less likely to migrate after the 20102011 flooding than more resource-poor households.

\subsection{Institutional Response to 2010-2011 Flooding}

The 2010-2011 floods created an opportunity to build local institutional capacity and raise public awareness on the issues of poverty and flooding in Ucayali. Due to the severity of the flooding in 2010-2011, recovery efforts depended on support from local government institutions and NGOs, as well as international cooperation from organizations like the Red Cross, COOPI, and CARE. Since UNICEF had already been working in Ucayali for several years, it played a particularly important role in attracting international attention to the region by contacting international media and newspapers, according to two institutional interviewees. As one institutional respondent stated: "UNICEF launched the alert because the local authorities did not have the capacity to do so" (Interview \#65, 7/8/2013).

Prior to the 2010-2011 floods, Ucayali had poor disaster preparation and a low presence of international organizations, with the exception of UNICEF. According to four institutional interviewees, the majority of local institutions had no specific budget designated for emergency situations. An interview with the Civil Defense for Yarinacocha further affirmed that Yarinacocha received no flood relief from its district government during the 2010-2011 floods due to budget misallocations and low financial resources. Vásquez et al. (2012) similarly commented that the frequent turnover of authorities and the lack of risk management policies on the agenda further constrained institutional response to the 2010 flooding.

The extreme climatic event in 2010-2011 created an opportunity to improve the disaster management and planning of local institutions. After the 2010-2011 flooding, the institutional organization of disaster management in Peru shifted dramatically. In May 
2011, the National System for Civil Defense (SINADECI) was replaced by the current National Disaster Risk Management System (SINAGERD). SINAGERD places a greater emphasis on prevention and risk reduction and introduces CENEPRED as an entire institution dedicated to these issues. The State also formed a Lima Working Group for Ucayali in 2011 to coordinate the collaboration between the Peruvian government and international institutions, which resulted in capacity-building sessions for Ucayali institutions to improve their disaster management skills (Vásquez et al., 2012). As a result, many local institutions increased their budgetary allocations for emergencies in 2011, as reported by three institutional respondents.

The increased presence and activity level of international organizations in Ucayali in 2011 also provided an impetus to introduce additional programming in the area. Many of the international institutions that started to work in Ucayali in response to the 2010-2011 floods began to work with general development issues in the region after the flood event, including the Mi Agua (My Water) project. The Mi Agua project is a collaborative effort from international organizations and local institutions to improve access to clean water in rural communities. However, most Panaillo residents do not actively use the water treatment materials provided by Mi Agua, mainly due to the time and effort involved in treating the water. As such, it is important to ensure that local institutions effectively monitor and evaluate these projects even after international organizations have left the area.

A remaining issue is the low perceived importance of climate change issues among Peruvian institutions. Changes in temperature, precipitation and flood regimes were explicitly attributed to climate change in less than half of institutional interviews ( $n=15)$ and in 10 percent of community interviews $(n=4)$. However, the National Weather Service and Hydrology Service of Peru (SENAMHI) reported that climate events have intensified without precedent since 2003, including extreme climate phenomena that are out of sync with the El Niño-La Niña phenomenon (Santa Cruz et al., 2013; Vegas de Cáceres, 2010). One institutional respondent noted: “We don't want to recognize it, but we're already seeing changes in climate. The climate has changed completely and we're already living it. The key is to teach people to live with the changes" (Interview \#72, 8/1/2013). Deforestation was reported to exacerbate local climate change in three institutional 
interviews, including one respondent who stated: "The climate has changed more than anything because of deforestation. If I deforest, the climate changes" (Interview \#62, $6 / 17 / 2013)$. However, over 25 percent of community members interviewed $(n=11)$ and two institutional respondents explicitly denied that recent extreme flooding events might be linked to changes in climate. The majority of these respondents believed that extreme floods are a normal event that occurs every 5 or 10 years, and that recent extreme flooding reflects this natural trend.

Only one-fourth of institutional respondents $(n=8)$ identified potential future problems for their institutions with the onset of climate change. These institutions represented disaster management, transportation, agriculture, and fishing sectors. For example, the Civil Defense at both the district and provincial levels were concerned over the lack of available budget and political interest to address these issues. One respondent stated,

If certain scenarios happen... with climate change, many people are going to die on the river... We've informed the public, but there isn't a response... There's not enough force for people to listen to this issue, and there's no pressure to do something now. We have laws, but the authorities today haven't taken into account that, according to the law, we have to work on this issue and resolve it (Interview \#53, 5/30/2013).

One institutional interview respondent cited an unpublished report by the Central Reserve Bank of Peru, which estimated that if no action is taken, climate change will cost up to $\$ 855,000,000$ between 2009-2050, which could be avoided by investing \$87, 975 in climate-proof infrastructure today (Interview \#64, 6/24/2013). However, two respondents reported that CENEPRED has not taken enough initiative on the issue. A respondent from CENEPRED itself commented that action has been inhibited because "For me, climate change is just a word" (Interview \#64, 6/24/2013), referring to the lack of available information on specific climate change impacts in Peru.

\section{Chapter Summary}

The flooding in 2010-2011 created several opportunities for increased fishing and agricultural production in Panaillo. However, households lacked the resources to fully exploit the opportunities presented by the extreme flood conditions. The damage to 
household assets constrained many traditional adaptive strategies. Community members have increasingly turned to temporary and permanent migration as a reactive and preventative response to the increased frequency of extreme flood years. Although the extreme flood event in 2010-2011 constrained community livelihoods and adaptive strategies, it had several positive effects on local institutions. International aid organizations were drawn to Ucayali as a result of the 2010-2011 floods, and further benefitted the region by introducing additional programming and providing capacitybuilding sessions for local institutions. However, local institutions continue to generally disregard climate change issues, and the long-term implications of migration and extreme poverty in communities could increase food system vulnerability in the future. These issues will be addressed in the following discussion chapter. 


\section{CHAPTER 8. DISCUSSION AND CONCLUSION}

This research aimed to characterize the current vulnerability and adaptive capacity of the Panaillo food system to flooding. This thesis identified the principal drivers of the Panaillo food system, as well as examined how socioeconomic and biophysical factors enable or constrain the implementation of adaptive strategies in response to climatic hazards over time. In this research, climatic hazards strongly shape the Panaillo food system. However, non-climatic factors, including economic development, low institutional capacity, and the assimilation social model, exacerbate the impact of seasonal flooding on household food security and ultimately increase the vulnerability of Panaillo's food system by changing resource availability, traditional livelihoods, and adaptive strategies.

\subsection{Current Food System Vulnerability}

Panaillo households depend on agro-fishing livelihoods for income as well as food, so the inability to fish and/or cultivate at certain times of the year due to seasonal flooding is detrimental to both household food security and financial well-being. Panaillo residents have developed several adaptive strategies to adjust to hydrological extremes, such as food preservation, the cultivation of fast-growing crops on riverbeds, and reliance on income from other livelihoods, such as traditional artisanal crafts. However, Panaillo residents generally lack the necessary human, physical, social and natural resources to effectively employ their adaptive mechanisms as a result of major social and environmental changes in the area. In addition to seasonal flooding, Panaillo currently contends with market integration, extractive industries, cultural and political marginalization, the loss of traditional knowledge, and local institutions characterized by limited financial resources, poor inter-institutional coordination, dependency issues, and corruption. These stressors have resulted in resource degradation, changing ecosystem dynamics, shifting flood regimes, and limited services and resources reaching indigenous communities, which compromises the traditional livelihoods and adaptive strategies used by Panaillo residents to maintain food security amidst flooding. As discussed in the literature review (Chapter 2), recent literature has similarly illustrated how traditional livelihoods and adaptive strategies in the Peruvian Amazon have been compromised by ineffective institutions, 
uneven economic development, resource degradation, and climate shifts (Goy \& WaltnerToews, 2005; Santa Cruz et al., 2013; Vegas de Cáceres, 2010).

\subsubsection{Migration and Adaptation in Panaillo}

According to research in the Peruvian Amazon, intensification of fishing efforts, increased resource extraction from forests, and reliance on upland cropping are often used to cope with flood shocks (Takasaki et al., 2010; Coomes et al., 2010). However, in this research, Panaillo's location in a low-lying area precluded the option of upland cropping. Community members were sometimes able to increase fishing efforts and extract timber products for sale, yet these strategies have also become increasingly less viable due to declines in fish populations, the over-extraction of desirable timber species, limited transportation and constrained market access. Amidst limited livelihoods and adaptive strategies, Panaillo community members increasingly rely on temporary or permanent migration in order to overcome flood shocks. In the lower Peruvian Amazon, small producers are increasingly migrating for temporary labor or permanent relocation due to the livelihood insecurity and financial losses that have resulted from resource degradation, frequent climatic hazards and market price fluctuations (Goy \& Waltner-Toews, 2005; Santa Cruz et al., 2013).

Several studies have examined migration as a response to the breakdown of ecosystem-dependent livelihoods, natural disasters, seasonality, as well as economic and political factors (Goy \& Waltner-Toews, 2005; Warner et al., 2009; McLeman \& Smit, 2006; McLeman \& Hunter, 2010; Adger, 1999). The relationship between migration, global environmental change, and adaptation has been widely discussed in climate change adaptation literature (see Black et al., 2011; Warner, 2010). An individual's decision to migrate is a reflection of several factors, including environmental, economic, political, social, demographic drivers (Black et al., 2011; Renaud et al., 2011; Oliver-Smith, 2012). It is thus difficult to directly attribute current or future migration patterns directly to climate change (Black et al., 2011; Renaud et al., 2011; Lilleør \& Van den Broeck, 2011; McLeman \& Hunter, 2010). Recent literature has explored the pathways through which climate change impacts might influence migration decisions, typically through the use of case studies and historical analogues (e.g., McLeman \& Hunter, 2010). Morrissey (2013) outlines four effects that may trigger environmental migration. As illustrated in Table 8 , these effects describe 
non-environmental factors that interact with environmental conditions and other socioeconomic factors to incentivize, enable, promote, constrain, or necessitate migration. Lilleør and Van den Broeck (2011) examined the influence of rainfall and temperature variability of economic drivers of migration in particular. Households may be motivated to migrate in order to diversify income sources if they have experienced significant income variability, although additional empirical studies are needed on the topic (Lilleør \& Van den Broeck, 2011).

Table 8. Effects that may trigger environmental migration.

\begin{tabular}{|l|l|}
\hline Type of Effect & Definition \\
\hline Additive effects & $\begin{array}{l}\text { Non-environmental factors which create an imperative to } \\
\text { move that is in addition to the stress generated by the } \\
\text { biophysical environment. }\end{array}$ \\
\hline Enabling effects & $\begin{array}{l}\text { Non-environmental factors which make mobility a particularly } \\
\text { suitable response to the livelihood insecurity generated by } \\
\text { environmental stress. }\end{array}$ \\
\hline Barrier effects & $\begin{array}{l}\text { Non-environmental factors which retard the imperative to } \\
\text { move. }\end{array}$ \\
\hline Vulnerability effects & $\begin{array}{l}\text { Non-environmental factors which exacerbate the negative } \\
\text { impacts of changes in the physical environment on livelihood } \\
\text { security. }\end{array}$ \\
\hline
\end{tabular}

Source: Morrissey, 2013

Renaud et al. (2011) distinguished between three types of environmental migrants: 1) environmental emergency migrants who must evacuate an area in response to a temporary environmental impact, 2) environmentally forced migrants who must leave an area as a result of severe environmental deterioration, and 3) environmentally motivated migrants who pre-emptively leave an area amidst signs of environmental deterioration. Environmental emergency migrants thus experience the greatest urgency in migration. Environmentally forced migrants must migrate as a last resort to a slower-paced environmental degradation and environmentally motivated migrants choose to relocate in anticipation of worse environmental effects. In the case of Panaillo, migration patterns could fit into any of these descriptions, depending on the household's particular reason for migrating (e.g., flooding vs. employment/education) and the permanence of the relocation. For example, individuals who temporarily migrate to the city to avoid the flood conditions 
each year could be considered environmental emergency migrants. Permanent migrants who relocate to urban centers for employment may qualify as environmentally forced migrants since they cannot successfully carry out livelihood activities in Panaillo due to resource degradation. Migrants who moved to the city permanently in response to experiencing severe flooding in consecutive years may be considered environmentally motivated migrants.

Another important contribution to understanding of the role of migration in climate change vulnerability can be found in Scheffran et al's (2012) discussion of adaptationpreventing-forced-migration, migration-as-adaptation, and migration-for-adaptation. Adaptation-preventing-forced-migration refers to how, in certain contexts, households may be able to avoid permanent migration by adapting to socioeconomic and biophysical changes. Seasonal migration can be considered an adaptive strategy in this case, since it prevents permanent migration out of distress. Several studies have also highlighted how migration of a household member may serve as a risk reduction strategy for climate and non-climate risks by diversifying household income sources (Scheffran et al., 2012; Renaud et al., 2011; Ellis, 2000; Warner, 2010; Adger, 1999).

The recent rise of permanent migration in Panaillo suggests that seasonal migration has not sufficiently mediated migration stressors. Given the precarious location of Panaillo on a shifting riverbed, permanent relocation to higher ground may be necessary if other preventative measures are lacking or ineffective. Accordingly, migration-as-adaptation describes situations when permanent migration serves as an appropriate adaptive response since climate change impacts threaten survival and local adaptation efforts and protection are insufficient (Scheffran et al., 2012).

Finally, migration-for-adaptation emphasizes the positive influence migrant networks can have on the origin area. Technology, knowledge, skills, social capital, and remittances may flow between migrants and original communities, resulting in benefits for both groups by building social resilience, increasing flexibility and diversity, and even fostering innovation (Scheffran et al., 2012; Adger, 1999). Although it is important to consider the positive role migrants can play on an original community, high levels of migration can have negative repercussions by overwhelming the destination area's capabilities and by weakening the original community's social structure, especially 
considering that most migrants in least developed countries tend to be younger and with greater resources (Lilleør \& Van den Broeck, 2011; Black et al., 2011; Raleigh, 2011). Larger migrant networks can also instigate migration, which was demonstrated in this thesis as well as other research (Lilleør \& Van den Broeck, 2011; Black et al., 2011). Although there is some interaction between former and current Panaillo residents, jealousy and conflict exist between the two groups, especially regarding the amount of support migrants provide for their original community. For Panaillo to develop migrant networks that serve an adaptive purpose, it is important to strengthen the mutual flow of resources between migrants and community members, as well as to strengthen livelihoods in the original community to preserve community structure and tradition. Furthermore, this research and the UNDP Human Development Report on Peru highlight how rural migrants in the Peruvian Amazon struggle to find permanent, fair-wage positions in the city, which further compromises the ability of migration to serve as adaptation (Goy \& Waltner-Toews, 2005; Santa Cruz et al., 2013).

\subsection{Dynamic Vulnerability and Extreme Climate Events}

Over the past decade, the Peruvian Amazon has experienced the most intense floods and droughts in recent history (Marengo et al., 2013; Espinoza et al., 2009), yet societal responses have been largely insufficient to mitigate the negative impact of such extreme events (Vásquez et al., 2012). In this research, the 2010-2011 flooding was used to examine how the Panaillo food system vulnerability is currently affected by extreme climatic events, as well as to make inferences for future food system vulnerability with the onset of climate change (Ford et al., 2010b). As discussed in Chapter 7, the extreme 2010-2011 floods had a differential affect on food system vulnerability at the community and institutional levels and over time. It is difficult to gauge the overall effect of the extreme flooding in 2010-2011 on the Panaillo food system's vulnerability due to the dynamic and context-specific response of individuals and organizations to the climatic event. However, the community and institutional responses to the extreme flooding in 2010-2011 provide insight into the multiple drivers of vulnerability that exist at different spatial and temporal scales. Travis (2012: 1) highlights the importance of understanding how extreme events influence vulnerability and adaptation in stating: "An extreme event becomes not just a reminder 
that climate distributions have tails, but a harbinger of more extremes to come".

\subsubsection{Vulnerability and the 2010-2011 Flooding}

In Panaillo, both livelihoods and adaptive strategies were negatively affected by the 20102011 flooding in the short-term. Community members were unable to take advantage of the improved fishing and agricultural conditions due to limited household resources. The flood conditions also compromised traditional adaptive strategies, mainly by shortening the harvest season and impeding fariña production. In this respect, Panaillo's food system vulnerability was exacerbated not only during the 2010-2011 flood year, but the following year as well.

Some new strategies emerged to adapt to the extreme flood conditions in 20102011, such as reinforcing housing structures with stronger materials and increasing the cultivation of more flood-resistant plantain species. However, these strategies have limited potential to withstand severe flooding. Stronger housing structures enable Panaillo residents to stay in their flood-prone location, placing them at high risk for another dramatic shift in river flow and erosion. As evidenced by the 2004 flooding event that led to Panaillo's relocation, this river shift could lead to the complete destruction of the community.

Additionally, flood-resistant species, such as campeón and sapo, are unable to withstand severe flooding, according to local knowledge. In 2011, community members had to rely on breadfruit after the plantain crops were wiped out during the extreme flooding. The flexibility and diversity of these adaptive strategies are encouraging for managing future extreme climate events. In other case studies, alternating between multiple adaptive strategies was shown to increase resilience (Eriksen et al., 2005; Ziervogel, Bharwani \& Downing, 2006a; Kvist \& Nebel, 2001). However, community interviews indicated that Panaillo residents still viewed campeón and sapo species as relatively flood-resistant, and decided to increasingly plant these species after 2011 due to experiencing more severe floods in recent years. Although these plantain species are more resilient to moderate flooding, the increased reliance on campeón and sapo species overlooks the need to find a staple food that could withstand the severe and prolonged flooding that is projected to occur with climate change (Adger et al., 2007). Breadfruit was 
not prioritized as an alternative flood-resistant food source according to community interviews and focus groups. Community members also reported that they do not cultivate breadfruit and have not attempted to limit the over-extraction of natural breadfruit in the area. Therefore, increased cultivation of campeón and sapo plantain species may reduce vulnerability to moderate flood events, but the reliance on these species may increase vulnerability overall amidst more extreme flood events in the future.

Institutional responses to the 2010-2011 extreme flooding triggered some actions that may have reduced vulnerability in the medium-term, but these initiatives are unlikely to benefit future resilience due to the poor functioning of existing institutions. As illustrated in Chapter 5, institutions at the local, district, regional, and national level often struggle with inefficiency, nepotism, and discrimination. These issues render local institutions largely ineffective in meeting the needs of vulnerable populations. The increased attention to the Ucayali region in the aftermath of the 2010-2011 floods presented as an opportunity to transform local institutions to be better able to respond to climatic events and to foster adaptation. Unfortunately, the interventions that resulted in response to the 2010-2011 floods were incorporated into the operations of weak existing institutions. Capacity-building in local institutions and the creation of new projects had minimal impact due to the high rate of employee turnover and the low capacity of current staff and organizations. The poor monitoring of the Mi Agua project in Panaillo exemplifies this issue and the low effectiveness of the programs initiated after the 2010-2011 flooding.

These examples support the recent literature that describe how vulnerability is differentially affected by an extreme climatic event over time and space and how multiple stressors act simultaneously to shape vulnerability outcomes (Watts \& Bohle, 1993; Lauer et al., 2013; Liu, Golding \& Gong, 2008; Belliveau, Smit, Bradshaw, 2006;).

\subsubsection{Fast and Slow Drivers of Vulnerability in Panaillo}

Since multiple stressors affected the vulnerability of the Panaillo food system, the concepts of fast and slow drivers of vulnerability are relevant to this case study. Fast variables determine whether or not a given exposure can be effectively coped with on relatively short time scales (i.e., weeks to years), whereas slow variables describe upstream drivers of vulnerability that operate on larger spatial and temporal scales and shape the context in 
which fast variables manifest (Ford et al., 2013). Although the interplay of both fast and slow variables is important for vulnerability, slow variables are outside of direct control and ultimately direct sensitivity and adaptive capacity (Ford et al., 2013; Chapin et al., 2004). Chapin et al. (2004: 347) explain that fast variables often receive the greatest attention from institutions, decision-makers, and the public, even though "failure to manage the slow variables can lead to irreversible changes, such as the loss of a fishery or traditional ties to the land, with grave societal consequences". Exclusively addressing fast variables also has the potential to lead to maladaptive trajectories if the resulting adaptations are inflexible, limiting, and/or have negative long-term consequences (Fazey et al., 2011).

In the case of the 2010-2011 extreme flooding, severe flooding was an immediate and visible fast driver of food insecurity in Panaillo. As discussed in chapters 5 and 6 , the food system was also directly impacted by a range of biophysical and socioeconomic factors, including resource degradation, limited resources and services in indigenous communities, changing ecosystem dynamics, and the decline in traditional practices, like food-sharing. Peru's rapid economic development, low institutional capacity, assimilation social model, and climate variability exacerbated these proximal drivers of vulnerability. However, to address Panaillo's food system vulnerability, it is also important to consider the larger context of these distal drivers, including Peru's political economy, promotion of export-led growth, and high income inequality, as well as globalization, international market demand, and global environmental changes. For example, Peru's economy almost doubled in size between 2002-2012, marking the country's highest 10-year growth rate in its history (Vera \& Wong, 2013). Mining, logging, oil exploration, and other extractive industries have been responsible for much of Peru's rapid economic growth (Sears \& Pinedo-Vasquez, 2011; Pantigoso, 2014). Leichenko and O'Brien (2002: 14) relatedly note that: "Economic changes associated with globalization processes are altering conditions for the production and marketing of agricultural products".

It is thus important to work with both fast and slow variables to truly enhance resilience for current and future climate change. At the community and institutional levels, slow variables seemed to be overlooked in the response to the 2010-2011 flooding. For example, at the community level, Panaillo residents increasingly relied on temporary or 
permanent migration to cope with the flood impacts after the 2010-2011 flood event. In this research, migration did not improve food security outcomes for Panaillo residents, primarily due to the difficulty finding employment and the increased importance of financial resources for household food. Furthermore, many migrants were employed in jobs in resource extraction, which was largely responsible for the changes in flood regimes and ecosystem dynamics that partially drove such migration at the outset.

Other studies have also discussed the negative feedback loops that can form when short-term coping methods lead to maladaptation and eventually heighten vulnerability (Fazey et al., 2011; Eriksen et al., 2005; Westerhoff \& Smit, 2009). In a Ghana case study, Westerhoff and Smit (2009) describe how declines in soil fertility constrained agricultural production and led individuals to pursue other income-generating livelihoods, such as charcoal production, which further depleted the soil and exacerbated resource degradation. In this research, temporary or permanent migration as an adaptive strategy for flooding has the potential to launch Panaillo residents on a maladaptive trajectory unless job security for Panaillo residents and the sustainability of extractive resources are addressed.

At the institutional level, post-flood interventions tended to directly focus on climate risk management, without addressing other important slow variables in food system vulnerability, such as resource degradation and uneven market integration. Furthermore, transformational changes to institutional structures were not considered in initiatives to build capacity in local institutions, in spite of the public's dissatisfaction and distrust of existing institutions. Adger et al. (2012) describe the importance of negotiating social contracts in order to support vulnerable groups and smooth adaptation. In their comparison of individual responses to flooding in western Ireland and northwest England, Adger et al. find that the failure of the Irish government to provide sufficient flood aid led to:

A sense of helplessness among sections of the population. This helplessness is then manifest in an unwillingness to take personal responsibility for flood protection. Reliance on charitable organizations, outside the formal humanitarian aid provided, was a source of government-directed anger from many Galway respondents (2012: 332).

Similarly, the UNDP describes how the regularity of climatic hazards in Peru has not 
resulted in better adaptation, but has rather led populations to rely on humanitarian aid as a way of life (Santa Cruz et al., 2013). In the Brazilian context, Marengo et al. (2013) also discuss the widespread dependence of rural inhabitants on government aid following a climatic hazard. The authors assert that ineffective Amazonian policies in response to climatic hazards have undermined resilience by encouraging maladaptation. To address slow variables driving Panaillo's food system vulnerability, profound changes need to be made to current Peruvian institutions in order to better promote equity, inter-institutional coordination, accountability, and environmental sustainability. Although the disaster management system was modified in 2011 to include a stronger focus on prevention, climate change issues are still not considered a high priority among Peruvian institutions, further exacerbating vulnerability to climate change in the future.

\subsection{Future Food System Vulnerability: The Role of Climatic and Non-Climatic Factors}

The examination of Panaillo's current food system vulnerability to climate variability provides insight into the food system's potential future vulnerability amidst climate change, and the temporal analogue of the 2010-2011 flooding may further enhance our understanding of how the Panaillo food system may respond to extreme climatic events in particular. However, the future vulnerability of Panaillo's food system depends on the uncertain evolution of several socioeconomic and biophysical factors. While the future is impossible to predict, examining projected climate change impacts and socioeconomic trajectories for the area may help to distill some potential future trends.

\subsubsection{Climate Change Projections for the Peruvian Amazon}

A recent study in Nature projected that extreme El Niño episodes will double in the future as a result of greenhouse warming (Cai et al., 2014). Transitions from extreme El Niño episodes to La Niña phases can also result in dramatic seasonal transitions, such as the 2010 drought followed by the 2010-2011 floods discussed in Chapter 7 (Espinoza et al., 2009). Several authors note the potential for the Amazon Basin to transition from a carbon sink to a carbon source as a result of global environmental changes and regional human activities, especially deforestation (Davidson et al., 2012; Cochrane \& Barber, 2009; Cook, 
Zeng \& Yoon, 2012).

However, studies have also found important distinctions in how different parts of Amazonia respond to climate change (Cook et al., 2012; Cochrane \& Barber, 2009). For example, the Peruvian Amazon, located in the western part of the Amazon Basin, is expected to have a wetter rainy season, whereas the southern Amazon and central Brazil are expected to experience a drier dry season, as well as a wetter rainy season. Temperatures are also expected to rise more in the western Amazon than in the east (Adger et al., 2007). Flood regimes will also change in response to higher air temperatures and increased precipitation variability. Langerwisch et al. (2013) calculated future flood duration and area in the Amazon Basin using 24 climate models from the IPCC Fourth Assessment Report. In 70\% of the 24 climate models, the area of flooding increased in the Amazon Basin by one-third. On average, flooding also lasted three months longer in the western Amazon and one month longer in the eastern Amazon. The lower river levels in the dry season and stronger currents and storms in the rainy season would severely impede transportation in the area (Santa Cruz et al., 2013; Vegas de Cáceres, 2010; Marengo et al., 2013).

The impact of these climate changes would have significant repercussions for the flora and fauna in the area, including impacts on food networks and competition, reproductive cycles and plant phenology (Santa Cruz et al., 2013; Langerwisch et al., 2013; Vegas de Cáceres, 2010; Marengo et al., 2013). Davidson et al. (2012) highlight that Amazonian species are accustomed to seasonal variability, but that extreme hydrological events could overwhelm the ecosystem's resilience. Since local markets are controlled by supply and demand, lower agricultural production and lower fish catches could raise food prices and increase reliance on food imports in the Ucayali region, which could further reduce incomes and food consumption for impoverished families that depend on agrofishing livelihoods, like those found in Panaillo (Santa Cruz et al., 2013). In this research, Panaillo community members and local institutions are already reporting significant challenges with food price fluctuations, diminishing incomes, and changes in climate, flora and fauna populations (Chapters 5-7). More severe flooding would likely destroy many tree and plant species (Santa Cruz et al., 2013; Langerwisch et al., 2013; Marengo et al., 2013), as illustrated in the 2010-2011 flooding event. Several studies project lower crop yield, 
increased soil erosion, reduced water availability, and increased plagues and diseases in response to changes in seasonality (Brondizio \& Moran, 2008; Santa Cruz et al., 2013; Vegas de Cáceres, 2010). Lakes may dry up due to high temperatures, which could potentially induce significant losses in fish populations from hypoxia and eutrophication (Santa Cruz et al., 2013; Marengo et al., 2013). The lack of predictability in climate patterns could also disrupt planting and harvest calendars and inhibit planning (Vegas de Cáceres, 2010; Santa Cruz et al., 2013). Therefore, projected climate change impacts have the potential to further impede agro-fishing livelihoods and traditional adaptive strategies in Panaillo.

Current human activities and significant changes in land-use are exacerbating climate change in the Amazon (Santa Cruz et al., 2013; Davidson et al., 2012; Vegas de Cáceres, 2010; Cook et al., 2012; Nebel, 2001). Deforestation, burning rainforests, agricultural expansion, and recent growth in urban populations have been crucial factors in generating climate changes in the Peruvian Amazon (Malhi et al., 2008; Vegas de Cáceres, 2010). Global and regional climate models predict that a tipping point will be passed once deforestation in the Amazon exceeds 40 percent, which will occur by 2050 at current deforestation rates (Santa Cruz et al., 2013; Cook et al., 2012). Land-use changes in the region are primarily driven by the logging industry, the expansion of agriculture, the extraction of minerals, coca, and forest products, urbanization and the construction of roads and infrastructure (Brondizio \& Moran, 2008; Vegas de Cáceres, 2010; Santa Cruz et al., 2013). These drivers have been stimulated by national and international demand, and have been closely linked to Peru's own recent economic growth as illustrated in this thesis (Santa Cruz et al., 2013; Davidson et al., 2012). It is thus important to consider the sustainability of current operations and Peru's economic trajectory.

\subsubsection{Potential Socioeconomic Trajectories for the Peruvian Amazon}

Recent trends in Peru's political economy indicate that current extractive practices will continue or even intensify in the future (Pantigoso, 2014; Finer \& Orta-Martínez, 2010). According to the World Economic Situation and Prospects 2014 (WESP) report, Peru's economy is expected to continue to grow by 6.1 percent in 2014 and 6.5 percent in 2015, making it the second fastest growing economy in Latin America (United Nations, 2014). To 
a great extent, this economic growth is expected to come from mining, oil and gas industries, rather than improvements in education or health (United Nations, 2014; Pantigoso, 2014). Since 2003, hydrocarbon investments in the Peruvian Amazon have increased to unprecedented levels (Pantigoso, 2014; Finer \& Martínez, 2010). Over 84\% of the Peruvian Amazon has been or is currently zoned for oil and gas activities and over half of those concessions are located on legally titled indigenous territories (Finer \& OrtaMartínez, 2010). Finer and Orta-Martínez (2010) argue that the Peruvian Amazon is undergoing a second hydrocarbon boom, and that current hydrocarbon concessions already exceed the concessions found in the Peruvian Amazon at the peak of the 1970s hydrocarbon boom. These hydrocarbon projects have been criticized for their poor regulation of environmental and socioeconomic impacts. For example, the Block 67 oil project is currently being carried out in an area with rich biodiversity and intact forest that is also utilized by uncontacted indigenous peoples (Finer \& Orta-Martínez, 2010). In spite of a petition to the Inter-American Commission on Human rights and several domestic lawsuits, the development of Block 67 has continued since it is expected to increase oil production in the Peruvian Amazon to the same total oil production levels reached in the late 1970s and early 1980s in the first hydrocarbon boom (Finer \& Orta-Martínez, 2010). The extent of environmental degradation from recent operations and the current price volatility of certain minerals, such as gold, silver and copper, could also jeopardize future economic stability (Pantigoso, 2014). Furthermore, several authors have explicitly highlighted the importance of traditional knowledge to adapt to novel changes in climate (Santa Cruz et al., 2013; Vegas de Cáceres, 2010; Weatherhead, Gearhead \& Barry, 2010; Orlove et al., 2010). Several authors assert that traditional farming systems are more resilient to climatic hazards than commercial ones due to their high biodiversity, exploitation of micro-climates, dependence on local resources and place-specificity (Altieri \& Nicholls, 2013; Lin, Perfecto, Vandermeer, 2008). Ortiz et al. (2013) also discuss the importance of small-scale traditional forms of agriculture in describing the "paradox of scale", which refers to the higher productivity per area found in diverse small farming systems in comparison to large monoculture systems. As illustrated in this case study, urbanization and the expansion of extractive industries in indigenous territories could seriously threaten traditional customs and knowledge. 
Since poor, rural households are more likely to be negatively affected by these biophysical and socioeconomic changes, rates of environmental migration are expected to increase. Warner et al. (2009) consider climate change-induced migration to be inevitable. The UN High Commissioner for Refugees, Antonio Guterres (2008), similarly affirms that climate change will worsen human displacement. Warner (2010) also discusses how existing governance structures might be ill-equipped to manage new forms of human mobility, which may overwhelm the capacity of humanitarian organizations and create new economic and environmental problems in host communities. According to Martin (2005), whether environmental migrants develop a cooperative or conflictive relationship with host communities is highly dependent on the context surrounding potential resource conflict, including physical, political, economic, cultural, historical and external intervention factors. Therefore, current economic activities have the potential to further compromise community food systems in the Peruvian Amazon and to exacerbate the impacts of climate change.

It is thus increasingly important that institutions properly manage the impacts of climate changes. However, existing institutions to manage climate change impacts are limited by low institutional capacity, as previously discussed. The current disaster management system, SINAGERD, has been criticized for several reasons in this research and the published literature (UNDP \& BCPR, 2013; Santa Cruz et al., 2013). The two main institutions of SINAGERD, INDECI and CENEPRED, do not have clearly defined roles and coordination between the two institutions is not operationalized (UNDP \& BCPR, 2013; Santa Cruz et al., 2013). Additionally, SINAGERD has not defined strategies and plans for the Civil Defense Platform at the local and regional levels (Santa Cruz et al., 2013). Furthermore, INDECI and CENEPRED are not part of the National Commission on Climate Change. Although CENEPRED was created with the aim of risk reduction and prevention for climatic hazards, the National Committee on Climate Change operates through the Ministry of Environment (Takahashi \& Meisner, 2013a). Recently, the Ministry of Environment has been criticized for not integrating disaster management thoroughly enough into the National Climate Change Strategy and the Third National Communication to the UNFCCC (UNDP \& BCPR, 2013).

Environmental institutions first emerged in Peru in the 1960s and the current 
Ministry of Environment was founded in 2008 (Takahashi \& Meisner, 2013a). However, environmental policies have remained relatively weak in the country (UNDP \& BCPR, 2013; Takahashi \& Meisner, 2013a). Environmental projects in Peru have been typically driven by the donor community and have experienced uneven implementation (Takahashi \& Meisner, 2013a). Over the past decade, climate change issues have been incorporated into existing institutions and the national development strategy (UNDP \& BCPR, 2013). The Ministry for Economy and Finance currently requires that public investments consider the sustainability of a project amidst probable climate change impact and some sectorial strategies to address climate change have emerged, such as the Ministry of Agriculture's National Plan on Risk Management and Adaptation to the Adverse Effects of Climate Change in the Agrarian Sector for the Period 2012-2021 (Santa Cruz et al., 2013).

However, the actual implementation of these regulations and plans is minimal. Marengo et al. (2013) discuss how Amazonian governments lack the awareness, understanding and capacity to address adaptation. Takahashi and Meisner (2013a) similarly note that agenda-setting and policy-formulation processes on climate change issues in Peru are limited by inaccurate information, competition with other policy issues, and highly politicized institutions. There is limited information about climate change effects in Peru, especially at the local level (Takahashi \& Meisner, 2013a; Santa Cruz et al., 2013). Politicians and advisers are also not specialized in climate change issues, and use the internet as a primary resource to characterize climate change issues and to formulate climate policy (Takahashi \& Meisner, 2013a). Takahashi and Meisner (2013a) also point out that climate change is not considered to be a threat to economic development, although the failure to manage the impacts of climate change might affect Peru's economic development. Environmental issues instead center on socio-environmental conflicts, such as mining issues and pollution (Takahashi \& Meisner, 2013a). Newspaper coverage of climate change was also shown to be strongly biased to cover mitigation topics over adaptation and to more frequently present the ecological effects of climate change over impacts on health, conflict or migration (Takahashi \& Meisner, 2013b). Preston et al. (2013) discuss how divergent priorities and competing values can impede adaptation in a given context. Accordingly, Takahashi and Meisner (2013a: 353) note that: "climate change is recognized as a problem, but not a problem that needs to be taken care of at this point in 
time, and especially in Congress".

Several authors hope that Lima hosting the upcoming UNFCCC Conference of Parties will provide the impetus needed to inspire climate change adaptation action (Santa Cruz et al., 2013). The continuation of current socioeconomic and biophysical trends would likely exacerbate food system vulnerability in the near future for indigenous and rural communities like Panaillo.

\subsection{Recommendations}

To pragmatically address Panaillo's food system vulnerability, it is important to address both the proximal and distal drivers of the food system. Firstly, building capacity among local institutions is crucial to ensure that the necessary services are provided to vulnerable populations and that climate risks are managed in an efficient and timely manner (Goy \& Waltner-Toews, 2005; Santa Cruz et al., 2013). Capacity building must foster a multidimensional and multi-disciplinary approach that enables institutions to address food system vulnerability at the local, regional, and national scale in a holistic manner (Santa Cruz et al., 2013; Ortiz et al., 2013). Enhancing institutional capacity may be brought about by facilitating cross-cultural communication, raising awareness of community needs, improving communication and collaboration between institutions, and building capacity among indigenous leaders so that they may properly solicit the services to which they are legally entitled (Goy \& Waltner-Toews, 2005; Santa Cruz et al., 2013; Vásquez et al., 2012). It is also important that climate change issues be more directly integrated into disaster management and other relevant sectors in Peru (UNDP \& BCPR, 2013). Climate risk management must be cohesive and consider multiple spatial and temporal scales. For example, infrastructure and development must consider climate change impacts by, for example, reinforcing existing structures, increasing territorial planning to avoid human settlements in dangerous zones and providing the necessary supports for relocation when appropriate (Santa Cruz et al., 2013). Reforestation can also help to protect floodplains from erosion and restore ecosystems.

Although capacity building among institutions may be accomplished in a decentralized system, it is critical that the Peruvian government supply the necessary resources and training to sub-regional levels in order to ensure effective and equitable 
development (Goy \& Waltner-Toews, 2005; Santa Cruz et al., 2013). It is also important to increase documentation in public institutions and to enforce a 15-day period to transfer functions between new and old officials (Vásquez et al., 2012). These efforts can help address the high turnover of leaders and facilitate knowledge transfer between elections.

Since vulnerable populations in Peru cannot always been relocated to safer places, feasible solutions must be implemented for housing and agriculture in low-lying areas like Panaillo. It is important to ensure that household agricultural production is at maximum capacity and to improve food storage abilities, for example, by introducing simple seedstorage technology and encouraging crop diversification (Vásquez et al., 2012; Vegas de Cáceres, 2010). Increasing the frequency and regularity of visits from agricultural extension workers, improving access to markets and information on market prices, and consistently building technical capacity among Panaillo residents could also improve agricultural livelihoods (Vásquez et al., 2012; Vegas de Cáceres, 2010; Lilleør \& Van den Broeck, 2011; Ziervogel et al., 2006a). Given the increasingly unpredictable nature of the flood regime, it will be particularly useful to improve the flexibility and adaptability of agricultural calendars (Santa Cruz et al., 2013; Lilleør \& Van den Broeck, 2011). Amidst production variability, agricultural households are also more likely to maintain household food consumption with increased access to financial resources through microfinance schemes, including disaster insurance (Lilleør \& Van den Broeck, 2011; UNDP \& BCPR, 2013). Several authors also recommend recuperating traditional knowledge for agriculture and fishing practices to enhance food system resilience, for example, by diversifying crops and relying on organic fertilizers (UNDP \& BCPR, 2013; Santa Cruz et al., 2013; Vegas de Cáceres, 2010).

To enhance fishing livelihoods, the UNDP Human Development Report on Peru also recommends increasing the sustainable management of fish populations, introducing alternative protein sources to fish, and minimizing activities that are altering the hydrological cycle (Santa Cruz et al., 2013). The latter option involves increased regulation and monitoring of extractive activities, which will likely require the institutional reform that was previously discussed. Aquaculture was shown in pilot projects to be a non-viable option for fishing livelihoods in the Peruvian Amazon due to the high production costs and low fish yield (Santa Cruz et al., 2013). 
Several authors also recommend improving early warning systems so that populations may better prepare for climatic hazards (Moran et al., 2006; Vásquez et al., 2012; Santa Cruz et al., 2013; Ziervogel et al., 2006a). Early warning systems already exist in Peru, primarily in coastal areas for tsunamis, and there have been recent efforts to introduce early warning systems in the Amazonian regions, including a recent initiative in Madre de Dios (Peru), Acre (Brazil) and Pando (Bolivia) (Dorfler, 2013). To provide information in a timely manner, Vásquez et al. (2012) propose to strengthen existing networks in the education and health systems and to introduce communication systems powered through solar panels. As shown in this research, early warning systems need to consider the characteristics of an extreme climate event that are perceived by local populations to be relevant, such as flood onset and flood duration in the case of Panaillo. In Peru, it will be necessary to address the aforementioned issues with institutional capacity and to improve weather and climate data collection so that early warning systems can be integrated into effective emergency response plans (Marengo et al., 2013).

Regardless, flooding will always constrain fishing and agricultural production at certain times of the year. It is thus critical to foster livelihood diversification, to improve the quality of education and skill level, and to create formal livelihood organizations (Goy \& Waltner-Toews, 2005; Vásquez et al., 2012; Santa Cruz et al., 2013; UNDP \& BCPR, 2013). Capacity-building in business management, technology, and basic professional skills may enable Panaillo residents to obtain secure, profitable employment and/or to better manage current income-generating livelihoods, such as traditional handicrafts (Vásquez et al., 2012).

Some of these recommendations were applied in the interventions following the 2010-2011 flooding. For example, in 2011, institutions provided trainings on disaster management and agricultural recovery to some indigenous communities in their native tongue, distributed certified consumption seeds, and delivered manual corn shellers and canvas to assist the drying and preservation of harvested seeds (Vásquez et al., 2012).

While these interventions represent a positive starting point, they need to be scaled up in order to reach all vulnerable communities in the region. Several authors emphasize the need to create a flexible fund in the Ucayali Regional Government to use for emergency situations, as well as special funds for risk reduction, climate change adaptation projects, 
and incorporating climate change into existing projects (Santa Cruz et al., 2013; Vásquez et al., 2012). The government generally needs to increase awareness of climate change issues and create better incentives for businesses to consider climate change impacts and to improve the sustainability of their operations (Santa Cruz et al., 2013). For example, the introduction of an information flowchart or a virtual platform for information exchange could improve institutional access to information as well as encourage institutional transparency (Vásquez et al., 2012). Monitoring and evaluation of household food security status, climate risks, and current project activities are essential for program development and implementation (Santa Cruz et al., 2013; Aguiar et al., 2007).

Even amidst improved institutions and strengthened livelihoods, current trends indicate a likely increase in environmental migration. Oliver-Smith (2012) outlines the importance of defining environmental migration and how certain terminology could result in blaming nature for migration rather than attributing migration to human-generated processes. However, Gibb and Ford (2012) discuss how lack of formal definition does not need to obstruct action. They argue that it is imperative that international institutions first legally recognize environmental migration and then ensure the protection and basic rights of environmental migrants (Gibb \& Ford, 2012). Several studies emphasize the importance of ensuring the basic rights of displaced persons, incorporating migration into adaptation strategies, increasing the resilience of vulnerable communities like Panaillo, and avoiding dangerous climate change (Warner et al., 2009; Gemenne, 2011; Scheffran, Marmer \& Sow, 2012). Furthermore, Martin (2005) recommends using participatory and inclusive resource management to foster cooperative migrant-host relationships and to avoid violent conflict.

\subsection{Areas of Future Research}

Further research is needed to inform the design and implementation of the initiatives recommended above. There is currently a limited understanding in the ways climate change might impact indigenous populations and their ability to adapt to such change (Hofmeijer, 2010; Harper, 2010). In a review of the literature for instance, Ford et al. (2012) documented only one such study in a developing nation health context. This lack of knowledge has rendered indigenous populations and their health systems unable to 
identify the risks posed by climate change and ill-prepared to develop and implement adaptations (Ford et al., 2010a; Berrang-Ford et al., 2011). Furthermore, a recent World Bank publication highlights the need for future research that addresses,

how climate change affects the vulnerability of indigenous peoples in LAC [Latin America and the Caribbean]; how to increase the resilience of vulnerable indigenous communities to climate change by strengthening the capacity of their institutions; [and] how to incorporate indigenous people's knowledge into the design of instruments to mitigate and adapt to climate change (Kronik \& Verner, 2010: 134).

Research is also needed to examine the dynamic nature of vulnerability, including the role of fast and slow variables, how vulnerability responds to multiple stressors, and how shortterm adaptive strategies may trigger feedback loops that negatively impact long-term adaptation (Ford et al., 2013; Eriksen \& Silva, 2009; Eriksen et al., 2005). Although the case study presented here can provide insight into some of these topics, further research is needed to increase the depth and breadth of the topics discussed in this thesis.

With regards to the Peruvian context, it is important to further study both the biophysical and socioeconomic drivers of food system vulnerability. According to Davidson et al. (2012), there is a limited understanding of the biophysical transition currently occurring in the Amazon and further research is needed to understand how recent changes in land-use have affected carbon stocks, water resources, human health, economic development and habitat conservation. There is also limited information on ecosystem roles in the Amazon, as well as the differentiation and distribution of vegetation in tropical forests (Milliken et al, 2010). Monitoring and surveillance are urgently needed to evaluate the extent of resource degradation, existing populations of flora and fauna, and changes in the hydrological cycle in the Peruvian Amazon (Santa Cruz et al., 2013; Ortiz et al., 2013). Peruvian institutions like the Peruvian Amazon Research Institute (IIAP), the National Institute of Agrarian Innovation (INIA), the Ministry of Agriculture, and the Peruvian Oceanographic Institute (Instituto del Mar de Perú) could potentially address these research gaps if provided the necessary resources and support (Santa Cruz et al., 2013).

In general, data collection related to climate change in Peru needs improvement in order to effectively collect, consolidate and diffuse information (Santa Cruz et al., 2013). Research on climate change issues in Peru has been sporadic and poorly coordinated, 
which is exacerbated by the limited availability of climate data (UNDP \& BCPR, 2013). Peruvian weather stations often only measure rainfall and are unevenly distributed in the country, with low coverage in the Amazon (UNDP \& BCPR, 2013). Weather data are also not collected centrally and is often taken manually, which reduces the reliability and continuity of data (UNDP \& BCPR, 2013). Although better data collection is needed, Preston, Mustelin, and Maloney (2013) also highlight how information on future trajectories can lead to maladaptation when applied uncritically. This research similarly supports that information needs to be collected in a meaningful way that will be most useful to decision-makers. Specific regional and local studies need to be carried out to prioritize areas of highest risk and develop appropriate solutions based on potential climate change impacts as well as resources, ecosystems, and human activities (Santa Cruz et al., 2013). Studies on climatic hazards in Peru have primarily focused on the El Niño phenomena (Santa Cruz et al., 2013). However, Espinoza et al. (2009) assert that additional research is needed to improve our understanding of the climatic causes of flooding, especially since many of the recent extreme floods were not linked to the El Niño-La Niña phenomenon (Vegas de Cáceres, 2010). The development of early warning systems will also necessitate improvements in the accuracy of regional climate forecasts (Marengo et al., 2013).

There are also limited available data on food security and related issues in the Amazon, and existing data do not include many important indicators of food security, such as food access and utilization (Ortiz et al., 2013). The development of highly resistant seed varieties could also contribute food system resilience (UNDP \& BCPR, 2013). It is also important to create monitoring and surveillance of agricultural and fishing conditions to prevent food crises (Santa Cruz et al., 2013). Similarly, Ziervogel et al. (2006b) also emphasize the need to further study how agriculturalists currently respond to multiple stresses and how to best support adaptation.

With regards to environmental migration, Renaud et al. (2011) believe that action is seriously impeded by the lack of information on how environmental changes affect migration. Lilleør and Van den Broeck (2011) discusses how only one working paper explicitly examines how climate change impacts affect financial drivers of migration, highlighting the need to carry out more empirical studies on the topic and to incorporate 
climate variables into existing datasets. McCleman and Hunter (2010) similarly emphasize the need to better understand when migration becomes the predominant form of adaptation and how households evaluate migration in comparison to other adaptation options. Without a more comprehensive conceptual framework, policymakers will be illequipped to prepare for, prevent or respond to environmental migration (Black et al., 2011; Renaud et al., 2011).

\subsection{Conclusion}

The findings from this research hope to improve the understanding of the adaptive capacity to extreme hydrological events in the Amazonian community of Panaillo, as well as to provide new insight to the climate change adaptation scholarship. Protecting food systems in flood-prone areas will require a holistic, dynamic understanding of food system vulnerability. Understanding how indigenous Amazonian communities like Panaillo currently adapt to extreme hydrological events to maintain food security is increasingly important given the current food system vulnerability and the imminent challenges climate change will bring to this area. This thesis can thus inform climate change policy and provide a point of reference for addressing food system vulnerability in other flood-prone communities around the world. 


\section{References}

Abad, J.D., Montoro, H., Frias, C., Paredes, J., \& Peralta, B. (2012). “The meandering Ucayali River, a cyclic adaptation of cutoff and planform migration." In Murillo, R. (Ed.) River Flow 2012. Pp. 523-528.

Abizaid, C. (2005). An anthropogenic meander cutoff along the Ucayali River, Peruvian Amazon. Geographical Review, 95(1), 122-135.

Adger, W.N. (1999). Social vulnerability to climate change and extremes in coastal Vietnam. World Development, 27(2), 249-269.

Adger, W.N. et al. (2009) Nested and teleconnected vulnerabilities to environmental change. Frontiers in Ecology and the Environment 7:150-157.

Adger, W.N., Agrawala, S., Mirza, M. M. Q., Conde, C., O’Brien, K., Pulhin, J., ... \& Takahashi, K. (2007). Assessment of adaptation practices, options, constraints and capacity. In M. L. Parry, O. F. Canziani, J. P. Palutikof, P. J. van der Linden, \& C. E. Hanson (Eds.), Climate change 2007: Impacts, adaptation and vulnerability (pp. 717 - 743). Contribution of Working Group II to the Fourth Assessment Report of the Intergovernmental Panel on Climate Change. Cambridge: Cambridge University Press.

Adger, W.N., Quinn, T., Lorenzoni, I., Murphy, C., \& Sweeney, J. (2012). Changing social contracts in climate-change adaptation. Nature Climate Change, 3(4), 330-333.

Aguiar, C., Rosenfeld, J., Stevens, B., Thanasombat, S. \& Masud, H. (2007). An Analysis of Malnutrition Programming and Policies in Peru. International Economic Development Program, The Gerald R. Ford School of Public Policy, and School of Public Health University of Michigan. Retrieved on November 14, 2013 from <http://www.mef.gob.pe/contenidos/pol_econ/documentos/An_Analysis_of_Malnu trition_Programming_and_Policies_in_Peru.pdf>.

Aikman, S. (2012). Interrogating discourses of intercultural education: from indigenous Amazon community to global policy forum. Compare: A Journal of Comparative and International Education, 42(2), 235-257.

Alayon-Gamboa, J. A. \& J. C. Ku-Vera (2011). "Vulnerability of smallholder agriculture in Calakmul, Campeche, Mexico." Indian Journal of Traditional Knowledge, 10(1): 125132.

Ali, A. \& Niehof, A. (2007). "Changing Gender Roles in Household Food Security and Rural Livelihoods in Bangladesh." Sustainable Poverty Reduction in Lessâ€ $\square$ Favoured Areas. Wallingford: CAB International: 228-247.

Altieri, M. A., \& Nicholls, C. I. (2013). The adaptation and mitigation potential of traditional agriculture in a changing climate. Climatic Change, 1-13.

Altieri, R.M. \& P. Koohafkan. (2008). Enduring farms, climate change, smallholders and traditional farming communities. Penang, Malaysia: Third World Network. ISBN 978-983-2729-55-6.

Appling, G \& Salisbury, D. (April, 2013). "Analysis of the Socio-Environmental Impacts of Transboundary Amazonian Transportation Infrastructure: the Pucallpa- Cruzeiro do Sul Road/Rail in Peru and Brazil." Unpublished paper presented at the American Association of Geography Annual Meeting, Los Angeles, CA. 
Arce-Nazario, J. A. (2007). Human landscapes have complex trajectories: reconstructing Peruvian Amazon landscape history from 1948 to 2005. Landscape ecology, 22(1), 89-101.

Arnell, N. W., Clark, M. J., \& Gurnell, A. M. (1984). Flood insurance and extreme events: the role of crisis in prompting changes in British institutional response to flood hazard. Applied Geography, 4(2), 167-181.

Behrens, C. A. (1986). Shipibo food categorization and preference: Relationships between indigenous and Western dietary concepts. American anthropologist, 88(3), 647-658.

Behrens, C. A. (1989). The scientific basis for Shipibo soil classification and land use: changes in soil-plant associations with cash cropping. American Anthropologist, 91(1), 83-100.

Behrens, C. A. (1992). Labor specialization and the formation of markets for food in a Shipibo subsistence economy. Human Ecology, 20(4), 435-462.

Belliveau, S., Smit, B., \& Bradshaw, B. (2006). Multiple exposures and dynamic vulnerability: evidence from the grape industry in the Okanagan Valley, Canada. Global Environmental Change, 16(4), 364-378.

Berrang-Ford, L., Ford, J. D. \& Patterson, J. (2011) Are we adapting to climate change? Global Environmental Change, 21, 25-33.

Bizikova, L., J. Robinson, \& S. Cohen (2007). Linking climate change and sustainable development at the local level. Climate Policy, 7: 271-277.

Black, R. E., Morris, S. S., \& Bryce, J. (2003). Where and why are 10 million children dying every year?. The Lancet, 361(9376), 2226-2234.

Black, R., Adger, W. N., Arnell, N. W., Dercon, S., Geddes, A., \& Thomas, D. (2011). The effect of environmental change on human migration. Global Environmental Change, 21, S3S11.

Boyd, E. (2008). Navigating Amazonia under uncertainty: past, present and future environmental governance. Philosophical Transactions of the Royal Society B: Biological Sciences, 363(1498), 1911-1916.

Brondizio, E. S., \& Moran, E. F. (2008). Human dimensions of climate change: the vulnerability of small farmers in the Amazon. Philosophical Transactions of the Royal Society B: Biological Sciences, 363(1498), 1803-1809.

Bureau of Democracy, Human Rights, and Labor. (2009). 2008 Human Rights Report: Peru. US Department of State, 2008 Country Reports on Human Rights Practices. Retrieved on December 3, 2013 from <http://www.state.gov/j/drl/rls/hrrpt/2008/wha/119170.htm\#>.

Cai, W., Borlace, S., Lengaigne, M., van Rensch, P., Collins, M., Vecchi, G., ... \& Jin, F. F. (2014). Increasing frequency of extreme El Nino events due to greenhouse warming. Nature Climate Change.

Calvo-Gonzalez, O., Apostolou, A., Aviles, A. M., Casas. C., Holt, P.C., Cunha, B., ... KoehlerGeib, F. (2010). Peru - El proceso de descentralizacion y su relacion con la eficiencia del gasto publico. Public expenditure review (PER). Washington, DC: World Bank. Retrieved on November 20, 2013 from <http://documents.worldbank.org/curated/en/2010/06/17204303/perudecentralization-process-links-public-expenditure-efficiency-peru-el-proceso-dedescentralizacion-y-su-relacion-con-la-eficiencia-del-gasto-publico>.

Campbell, D. \& Beckford, C. (2009). "Negotiating Uncertainty: Jamaican Small Farmers' 
Adaptation and Coping Strategies, Before and After Hurricanes: A Case Study of Hurricane Dean." Sustainability 1(4): 1366-1387.

Campbell, J.R. (2006). “Traditional Disaster Reduction in Pacific Island Communities” (GNS Science Report 2006/038). Avalon, NZ: Institute of Geological and Nuclear Sciences. Retrieved August 17, 2012, from http://unpan1.un.org/intradoc/groups/public/documents/apcity/unpan029291.p df.

Carmona, C. \& Cristóbal, G. (2009). Pueblos indígenas y la tolerancia occidental: Los derechos humanos como forma sublimada de asimilación. Polis, 8 (23): 301-321. ISSN 0718-6568.

Carranza, J. (2012). Boletin extraordinario de la evaluación hidrológica y pluviométrica en la Cuenca amazónica peruana. (Hydrological Bulletins- January 2012). Senamhi. Lima. Retrieved on November 12, 2013 from <http://www.draucayali.gob.pe/sites/all/themes/texto2012/nivel_rio/senamhi.pd $\mathrm{f}>$.

Carranza, J. (2013a). Boletin extraordinario de la evaluación hidrológica y pluviométrica en la Cuenca amazónica peruana. (Hydrological Bulletins- August 2013). Senamhi, Lima. Retrieved on November 11, 2013 from $<$ http://www.senamhi.gob.pe/?p=0701>.

Carranza, J. (2013b). Boletin extraordinario de la evaluación hidrológica y pluviométrica en la Cuenca amazónica peruana. (Hydrological Bulletins- May 2013). Senamhi. Lima. Retrieved on September 14, 2013 from <http://www.senamhi.gob.pe/?p=0701>.

Castleden, H., Morgan, V. S., \& Lamb, C. (2012). "I spent the first year drinking tea": Exploring Canadian university researchers' perspectives on community - based participatory research involving Indigenous peoples. The Canadian Geographer/Le Géographe canadien, 56(2), 160-179.

Chambers, R. (1994). The origins and practice of participatory rural appraisal. World Development, 22:953-969.

Chapin III, F. S., Peterson, G., Berkes, F., Callaghan, T. V., Angelstam, P., Apps, M., ... \& Whiteman, G. (2004). Resilience and vulnerability of northern regions to social and environmental change. AMBIO: A Journal of the Human Environment, 33(6), 344-349.

Chibnik, M. (1994) Risky Rivers: The Economics and Politics of Floodplain Farming in Amazonia. The University of Arizona Press, Tucson.

Chibnik, M. (1995). The Emergence of "Campesinos" in the Peruvian Amazon. Anthropology of Work Review, 16(1-2), 10-14.

Cochrane, M. A., \& Barber, C. P. (2009). Climate change, human land use and future fires in the Amazon. Global Change Biology, 15(3), 601-612.

Comisión de alto nivel anticorrupción (2013). Estudios a nivel nacional. Estadísticas de la corrupción. Plan Nacional de Lucha Contra la Corupción 2012-2016. Retrieved on November 3, 2013 from <http://can.pcm.gob.pe/category/estadisticas-de-lacorrupcion/>.

Consorcio H\&O (2005). “ESTUDIO DE LA NAVEGABILIDAD DEL RÍO UCAYALI EN EL TRAMO COMPRENDIDO ENTRE PUCALLPA Y LA CONFLUENCIA CON EL RÍO MARAÑ́N". Ministerio de transportes y comunicaciones dirección general de transporte acuático. Retrieved on April 4, 2013 from 
<http://www.mtc.gob.pe/portal/transportes/acuatico/s_nosotros/NavegabilidadUcayali/VOLUMEN\%204\%20-\%20Informaci\%C3\%B3n\%20SocioEcon\%C3\%B3mica/Informaci\%C3\%B3n\%20Socio-Econ\%C3\%B3mica\%20\%20Informe\%20Final.pdf>.

Cook, B., Zeng, N., \& Yoon, J. H. (2012). Will Amazonia dry out? Magnitude and causes of change from IPCC climate model projections. Earth Interactions,16(3), 1-27.

Coomes, O. T. (2010). Of Stakes, Stems, and Cuttings: The Importance of Local Seed Systems in Traditional Amazonian Societies*. The Professional Geographer, 62(3), 323-334.

Coomes, O. T., Takasaki, Y., Abizaid, C., \& Barham, B. L. (2010). Floodplain fisheries as natural insurance for the rural poor in tropical forest environments: evidence from Amazonia. Fisheries management and ecology, 17(6), 513-521.

Coronel Cáceres, J.C., Zavala Soto, J. L. \& Estrada Vitorino, M.A. (2008, June, 3). Educación intercultural bilingüe: Meta para el desarrollo [Powerpoint slides]. Universidad Peruana Cayetano Heredia. Fundamentos y enfoques de la educación y de la apredizaje course lecture. Retrieved on December 3, 2013 from <http://www.slideshare.net/guest176cf5/interculturalidad-467930>.

Cossío, R., Menton, M., Cronkleton, P. \& Larson, A. (2014). Community forest management in the Peruvian Amazon: A literature review. Center for International Forestry Research, Working Paper 136. Retrieved on March 17, 2014 from <http://www.cifor.org/publications/pdf_files/WPapers/WP136Menton.pdf>.

Cueto, S., Escobal, J., Penny, M., Ames, P. (2011). ¿Quién se queda atrás? : resultados iniciales del estudio Niños del Milenio. Tercera ronda de encuestas en el Perú. Niños del Milenio: Información para el desarrollo, Young Lives, Instituto de Invesetigación Nutricional, Grupo de analisis para el desarrollo (GRADE). Retrieved on November 18, 2013 from <http://dide.minedu.gob.pe/xmlui/handle/123456789/82>.

Cueto, S., Guerrero, G., León, J., Seguin, E., \& Muñoz, I. (2012). "Explaining and overcoming marginalization in education: Ethnic and language minorities in Peru." In Boyden, J. \& Bourdillon, M. (Eds.) Childhood poverty: Multidisciplinary Approaches. London: Macmillan Publishers Limited. Pp. 261-282.

Davidson, E. A., de Araújo, A. C., Artaxo, P., Balch, J. K., Brown, I. F., Bustamante, M. M., ... \& Wofsy, S. C. (2012). The Amazon basin in transition. Nature, 481(7381), 321-328.

Davis, S. C. 2001. La evaluación rural participativa. Base de conocimientos de transporte rural. Transport Research Laboratory Limited. Retrieved on May 15, 2011 from http://www.transport-links.org/rtkb/ Spanish/Module\%205\%5C5 6a\%20PRA\%20-\%20Spanish.pdf.

Del Ninno, C., Dorosh, P. A., \& Smith, L. C. (2003). Public policy, markets and household coping strategies in Bangladesh: Avoiding a food security crisis following the 1998 floods. World Development, 31(7), 1221-1238.

Devereux, S. (2007). "The impact of droughts and floods on food security and policy options to alleviate negative effects." Agricultural Economics, 37: 47-58.

Dorfler, M. (2013). Manejo integrado y sostenible de los recursos hídricos transfronterizos en la Cuenca del Río Amazonas, considerando la variabilidad y los cambios del clima: Factor Estratégico en la Cooperacion Amazónica. Organización del Tratado de Cooperación Amazónica, Global Environment Fund (GEF), GEF Amazonas, United Nations Environment Program. Retrieved on February 6, 2014 from <http://www.mtnforum.org/sites/default/files/news/files/ppt_otca_gef_mdorfler_l 
ima_13.12.pdf>.

Duncan, K. (1992). The impacts of global warming in south-east Scotland: An historical analogue approach. The Scottish Geographical Magazine, 108(3), 172-178.

Eakin, H., \& Luers, A. L. (2006). Assessing the vulnerability of social-environmental systems. Annual Review of Environment and Resources, 31(1), 365.

Eakin, H., Winkels, A., \& Sendzimir, J. (2009). Nested vulnerability: exploring cross-scale linkages and vulnerability teleconnections in Mexican and Vietnamese coffee systems. Environmental Science \& Policy, 12(4), 398-412.

El Comercio. (2013a, October, 28). Midis: intoxicaciones en Qali Warma son 'menos de uno en un millón'. El Comercio. Retrieved on November 3, 2013 from <http://elcomercio.pe/actualidad/1650743/noticia-midis-casos-intoxicacion-qaliwarma-menos-uno-millon?ref=ecr $>$.

Ellis, F. (2000). Rural livelihoods and diversity in developing countries. Oxford University Press.

Eriksen, S. (2008). "What Is the Vulnerability of a Food System to Global Environmental Change?" Ecology and Society, 13(2): 14.

Eriksen, S. \& Silva, J.A. (2009). "The vulnerability context of a savanna area in Mozambique: household drought coping strategies and responses to economic change." Environmental Science \& Policy, 12(1): 33-52.

Eriksen, S. H., Brown, K., \& Kelly, P. M. (2005). The dynamics of vulnerability: locating coping strategies in Kenya and Tanzania. The Geographical Journal,171(4), 287-305.

Erlat, E., \& Türkeş, M. (2013). Observed changes and trends in numbers of summer and tropical days, and the 2010 hot summer in Turkey. International Journal of Climatology, 33(8), 1898-1908.

Espinosa, M. C. (2008). What has globalization to do with wildlife use in the remote Amazon? Exploring the links between macroeconomic changes, markets and community entitlements. Journal of Developing Societies, 24(4), 489-521.

Espinoza Villar, J. C., Ronchail, J., Guyot, J. L., Cochonneau, G., Naziano, F., Lavado, W., ... \& Vauchel, P. (2009). Spatio-temporal rainfall variability in the Amazon basin countries (Brazil, Peru, Bolivia, Colombia, and Ecuador). International Journal of Climatology, 29(11), 1574-1594.

Espinoza, J. C., Guyot, J. L., Ronchail, J., Cochonneau, G., Filizola, N., Fraizy, P., ... \& Vauchel, P. (2009). Contrasting regional discharge evolutions in the Amazon basin (19742004). Journal of Hydrology, 375(3), 297-311.

Espinoza, J. C., Ronchail, J., Guyot, J. L., Junquas, C., Drapeau, G., Martinez, J. M., ... \& Espinoza, R. (2012). From drought to flooding: understanding the abrupt 2010-11 hydrological annual cycle in the Amazonas River and tributaries. Environmental Research Letters, 7(2), 024008.

FAO (1999). "The state of food insecurity in the world." FAO, Rome.

FAO (2008). "Climate change and food security: a framework document." FAO Corporate Document Repository. FAO, Rome. Retrieved on March 13, 2013 from <http://www.fao.org/docrep/010/k2595e/k2595e00.htm>.

FAO (2011a). "FAO-Adapt Framework Programme on Climate Change Adaptation." FAO, Rome. Retrieved on January 24, 2013 from <http://www.fao.org/docrep/014/i2316e/i2316e00.pdf>.

FAO (2011b). Training guide: Gender and climate change research in agriculture and food 
security for development. Rome, Italy. Retrieved on January 10, 2013 from http://www.fao.org/docrep/015/md280e/md280e00.htm.

Fazey, I., Pettorelli, N., Kenter, J., Wagatora, D., \& Schuett, D. (2011). Maladaptive trajectories of change in Makira, Solomon Islands. Global Environmental Change, 21(4), 1275-1289.

Few, R. (2003). Flooding, vulnerability and coping strategies: local responses to a global threat. Progress in Development Studies, 3(1), 43-58.

Figueroa, A. \& Barrón, M. (2005). Inequality, Ethnicity and Social Disorder in Peru (CRISE Working Paper No. 8). Retrieved on November 9, 2013 from <http://r4d.dfid.gov.uk/pdf/outputs/inequality/wp8.pdf>.

Finer, M., \& Orta-Martínez, M. (2010). A second hydrocarbon boom threatens the Peruvian Amazon: trends, projections, and policy implications. Environmental research letters, 5(1), 014012.

Finer, M., Jenkins, C. N., Pimm, S. L., Keane, B., \& Ross, C. (2008). Oil and gas projects in the western Amazon: threats to wilderness, biodiversity, and indigenous peoples. PloS one, 3(8), e2932.

Ford, J.D. (2009). Vulnerability of Inuit food systems to food insecurity as a consequence of climate change: A case study from Igloolik, Nunavut. Regional Environmental Change, 9(2), 83-100, doi: 10.1007/s10113-008-0060-x.

Ford, J.D. (2012). Indigenous health and climate change. American journal of public health, 102(7), 1260-1266.

Ford, J.D., \& Smit, B. (2004). A framework for assessing the vulnerability of communities in the Canadian Arctic to risks associated with climate change.Arctic, 57(4).

Ford, J.D., Berrang-Ford, L., King, M., \& Furgal, C. (2010a). Vulnerability of Aboriginal health systems in Canada to climate change. Global Environmental Change, 20(4), 668-680.

Ford, J.D., Bolton, K., Shirley, J., Pearce, T., Tremblay, M., \& Westlake, M. (2012). Mapping human dimensions of climate change research in the Canadian Arctic. Ambio, 41(8), 808-822.

Ford, J.D., Keskitalo, E. C. H., Smith, T., Pearce, T., Berrang-Ford, L., Duerden, F., \& Smit, B. (2010b). Case study and analogue methodologies in climate change vulnerability research. Wiley Interdisciplinary Reviews: Climate Change, 1(3), 374-392.

Ford, J.D., McDowell, G., Shirley, J., Pitre, M., Siewierski, R., Gough, W., ... \& Statham, S. (2013). The Dynamic Multiscale Nature of Climate Change Vulnerability: An Inuit Harvesting Example. Annals of the Association of American Geographers, 103(5): 1193-1211.

Ford, J.D., Smit, B., Wandel, J., \& MacDonald, J. (2006). Vulnerability to climate change in Igloolik, Nunavut: what we can learn from the past and present. Polar Record, 42(02), 127-138.

Futemma, C., \& Brondízio, E. S. (2003). Land reform and land-use changes in the lower Amazon: Implications for agricultural intensification. Human Ecology,31(3), 369402.

Garcia, A., Tello, S., Vargas, G., \& Duponchelle, F. (2009). Patterns of commercial fish landings in the Loreto region (Peruvian Amazon) between 1984 and 2006. Fish physiology and biochemistry, 35(1), 53-67.

Gemenne, F. (2011). Climate-induced population displacements in a $4 \mathrm{C}+$ world. Philosophical Transactions of the Royal Society A: Mathematical, Physical and 
Engineering Sciences, 369(1934), 182-195.

Gibb, C., \& Ford, J. (2012). Should the United Nations Framework Convention on Climate Change recognize climate migrants?. Environmental Research Letters, 7(4), 045601.

Giles, A. R., \& Perry, A. H. (1998). The use of a temporal analogue to investigate the possible impact of projected global warming on the UK tourist industry. Tourism management, 19(1), 75-80.

Glantz, M. H. (1991). The use of Analogies: In Forecasting Ecological and Societal Responses to Global Warming. Environment: Science and Policy for Sustainable Development, 33(5), 10-33.

Goy, J., \& Waltner-Toews, D. (2005). Improving Health in Ucayali, Peru: A Multisector and Multilevel Analysis. EcoHealth, 2(1), 47-57.

Gram, S., Peter Kvist, L., \& Cáseres, A. (2001). The economic importance of products extracted from Amazonian flood plain forests. AMBIO: A Journal of the Human Environment, 30(6), 365-368.

Gray, C. L., Bilsborrow, R. E., Bremner, J. L., \& Lu, F. (2008). Indigenous land use in the Ecuadorian Amazon: a cross-cultural and multilevel analysis. Human Ecology, 36(1), 97-109.

Green, D., King, U., \& Morrison, J. (2009). Disproportionate burdens: the multidimensional impacts of climate change on the health of Indigenous Australians. Medical Journal of Australia, 190(1), 4.

Green, L. W., \& Mercer, S. L. (2001). Can public health researchers and agencies reconcile the push from funding bodies and the pull from communities?. American journal of public health, 91(12), 1926-1929.

Gregory, P. J., Ingram, J. S., \& Brklacich, M. (2005). Climate change and food security. Philosophical Transactions of the Royal Society B: Biological Sciences, 360(1463), 2139-2148.

Guterres, A. (2008). Climate Change, natural disasters and human displacement: a UNHCR perspective. United Nations High Commissioner for Refugees, Geneva. Retrieved on January 29, 2014 from < http://www.refworld.org/docid/492bb6b92.html>.

Hallegatte, S., Hourcade, J. C., \& Ambrosi, P. (2007). Using climate analogues for assessing climate change economic impacts in urban areas. Climatic change, 82(1-2), 47-60.

Harper, S. (2010). "Green Christmas, full graveyard": Government and community identified climate change and health priorities in Nunatsiavut, Canada - A report supporting the development of the IHACC research program. Retrieved on September 14, 2013 from <http://ihacc.ca/archives/183>.

Harris, M. (2005). Nature makes them lazy: contested perceptions of place and knowledge in the lower Amazon floodplain of Brazil. Conservation and Society, 3(2), 461.

Hayman, P., Rickards, L., Eckard, R., \& Lemerle, D. (2012). Climate change through the farming systems lens: challenges and opportunities for farming in Australia. Crop and Pasture Science, 63(3), 203-214.

Heise, M. (1999). Relaciones de género en la amazonia peruana. Lima: CAAAP.

Heltberg, R., Siegel, P. B., \& Jorgensen, S. L. (2009). Addressing human vulnerability to climate change: Toward a 'no-regrets' approach. Global Environmental Change, 19(1), 89-99.

Hern, W. M. (1992). The Impact of Cultural Change and Population Growth On The Shipibo of the Peruvian Amazon. The Latin American Anthropology Review, 4(1), 3-8. 
Hewitt, K. (1983). The idea of calamity in a technocratic age. In Hewitt K (ed) (1983) Interpretations of Calamity, Allen \& Unwin, pg. 1-30.

Hofmeijer, I. (2010). "The lakes are drying and the fish are scarce": Community Identified Climate Change and Health Priorities in Panaillo - A report supporting the development of the IHACC research program. Montreal: McGill University. Retrieved on February 12, 2013 from <http://ihacc.ca/archives/256>.

Hofmeijer, I., Ford, J. D., Berrang-Ford, L., Zavaleta, C., Carcamo, C., Llanos, E., ... \& Namanya, D. (2013). Community vulnerability to the health effects of climate change among indigenous populations in the Peruvian Amazon: a case study from Panaillo and Nuevo Progreso. Mitigation and Adaptation Strategies for Global Change, 18(7), 957978.

Howden, S. M., Soussana, J. F., Tubiello, F. N., Chhetri, N., Dunlop, M., \& Meinke, H. (2007). Adapting agriculture to climate change. Proceedings of the National Academy of Sciences, 104(50), 19691-19696.

Ingram, J., P. Ericksen, \& D. Liverman. (2010). Food Security and Global Environmental Change. London: Earthscan.

International Monetary Fund (IMF). (2013). Peru-Concluding Statement of the 2013 Article IV Consultation Mission. Retrieved on December 11, 2013 from <http://www.imf.org/external/np/ms/2013/112013a.htm>.

Iwasaki, S., Razafindrabe, B. H. N., \& Shaw, R. (2009). Fishery livelihoods and adaptation to climate change: a case study of Chilika lagoon, India. Mitigation and adaptation strategies for global change, 14(4), 339-355.

Junk, W. J., Bayley, P. B., \& Sparks, R. E. (1989). The flood pulse concept in river-floodplain systems. Canadian special publication of fisheries and aquatic sciences, 106(1), 110127.

Kates, R. W., Travis, W. R., \& Wilbanks, T. J. (2012). Transformational adaptation when incremental adaptations to climate change are insufficient.Proceedings of the National Academy of Sciences, 109(19), 7156-7161.

Kelly, P. M., \& Adger, W. N. (2000). Theory and practice in assessing vulnerability to climate change and Facilitating adaptation. Climatic change,47(4), 325-352.

Kesby, M. (2000). Participatory diagramming: deploying qualitative methods through an action research epistemology. Area, 32(4), 423-435.

Keys, E., \& McConnell, W. J. (2005). Global change and the intensification of agriculture in the tropics. Global Environmental Change, 15(4), 320-337.

Kleinwechter, U., \& Lara, T. R. (2010, September). Market Integration and Deforestation in the Peruvian Amazon. Paper presented at the annual Conference on Tropical and Subtropical Agricultural and Natural Resource Management, Stuttgart-Hohenheim, Germany. Retrieved on December 11, 2013 from $<$ http://www.tropentag.de/conference/general.php?menu=2>.

Kronik, J. \& Verner, D. (2010). Indigenous Peoples and Climate Change in Latin America and the Caribbean. Washington, DC: World Bank.

Kvist, L. P., \& Nebel, G. (2001). A review of Peruvian flood plain forests: ecosystems, inhabitants and resource use. Forest Ecology and Management,150(1), 3-26.

Kvist, L. P., Andersen, M. K., Stagegaard, J., Hesselsøe, M., \& Llapapasca, C. (2001a). Extraction from woody forest plants in flood plain communities in Amazonian Peru: use, choice, evaluation and conservation status of resources. Forest Ecology and 
Management, 150(1), 147-174.

Kvist, L. P., Gram, S., Cácares C, A., \& Ore B, I. (2001b). Socio-economy of flood plain households in the Peruvian Amazon. Forest Ecology and Management, 150(1), 175186.

Langerwisch, F., Rost, S., Gerten, D., Poulter, B., Rammig, A., \& Cramer, W. (2013). Potential effects of climate change on inundation patterns in the Amazon Basin. Hydrology and Earth System Sciences, 17(6), 2247-2262.

Lardeau, M. P., Healey, G., \& Ford, J. (2011). The use of Photovoice to document and characterize the food security of users of community food programs in Iqaluit, Nunavut. Rural \& Remote Health, 11(2).

Latrubesse, E.M. "A Latin American Perspective on Geomorphologic Hazards and Related Disasters." In Latrubesse, E.M. (Ed.) Natural Hazards and Human-Exacerbated Disasters in Latin America: Special volumes of geomorphology. Elsevier Science.

Lauer, M. (2012). Oral traditions or situated practices? Understanding how indigenous communities respond to environmental disasters. Human Organization, 71(2), 176187.

Lauer, M., Albert, S., Aswani, S., Halpern, B. S., Campanella, L., \& La Rose, D. (2013). Globalization, Pacific Islands, and the paradox of resilience. Global Environmental Change, 23(1), 40-50.

Leary, N., J. Adejuwon, V. Barros, et al. (2008). "A Stitch in Time: General Lessons from Specific Cases", In Leary, N., Adejuwon, J., Barros, V., Burton, I., Kulkarni, I, Lasco, R. (eds.) Climate Change and Adaptation. London: Earthscan.

Lebel, L. (2013). Local knowledge and adaptation to climate change in natural resourcebased societies of the Asia-Pacific. Mitigation and Adaptation Strategies for Global Change, 18(7), 1057-1076.

Leichenko, R. M., \& O'Brien, K. L. (2002). The dynamics of rural vulnerability to global change: the case of southern Africa. Mitigation and adaptation strategies for global change, 7(1), 1-18.

Lemos, M. C., Nelson, D., Finan, T. \& Fox, R. (2004). "The Social and Policy Implications of Seasonal Forecasting: A Case Study of Ceara, Northeast Brazil" (NOAA Report). University of Arizona. Retrieved September 3, 2012, from <http://projectceara.arizona.edu/sites/default/files/2002-Lemos-etal-NOAA.pdf>.

Lilleør, H. B., \& Van den Broeck, K. (2011). Economic drivers of migration and climate change in LDCs. Global Environmental Change, 21, S70-S81.

Lin, B. B., Perfecto, I., \& Vandermeer, J. (2008). Synergies between agricultural intensification and climate change could create surprising vulnerabilities for crops. Bioscience, 58(9), 847-854.

Liswanti, N., Sheil, D., Basuki, I., Padmanaba, M., \& Mulcahy, G. (2011). Falling back on forests: how forest-dwelling people cope with catastrophe in a changing landscape. International Forestry Review, 13(4), 442-455.

Little, P. D., Stone, M. P., Mogues, T., Castro, A. P., \& Negatu, W. (2006). 'Moving in place': Drought and poverty dynamics in South Wollo, Ethiopia. The Journal of Development Studies, 42(2), 200-225.

Liu, C., Golding, D., \& Gong, G. (2008). Farmers' coping response to the low flows in the lower Yellow River: a case study of temporal dimensions of vulnerability. Global Environmental Change, 18(4), 543-553. 
Longhurst, R. (2003). "Semi-structured interviews and focus groups" In Clifford, N \& Valendtine, G. (eds.) Key methods in geography. Sage, London. Pp. 117-32.

Lopez-Marrero, T. (2010). An integrative approach to study and promote natural hazards adaptive capacity: a case study of two flood-prone communities in Puerto Rico. The Geographical Journal, 176(2), 150-163.

López-Marrero, T., \& Tschakert, P. (2011). From theory to practice: building more resilient communities in flood-prone areas. Environment and Urbanization,23(1), 229-249.

López-Marrero, T., \& Yarnal, B. (2010). Putting adaptive capacity into the context of people's lives: a case study of two flood-prone communities in Puerto Rico. Natural hazards, 52(2), 277-297.

Lovendal, C. R. \& Knowles, M. (2006). Tomorrow's hunger: A framework for analysing vulnerability to food security, Research Paper, UNU-WIDER, United Nations University (UNU), No. 2006/119. Retrieved on January 22, 2013 from <http://hdl.handle.net/10419/63319>.

Malhi, Y., Roberts, J. T., Betts, R. A., Killeen, T. J., Li, W., \& Nobre, C. A. (2008). Climate change, deforestation, and the fate of the Amazon. science,319(5860), 169-172.

Marengo, J. A., Borma, L. S., Rodriguez, D. A., Pinho, P., Soares, W. R., \& Alves, L. M. (2013). Recent Extremes of Drought and Flooding in Amazonia: Vulnerabilities and Human Adaptation. American Journal of Climate Change, 2, 87.

Marengo, J. A., Borma, L. S., Rodriguez, D. A., Pinho, P., Soares, W. R., \& Alves, L. M. (2013). Recent Extremes of Drought and Flooding in Amazonia: Vulnerabilities and Human Adaptation. American Journal of Climate Change, 2, 87.

Martin, A. (2005). Environmental conflict between refugee and host communities. Journal of Peace Research, 42(3), 329-346.

Maurial, M. \& Suxo, M. (2011). "Does intercultural bilingual education open spaces for inclusion at higher education?” In Hawkins, M.R (Ed.) Social Justice Language Teacher Education. Bristol, UK: Multilingual Matters. Pp. 23-48.

Mayoux, L. (2005). PALS enterprise training, trickle-up. Participatory Action Learning System Network. Uganda: Kabarole Research and Resource Centre.

Mayring, P. (2004). Qualitative content analysis. A companion to qualitative research, 266269.

Mazzeo, J. (2011). Cattle, livelihoods, and coping with food insecurity in the context of drought and HIV/AIDS in rural Zimbabwe. Human Organization http://sfaa. metapress. com/openurl. asp $?$ genre $=$ article\&issn $=0018-7259 \&$ volume $=70 \& i s s u e=$ 4\&spage $=405,70(4), 405-415$.

McDowell, J. Z., \& Hess, J. J. (2012). Accessing adaptation: Multiple stressors on livelihoods in the Bolivian highlands under a changing climate. Global Environmental Change, 22(2), 342-352.

McLeman, R. A., \& Hunter, L. M. (2010). Migration in the context of vulnerability and adaptation to climate change: insights from analogues. Wiley Interdisciplinary Reviews: Climate Change, 1(3), 450-461.

McLeman, R., \& Smit, B. (2006). Migration as an adaptation to climate change.Climatic Change, 76(1-2), 31-53

McSweeney, K. (2005). Natural insurance, forest access, and compounded misfortune: Forest resources in smallholder coping strategies before and after Hurricane Mitch, northeastern Honduras. World Development, 33(9), 1453-1471. 
McSweeney, K., \& Coomes, O. T. (2011). Climate-related disaster opens a window of opportunity for rural poor in northeastern Honduras. Proceedings of the National Academy of Sciences, 108(13), 5203-5208.

Mendes, C. M., \& Junior, S. P. (2012). Deforestation, economic growth and corruption: a nonparametric analysis on the case of Amazon forest. Applied Economics Letters, 19(13), 1285-1291.

Mercer, J., Kelman, I., Suchet-Pearson, S., \& Lloyd, K. (2009). Integrating indigenous and scientific knowledge bases for disaster risk reduction in Papua New Guinea. Geografiska Annaler: Series B, Human Geography, 91(2), 157-183.

Milliken, W., Zappi, D., Sasaki, D., Hopkins, M., \& Pennington, R. T. (2010). Amazon vegetation: how much don't we know and how much does it matter?.Kew Bulletin, 65(4), 691-709.

Minzenberg, E., \& Wallace, R. (2011). Amazonian agriculturalists bound by subsistence hunting. Journal of Cultural Geography, 28(1), 99-121.

Misselhorn, A., Aggarwal, P., Ericksen, P., Gregory, P., Horn-Phathanothai, L., Ingram, J., \& Wiebe, K. (2012). A vision for attaining food security. Current opinion in environmental sustainability, 4(1), 7-17.

Moran, E. F., Adams, R., Bakoyéma, B., Fiorini, S., \& Boucek, B. (2006). Human strategies for coping with El Niño related drought in Amazônia. Climatic Change, 77(3-4), 343361.

Morrissey, J.W. (2013). Understanding the relationship between environmental change and migration: The development of an effects framework based on the case of northern Ethiopia. Global Environmental Change, 23, 1501-1510.

Motsholapheko, M. R., Kgathi, D. L., \& Vanderpost, C. (2011). Rural livelihoods and household adaptation to extreme flooding in the Okavango Delta, Botswana. Physics and Chemistry of the Earth, Parts $A / B / C, 36(14), 984-995$.

Nebel, G. (2001). Sustainable land-use in Peruvian flood plain forests: options, planning and implementation. Forest Ecology and Management, 150(1), 187-198.

Ngaira, J. (2009). Challenges of water resource management and food production in a changing climate in Kenya. Journal of Geography and Regional Planning, 2(4), 79103. Retrieved from <http://search.proquest.com/docview/746273197?accountid=12339>.

Nyong, A., Adesina, F., \& Elasha, B. O. (2007). The value of indigenous knowledge in climate change mitigation and adaptation strategies in the African Sahel. Mitigation and Adaptation Strategies for Global Change, 12(5), 787-797.

O’Brien, K., Eriksen, S., Nygaard, L. P., \& Schjolden, A. (2007). Why different interpretations of vulnerability matter in climate change discourses. Climate Policy (Earthscan), 7(1): 73-88.

Oliver-Smith, A. (2012). Debating environmental migration: society, nature and population displacement in climate change. Journal of International Development, 24(8), 10581070.

Orlove, B., Roncoli, C., Kabugo, M., \& Majugu, A. (2010). Indigenous climate knowledge in southern Uganda: the multiple components of a dynamic regional system. Climatic Change, 100(2), 243-265.

Ortiz, R., Nowak, A., Lavado, A. \& Parker, L. (2013) Food Security in Amazonia. Report for Global Canopy Programme and International Center for Tropical Agriculture as part 
of the Amazonia Security Agenda project. Retrieved on January 29, 2014 from <http://segamazonia.org/sites/default/files/press_releases/food_security_in_amaz onia.pdf $>$.

Pantigoso, P. (2014) Peru's mining and metals investment 2014-2015. Ministry of Foreign Affairs Peru, Lima. Retrieved on March 11, 2014 from $<$ http://www.ey.com/Publication/vwLUAssets/EY-Peru-mining-metalsinvestment-guide-14-15/\$FILE/EY-Peru-mining-and-metals-investment-guide2014-2015.pdf>.

Pearce, T. D., Ford, J. D., Laidler, G. J., Smit, B., Duerden, F., Allarut, M., ... \& Wandel, J. (2009). Community collaboration and climate change research in the Canadian Arctic. Polar Research, 28(1), 10-27.

Perreault, T. (2005). Why chacras (swidden gardens) persist: agrobiodiversity, food security, and cultural identity in the Ecuadorian Amazon. Human Organization, 64(4), 327-339.

Preston, B. L., Mustelin, J., \& Maloney, M. C. (2013). Climate adaptation heuristics and the science/policy divide. Mitigation and Adaptation Strategies for Global Change, 1-31.

Raleigh, C. (2011). The search for safety: The effects of conflict, poverty and ecological influences on migration in the developing world. Global Environmental Change, 21, S82-S93.

Reenberg, A., Birch-Thomsen, T., Mertz, O., Fog, B., \& Christiansen, S. (2008). Adaptation of human coping strategies in a small island society in the SW pacific-50 years of change in the coupled human-environment system on Bellona, Solomon Islands. Human Ecology, 36(6), 807-819.

Renaud, F. G., Dun, O., Warner, K., \& Bogardi, J. (2011). A decision framework for environmentally induced migration. International Migration,49(s1), e5-e29.

Roncoli, C., Ingram, K., \& Kirshen, P. (2001). The costs and risks of coping with drought: livelihood impacts and farmers' responses in Burkina Faso.Climate Research, 19(2), 119-132.

Ruffino, M. L., \& Isaac, V. J. (1995). Life cycle and biological parameters of several Brazilian Amazon fish species. Naga, the ICLARM Quarterly, 18(4), 41-45.

Saldaña, J. (2009). The coding manual for qualitative researchers. Los Angeles: Sage.

Saleska, S. R., Didan, K., Huete, A. R., \& Da Rocha, H. R. (2007). Amazon forests green-up during 2005 drought. Science, 318(5850), 612-612.

Santa Cruz, F., Mujica M. E., Álvarez, J., \& Leslie, J. (2013). Informe sobre Desarrollo Humano Perú 2013. Cambio climático y territorio: Desafíos y respuestas para un futuro sostenible. Lima: UNDP. Retrieved on January 2, 2014 from <http://www.undp.org/content/peru/es/home/library/poverty/Informesobredes arrollohumano2013/IDHPeru2013/>.

Scheffran, J., Marmer, E., \& Sow, P. (2012). Migration as a contribution to resilience and innovation in climate adaptation: Social networks and co-development in Northwest Africa. Applied Geography, 33, 119-127.

Sears, R. R., \& Pinedo-Vasquez, M. (2011). Forest policy reform and the organization of logging in Peruvian Amazonia. Development and Change, 42(2), 609-631.

Sen, A. (1981) Poverty and famines: an essay on entitlement and deprivation. Clarendon Press, Oxford, p 416.

Sherman, M., \& Ford, J. D. (2013). Market engagement and food insecurity after a climatic 
hazard. Global Food Security, 2(3), 144-155.

Sirén, A. H. (2006). Natural resources in indigenous peoples' land in Amazonia: A tragedy of the commons?. The International Journal of Sustainable Development and World Ecology, 13(5), 363-374.

Smit, B. \& Wandel, J. (2006). Adaptation, adaptive capacity and vulnerability.Global environmental change, 16(3), 282-292.

Smit, B., Burton, I., Klein, R. J., \& Wandel, J. (2000). An anatomy of adaptation to climate change and variability. Climatic change, 45(1), 223-251.

Smith, D. L. \& Almaraz, J. J. (2004). Climate change and crop production: contributions, impacts, and adaptations. Canadian journal of plant pathology,26(3), 253-266.

Smith, H. A., \& Sharp, K. (2012). Indigenous climate knowledges. Wiley Interdisciplinary Reviews: Climate Change, 3(5), 467-476.

Smith, N. (2001). Are indigenous people conservationists? Preliminary results from the Machiguenga of the Peruvian Amazon. Rationality and society, 13(4), 429-461.

Speranza, C. I., Kiteme, B., \& Wiesmann, U. (2008). Droughts and famines: The underlying factors and the causal links among agro-pastoral households in semi-arid Makueni district, Kenya. Global Environmental Change, 18(1), 220-233.

Sumida Huaman, E. (2014). "You're Trying Hard, but It's Still Going to Die": Indigenous Youth and Language Tensions in Peru and the United States.Anthropology \& Education Quarterly, 45(1), 71-86.

Takahashi, B., \& Meisner, M. (2013a). Agenda Setting and Issue Definition at the Micro Level: Giving Climate Change a Voice in the Peruvian Congress. Latin American Policy, 4(2), 340-357.

Takahashi, B., \& Meisner, M. (2013b). Climate change in Peruvian newspapers: The role of foreign voices in a context of vulnerability. Public Understanding of Science, 22(4), 427-442.

Takasaki, Y., Barham, B. L., \& Coomes, O. T. (2010). Smoothing Income against Crop Flood Losses in Amazonia: Rain Forest or Rivers as a Safety Net?. Review of Development Economics, 14(1), 48-63.

Takasaki, Y., Coomes, O. T., Abizaid, C., \& Brisson, S. (2014). An efficient nonmarket institution under imperfect markets: Labor sharing for tropical forest clearing. American Journal of Agricultural Economics, aat102.

Temple, B. (2002). Crossed wires: Interpreters, translators, and bilingual workers in crosslanguage research. Qualitative Health Research, 12(6), 844-854.

Tol, R. S., Fankhauser, S., \& Smith, J. B. (1998). The scope for adaptation to climate change: what can we learn from the impact literature?. Global Environmental Change, 8(2), 109-123.

Tomasella, J., Pinho, P. F., Borma, L. S., Marengo, J. A., Nobre, C. A., Bittencourt, O. R., ... \& Cuartas, L. A. (2013). The droughts of 1997 and 2005 in Amazonia: floodplain hydrology and its potential ecological and human impacts. Climatic change, 116(34), 723-746.

Tournon, J. (2002). La merma mágica: Vida e historia de los Shipibo- Conibo del Ucayali. Lima, Peru: Centro Amazónica de Antropología y Aplicación.

Travis, W.R. (2010). Going to extremes: propositions on the social response to severe climate change. Climatic Change, 98(1-2), 1-19.

Travis, W.R. (2012). Extreme Events as Pacemaker of Adaptation to Climate Change. Paper 
presented at Adaptation Futures: 2012 International Conference on Climate Adaptation, Tucson, AZ. Retrieved on April 14, 2013 from <http://sciencepolicy.colorado.edu/admin/publication_files/2012.08.pdf>.

Travis, W.R., \& Huisenga, M. T. (2013). The effect of rate of change, variability, and extreme events on the pace of adaptation to a changing climate.Climatic change, 121(2), 209222.

Trenberth, K. E., \& Fasullo, J. T. (2012). Climate extremes and climate change: the Russian heat wave and other climate extremes of 2010. Journal of Geophysical Research: Atmospheres (1984-2012), 117(D17).

Tschakert, P. (2007). Views from the vulnerable: understanding climatic and other stressors in the Sahel. Global Environmental Change, 17(3), 381-396.

Tschakert, P., Sagoe, R., Ofori-Darko, G., \& Codjoe, S. N. (2010). Floods in the Sahel: an analysis of anomalies, memory, and anticipatory learning.Climatic change, 103(3-4), 471-502.

United Nations (2014). World Economic Situation and Prospects. New York. Retrieved on January 5, 2014 from <http://www.un.org/en/development/desa/policy/wesp/wesp_current/wesp201 4.pdf>.

United Nations Development Programme (UNDP) \& Bureau for Crisis Prevention and Recovery (BCPR). (2013). Climate Risk Management for Agriculture in Peru: Focus on the Regions of Junín and Piura. New York, NY: UNDP BCPR.

Urby Jr, H.,McEntire, D. A. \& Peters, E.J. (2011). Peru: An Andean Country with Significant Disaster and Emergency Management Challenges. Comparative Emergency Management: Understanding Disaster Policies, Organizations, and Initiatives from Around the World. Retrieved on September 12, 2012 from $<$ https://training.fema.gov/EMIWeb/edu/Comparative\%20EM\%20Book\%20\%20EM\%20in\%20Peru.pdf>.

Valdivia, N., Benavides, M. \& Torero, M. (2007). Exclusión, identidad étnica y políticas de inclusion social en el Perú: El caso de la población indígena y la población afrodescendiente. In Investigación, políticas y desarrollo en el Perú. (Edition 1, pp. 603-655). Grupo de Análisis para el Desarrollo (GRADE), Capitulos de Libros. Retrieved on November 22, 2013 from <http://www.grade.org.pe/download/pubs/InvPolitDesarr-14.pdf>.

Van Vliet, N., Mertz, O., Heinimann, A., Langanke, T., Pascual, U., Schmook, B., ... \& Ziegler, A. D. (2012). Trends, drivers and impacts of changes in swidden cultivation in tropical forest-agriculture frontiers: A global assessment. Global Environmental Change, 22(2), 418-429.

Vásquez, J., Mori, R., Zucchelli, M., Zito, A., Lindner, A., Rebaza, A.M. (2012). Emergency support to the communities most affected by the flood in Ucayali - 2011. INDECI, Ucayali Regional Government, ECHO, OCHA, FAO, UNICEF, , COOPI, German Red Cross (Peru). Retrieved on June 15, 2013 from <http://bvpad.indeci.gob.pe/doc/pdf/esp/doc2222/doc2222-2.pdf>.

Vegas de Cáceres, I. (2010). Cambio climático en el Perú. Amazonía. Fundación M.J. Bustamente de la Fuente. Lima.

Vera, M. \& Wong, Y. C. (2013, February, 22). Peru: Latin America's Economic Performer. International Monetary Fund Economic Health Check. Retrieved on November 5, 
2013 from

<http://www.imf.org/external/pubs/ft/survey/so/2013/car022213d.htm>.

Verner, D. (2010). Reducing Poverty, Protecting Livelihoods and Building Assets in a Changing Climate: Social Implications of Climate Change in Latin America and the Caribbean. Washington, DC: World Bank.

Vuori, M. (2009). Accessibility as a determinant of opportunities- a case study from Peruvian Amazon. Unpublished masters thesis, University of Helsinki, Helsinki, Finland.

Warner, K. (2010). Global environmental change and migration: Governance challenges. Global Environmental Change, 20(3), 402-413.

Warner, K., Ehrhart, C., de Sherbinin, A., Adamo, S., \& Chai-Onn, T. (2009). In search of shelter: Mapping the effects of climate change on human migration and displacement. In In search of shelter: Mapping the effects of climate change on human migration and displacement. CARE; United Nations University; Columbia University. CIESIN; The World Bank. Social Dimensions of Climate Change; UN. High Commisiones for Refugees.

Watts, M. J., \& Bohle, H. G. (1993). The space of vulnerability: the causal structure of hunger and famine. Progress in human geography, 17(1), 43-67.

Weatherhead, E., Gearheard, S., \& Barry, R. G. (2010). Changes in weather persistence: Insight from Inuit knowledge. Global Environmental Change, 20(3), 523-528.

Westerhoff, L., \& Smit, B. (2009). The rains are disappointing us: dynamic vulnerability and adaptation to multiple stressors in the Afram Plains, Ghana.Mitigation and adaptation strategies for global change, 14(4), 317-337.

White, R., \& Etkin, D. (1998). Climate change, extreme events and the Canadian insurance industry. In Earthquake and Atmospheric Hazards (pp. 135-163). Springer Netherlands.

World Bank Peru. (2013). How corruption affects the development of Peru [Video]. Peru: World Bank Peru.

Yohe, G., \& Tol, R. S. (2002). Indicators for social and economic coping capacity-moving toward a working definition of adaptive capacity. Global Environmental Change, 12(1), 25-40.

Zambrano, A. M. A., Broadbent, E. N., Schmink, M., Perz, S. G., \& Asner, G. P. (2010). Deforestation Drivers in Southwest Amazonia: Comparing Smallholder Farmers in Iñapari, Peru, and Assis Brasil, Brazil. Conservation \& Society, 8(3).

Ziervogel, G., Bharwani, S., \& Downing, T. E. (2006a). Adapting to climate variability: pumpkins, people and policy. In Natural Resources Forum(Vol. 30, No. 4, pp. 294305). Blackwell Publishing Ltd.

Ziervogel, G., Taylor, A., Thomalla, F., Takama, T., \& Quinn, C. (2006b).Adapting to climate, water and health stresses: insights from Sekhukhune, South Africa. Stockholm Environment Institute (SEI). Retrieved February 7, 2013, from $<$ http://www.fanrpan.org/documents/d00286/>. 


\section{Appendix A - Characteristics of Interview Respondents}

\begin{tabular}{|c|c|c|}
\hline $\begin{array}{l}\text { Interview } \\
\text { Number }\end{array}$ & Type of Interview & $\begin{array}{l}\text { Position/ Focus of Organization } \\
\text { (if applicable) }\end{array}$ \\
\hline 1 & Panaillo Resident & Community founder \\
\hline 2 & Community Institution & Education \\
\hline 3 & Panaillo Resident & Former chief \\
\hline 4 & Panaillo Resident & Current chief \\
\hline 5 & Panaillo Migrant & \\
\hline 6 & Panaillo Migrant & \\
\hline 7 & Panaillo Migrant & \\
\hline 8 & Panaillo Resident & \\
\hline 9 & Panaillo Resident & Community leader \\
\hline 10 & Panaillo Resident & Community leader \\
\hline 11 & Panaillo Resident & Community leader \\
\hline 12 & Panaillo Resident & Community leader \\
\hline 13 & Panaillo Resident & \\
\hline 14 & Panaillo Resident & \\
\hline 15 & Panaillo Resident & Community leader \\
\hline 16 & Panaillo Resident & \\
\hline 17 & Panaillo Resident & \\
\hline 18 & Panaillo Resident & Community founder \\
\hline 19 & Panaillo Resident & \\
\hline 20 & Panaillo Resident & Community founder \\
\hline 21 & Panaillo Resident & \\
\hline 22 & Panaillo Resident & \\
\hline 23 & Panaillo Resident & \\
\hline 24 & Panaillo Resident & Community leader \\
\hline 25 & Panaillo Resident & \\
\hline 26 & Panaillo Resident & Community founder \\
\hline 27 & Panaillo Resident & Community founder \\
\hline 28 & Panaillo Resident & \\
\hline 29 & Panaillo Resident & \\
\hline 30 & Panaillo Migrant & \\
\hline 31 & Panaillo Migrant & \\
\hline 32 & Panaillo Migrant & \\
\hline 33 & Panaillo Migrant & \\
\hline 34 & Panaillo Migrant & \\
\hline 35 & Panaillo Migrant & \\
\hline 36 & Panaillo Resident & Community leader \\
\hline 37 & Panaillo Resident & \\
\hline 38 & Panaillo Migrant & \\
\hline
\end{tabular}




\begin{tabular}{|c|c|c|}
\hline 39 & Panaillo Migrant & Former community leader \\
\hline 40 & Panaillo Migrant & \\
\hline 41 & Panaillo Migrant & \\
\hline 42 & Panaillo Migrant & \\
\hline 43 & Provincial Institution & Health/ Food Security \\
\hline 44 & Regional Institution & Disaster Management \\
\hline 45 & NGO & Indigenous Issues \\
\hline 46 & Provincial Institution & Development \\
\hline 47 & Provincial Institution & Health/ Food Security \\
\hline 48 & Community Institution & Health \\
\hline 49 & Regional Institution & Health/ Indigenous Issues \\
\hline 50 & Regional Institution & Transportation \\
\hline 51 & Regional Institution & Indigenous Issues \\
\hline 52 & Regional Institution & Health/ Food Security \\
\hline 53 & Provincial Institution & Disaster Management \\
\hline 54 & Provincial Institution & Agriculture and Food Security \\
\hline 55 & District Institution & Disaster Management \\
\hline 56 & NGO & Disaster Management \\
\hline 57 & Community Institution & Education \\
\hline 58 & Community Institution & Education \\
\hline 59 & Regional Institution & Agriculture \\
\hline 60 & Regional Institution & Food Security \\
\hline 61 & Regional Institution & Agriculture \\
\hline 62 & National Institution & Disaster Management \\
\hline 63 & National Institution & Disaster Management \\
\hline 64 & National Institution & Disaster Management \\
\hline 65 & NGO & Agriculture / Food Security \\
\hline 66 & Community Institution & Education \\
\hline 67 & Regional Institution & Fishing \\
\hline 68 & Regional Institution & Research \\
\hline 69 & Provincial Institution & Research \\
\hline 70 & Regional Institution & Research \\
\hline 71 & NGO & Development \\
\hline 72 & National Institution & Indigenous Issues \\
\hline 73 & National Institution & Indigenous Issues \\
\hline 74 & Panaillo Migrant & \\
\hline
\end{tabular}




\title{
Appendix B - Community Interview Guide
}

\author{
Interview Guide for Key Informant Semi-Structured Interviews
}

(Modified from the Arctic In-Depth Interview Guide for IHACC Qualitative Research)

Describe study: The study is following up on concerns identified in the IHACC project conducted in Panaillo regarding the availability of food, and changes in the environment. I will be asking you questions about the food you eat, difficulties you have in obtaining food, help that you get, and if things are getting better or worse.

\section{Personal and Food System Information}

Can you tell me a little bit about yourself?

- How long have you lived here? (where else have you lived, where did you live before, when did you move here?)

- What you do for a living? (how long, what did you do beforehand)

o Who lives with you in your household?

o What do the other household members do for a living?

o Are there people in your household who earn a regular income?

o Do you or any household members work outside of the community (e.g., Pucallpa)?

o How many people work outside of the community?

o What do they do? How long have they done this? Why did they start? How long do they plan to work outside of the community? Is their job secure for this amount of time?

o When do they work outside of the community (e.g., rainy season, dry season, etc.)? Does the whole family live outside of the community at this time?

\section{Can you tell me about where you get your food from?}

- Do you get food from harvesting from the chakra (family plot)/monte (forest) or fishing that you or other members of your household do?

o Do you have a chakra?

- If so, where is your chakra (including proximity to house/water resource)? How big is it? How many plots do you have? What do you grow in the chakra? When do you plant? When do you harvest?

- Do you practice slash-and-burn? Do you use fertilizers/inputs?

- Does your land have problems in production? If so, what are these problems? What do you think the cause is?

o Do other households also have problems with production? Why/why not? Are they the same problems? Why/why not?

0 Are there more problems with production now than in the past?

- Of the crops that you grow, what do you eat? What do you do with the other crops?

- Do you sell at the market? When do you sell at the market? Which market?

o Do you harvest from the monte?

- If so, what do you harvest from the monte? (e.g., hunting, wild plants)

- Do you eat this food? What else do you do with what you harvest from the monte?

- Do you sell any of it? When/where do you harvest/sell?

- Is there enough in the monte? Do you ever have problems getting things from the monte? Is it better/worse now than in the past?

- Do other households harvest from the monte?

o Do you go fishing?

- If so, what type of fish you do get from the river?

- When is the best time to go fishing? 
- Do you consume this fish and/or sell it?

- Is there enough fish in the river? Is it better/worse now than in the past?

- Do other households go fishing?

- How much of your food would you say is from the chakra, monte, or fishing in the dry season?

- How much of your food is bought in a market in the dry season?

o Which market do you buy from? When? Why do you buy from this market?

o Are you always able to buy from this market? If no, why not?

o How long have you been buying food from the market?

- How much of your food would you say is from the chakra, monte, or fishing in the rainy season?

- How much of your food is bought in a market in the dry season?

o Which market do you buy from? When? Why do you buy from this market? (Note: is this the same market as the dry season?)

o Are you always able to buy from this market? If no, why not?

Which do you prefer, market food or homegrown food? Why?

- Do you eat as much market food as your parents? Your grandparents?

- Do your parents/grandparents think market food or homegrown food is better?

o Do they buy from the market? What do they buy, when, and which market?

\section{What is a normal meal/eating schedule in the community?}

- How many times per day do people eat?

- Do people eat at the same time/same number of times everyday?

- Who do people eat with? Who cooks? Who cleans?

- How much do people eat at one time? Is this a good meal size?

- What is a healthy meal?

\section{Current Food Security}

Are you always able to get homegrown foods (i.e., chakra, monte, fishing) when you want them?

- IF YES - some households are not able to get homegrown food, what makes yours different?

- When you can't get homegrown food why is that? What other barriers are there? [Probes: money; land quality; labor availability]

- When are the most difficult times to get homegrown food? Why is that?

- If you can't get homegrown food, what do you do?

o Do you ever buy homegrown food from the store / other people?

o Does the government ever provide any support? When? How?

- Do people share food with you? If so, who shares food with you?

o How do they share with you (feast, or just bring food over)?

0 Are there times when people are less likely to share? When and why?

- Do you ever have to ask people for food if you don't have any?

- Do you ever get food from people from other communities?

- Is there any other support you can get?

- Does not being able to get food from the chakra/monte/fishing cause you or your family stress?

Are you always able to get market foods when you want them? (specify which market- local convenience store, Tacshitea, and/or Pucallpa)

- IF YES - some households are not able to get market food, what makes yours different?

- Can your family afford to buy all the food it needs at the market? Which one is most affordable?

- When you can't get market food, why is that? What other barriers are there?

- When are the most difficult times to get market food? Why is that?

- If you can't get market food what do you do?

o Do you ever have to ask other people for food? Who?

o Does the government provide any support? When? How?

o What other support do you get? 
- How was your ability to get market food this year compared to what it is normally like?

o How did the road change your ability to get market food?

- How do you feel when you can't get market food?

- How well does the market do in meeting peoples' needs?

- Does not being able to get market food cause you or your family stress?

Do you have any other concerns about homegrown foods or market foods?

- What about the new road/logging/oil exploration? Good or bad for food?

Is it common to skip meals? (who skips meals, when, how frequently, why)

- In the last year, has any one in your household had to skip meals or cut meal size because there wasn't enough food?

- If someone in your household had to cut or skip a meal, would it more likely to be a female or male household member?

Do you ever worry that your food will run out before you can afford to purchase any more or are able to go fishing/hunting?

- Who do you think worries more about food, women or men in the household?

Do you ever have difficulty being able to afford to have healthy meals?

- What makes it difficult to eat healthily?

- Is anything being done in the community to encourage healthy eating?

- Do you have access to information on eating healthily?

- Is there a way to make your eating healthier? What prevents you from doing this?

In the last year, did you ever eat less than you felt you should because there wasn't enough food?

- If yes, would it be the females or the males who would first do this?

- When did this happen? (rainy season, dry season, proximity to specific event)

In the last year, were you ever hungry but didn't eat because you couldn't afford enough food OR were not able eat food from the chakra/monte/river?

- Would it be men or women who are more likely to go hungry?

In the last year, did you lose weight because you didn't eat enough food?

Which households do you think have the most difficulty getting enough food?

Climatic Hazards and the Current Food System

Other IHACC researchers told me that Panaillo experiences annual flooding. People also said that things are changing a lot. I am interested in finding out if these changes are affecting your ability to get food.

Can you tell me about the floods that happen during the rainy season?

- What usually happens? When? What is flooded? From when the flooding starts, how long does it take for everything to get flooded? How long do the floods last?

- When the flooding comes early/late, how does that affect your homegrown food access? Market food access?

- How intense are the floods usually? Do you get many extreme flooding events?

o When was the last extreme flooding event?

0 Are there more extreme flooding events now than in the past?

o Can you tell me what makes these events different from normal flooding?

How do the floods affect your well-being?

- Do you eat different foods when there are floods? Why? Do you prefer these foods to your normal diet? 
Can you tell me about how the floods affect homegrown?

- How do the floods affect the food you're producing in the chakra?

- Is the monte affected by floods? How?

- Are there more/less/equal amounts of fish in the rivers during/after the floods?

- Do the floods affect any food you have stored?

How do the markets change when there are floods?

- Are you able to access them as easily?

- Are the prices different?

- Is it harder/easier to sell/buy food?

How did your diet and ability to get food change after the community was relocated 10 years ago?

What else in the last year affected your ability to get homegrown/market foods?

\section{Adaptive Strategies with Climatic Risks}

What do you do the cope with the floods?

- Do you know when the floods are coming? How?

o If you know the floods are coming, can you take any actions to reduce the damage from the floods? Why/why not?

- What do you do during the floods to cope?

- What do you do after the floods to cope?

- Do these actions always work? When are they more/less effective?

- Do you prefer to use certain strategies to others? Why?

- Are you always able to use these adaptive strategies? Are other households also always able to use these adaptive strategies? Why/why not?

- Who do these strategies involve? Do you need to rely on others from within/outside the community?

- What are the consequences of the floods for you, your household, and your community? Are there positive and negative benefits? Under what circumstances?

Do you also have droughts?

- If so, which cause more damage, floods or droughts? How/why?

- Which are you better able to cope with? How/why?

o Which causes more disruption to the local/regional market? How?

- Which do you consider to affect your food and well-being more? How/why?

Climatic Hazards and Perceived Future Impacts on Food Security

Scientists are saying the climate will continue to change in the future here in Panaillo. Do you think that will have a big impact on the country foods?

- Will it have positive impacts too?

- Will it have negative impacts too?

- Can anything be done to help local people?

What other problems do you see affecting your ability to obtain enough food in the future?

- Who will that affect the most?

- What can be done?

[If people have identified that food is hard to get for themselves ask this question, if not go to the next question]

What do you think can be done to increase access to: market food, homegrown food? 


\title{
Appendix C - Institutional Interview Guide
}

\author{
Semi-structured interview guide for institutional respondents \\ (Adapted from the interview guide developed by Irene Hofmeijer for IHACC Pilot research \\ in 2010)
}

Note: The questions from the community interview guide can also be posed to institutional respondents to verify the information collected directly from community members. This guide aims to increase the understanding of how institutions function and of their role in indigenous communities.

Describe study: The study is following up on concerns identified in the IHACC project conducted in Panaillo regarding the availability of food, and changes in the environment. I will be asking you questions about the local diet, the difficulties that exist in obtaining food, the help is available for food insecure households, and if things are getting better or worse.

For each interview respondent, note the following:

Organization that the person represents: national, regional, local/municipal government; health professional (i.e., doctor, nurse, etc); natural disaster management professional; NGO; indigenous health provider, researcher

Role of the person in the organization:

Years in the position:

Do they interact directly with indigenous communities? Yes or No

What is the role of your organization/department with regards to indigenous health?

Can you tell me about your duties and responsibilities?

Are there other organizations/ individuals that provide a similar service/knowledge?

Who funds your organization?

What type of interaction do you/your organization/department have with indigenous communities or indigenous organizations?

Do you or your organization have difficulties achieving your mandate? Is this changing over time?

Regarding collaboration with other groups

Do you or your organization collaborate with the district/provincial/regional/national levels? What type of relationship do you have? How do you communicate?

Do you or your organization collaborate with other departments (e.g., MINSA, Ministry of Envio, etc)? What type of relationship do you have? How do you communicate?

Do you or your organization collaborate with other organizations (e.g., NGOs, United NAtions etc)? What type of relationship do you have? How do you communicate?

Is there good communication between the different government levels and sectors?

What are the benefits and challenges of this collaboration?

Regarding the history of your organization in Ucayali

When did you start to work in Ucayali?

In which area have you worked/are currently working?

What type of projects are you carrying out/ have you completed?

Why did you decide to work in this region?

Regarding health and food security in the region

In your experience, how is the health and food security in Ucayali (specifically in indigenous communities if you have this knowledge)?

What are the main challenges for health/food security?

What are the main factors that help the population maintain their health/food security? 
Are there families that have greater difficulty maintaining food security? What are these families like? Why do they have difficulty? What sorts of challenges do they face?

\section{Regarding flooding}

In your opinion, how is flood management in the region currently? What is needed in the management and response to annual flooding? What works well?

Did you collaborate with the region in 2010-2011 during the state of emergency from severe flooding? What was the situation like? How were you/your organization involved? What were the challenges to this work?

Are there families that struggle more in the rainy season because of the flooding? What are these families like? Why do they have difficulty? What sorts of challenges do they face?

About the region

What does Ucayali need to further develop?

What are the most worrisome problems that the region is facing? 